\author{
UNIVERSIDADE DE SÃO PAULO \\ ESCOLA DE ENGENHARIA DE SÃO CARLOS \\ DEPARTAMENTO DE ENGENHARIA DE PRODUÇÃO
}

ENNIO POLITI LOPES

Alastramento de risco do setor financeiro para a economia real e a relação com a restrição financeira nas decisões de investimento da firma 
ENNIO POLITI LOPES

\section{Alastramento de risco do setor financeiro para a economia real e a relação com a restrição financeira nas decisões de investimento da firma}

Dissertação apresentada ao Departamento de Engenharia de Produção da Escola de Engenharia de São Carlos da Universidade de São Paulo como requisito para obtenção do título de Mestre em Ciências

Área de Concentração: Economia, Organizações e Gestão do Conhecimento

Orientador: Prof. Dr. Aquiles Elie Guimarães Kalatzis 
AUTORIZO A REPRODUÇÃO TOTAL OU PARCIAL DESTE TRABALHO, POR QUALQUER MEIO CONVENCIONAL OU ELETRÔNICO, PARA FINS DE ESTUDO E PESQUISA, DESDE QUE CITADA A FONTE.

P864a Politi Lopes, Ennio

Alastramento de risco do setor financeiro para a economia real e a relação com a restrição financeira nas decisões de investimento da firma / Ennio Politi Lopes; orientador Aquiles Elie Guimarães Kalatzis. São Carlos, 2016.

Dissertação (Mestrado) - Programa de Pós-Graduação em Engenharia de Produção e Área de Concentração em Economia, Organizações e Gestão Conhecimento -- Escola de Engenharia de São Carlos da Universidade de São Paulo, 2016.

1. Decisões de investimento. 2. Alastramento de risco. 3. Restrição financeira. 4. Contágio financeiro. I. Título. 


\section{FOLHA DE JULGAMENTO}

Candidato: Bacharel ENNIO POLITI LOPES.

Título da dissertação: "Alastramento de risco do setor financeiro para a economia real e a relação com a restrição financeira nas decisões de investimento".

Data da defesa: 08.12.2016.

Comissão Julgadora:

Prof. Associado Aquiles Elie Guimarães Kalatzis (Orientador)

(Escola de Engenharia de São Carlos/EESC)

Prof. Associado Márcio Poletti Laurini (Faculdade de Economia, Administração e Contabilidade de Ribeirão Preto/FEARP-USP)

Prof. Dr. Alexandre Sartoris Neto

(Universidade Estadual Paulista "Júlio de Mesquita Filho"/UNESP _ Araraquara)

Coordenador do Programa de Pós-Graduação em Engenharia de Produção:

Prof. Associado Aldo Roberto Ometto

Presidente da Comissão de Pós-Graduação: Prof. Associado Luis Fernando Costa Alberto 


\section{AGRADECIMENTOS}

A minha família pelo apoio durante este processo da minha vida. Em especial à minha mãe Solange e minha irmã Elis.

À Ana Carolina e sua família pela paciência e suporte nos momentos de sufoco.

Aos professores do departamento de Engenharia de Produção.

Um agradecimento especial ao meu orientador Prof. Aquiles pela paciência, disposição e ensinamentos.

Aos amigos de estudo e café do laboratório de economia e administração do departamento de Engenharia de Produção da EESC.

Por fim, aos funcionários do Departamento de Engenharia de Produção da EESC, em especial à Jéssyca Duarte, pelo atendimento e compreensão. 
"No hay regla sin excepción"

Miguel de Cervantes 


\section{RESUMO}

LOPES, E. P. Alastramento de risco do setor financeiro para a economia real e a relação com a restrição financeira nas decisões de investimento da firma. 2016. 81p. Dissertação (Mestrado) - Escola de Engenharia de São Carlos, Universidade de São Paulo, São Paulo, 2016.

Considerando a importância dos fatores financeiros nas decisões de investimento e as restrições financeiras das firmas, os intermediários financeiros mostram-se como importantes provedores de fonte de recursos para a viabilização dos investimentos. Devido a esta ligação, um possível canal de transmissão no qual o setor financeiro afeta o crescimento e risco das empresas ocorre pela dependência de recursos financeiros externos, portanto, o risco e retorno das firmas devem ser afetados pelas dificuldades das entidades financeiras. Atentando a esta circunstância o objetivo deste estudo é de verificar na economia brasileira os efeitos do alastramento de risco do setor financeiro para a economia real nas decisões de investimentos das firmas, as quais perpassam por conjunturas de restrição financeira. Para atingir tal objetivo utiliza-se informações financeiras e retorno das ações das empresas de capital aberto no Brasil no período de 1997 a 2015. O alastramento do risco do retorno é estimado por um processo VAR-GARCH, e o contágio financeiro pelo indicador de co-excessos condicionais. Essas variáveis são inseridas em um modelo neoclássico acelerador de investimento modificado, para um grupo de firmas restritas e outro de não restritas, classificadas pelos índices $\mathrm{KZ}$ e WW. A estimação do modelo de investimento é realizada pelo GMM system e os resultados mostram que o nível do alastramento do risco do setor financeiro para as firmas impacta negativamente nas taxas de investimento das empresas restritas tanto pelo índice KZ, quanto pelo WW. O estudo amplia a literatura nacional utilizando um enfoque microeconômico do alastramento do risco e dos coexcessos condicionais e abordando a questão do alastramento do risco no modelo de investimento.

Palavras chaves: Decisões de investimento. Alastramento de risco. Restrição financeira. Contágio financeiro. 


\begin{abstract}
LOPES, E. P. Risk spillover from the financial sector to the real economy and the relationship with the financial constraint on firm's investment decisions. 2016. 81p. Dissertation (Master) - Engineering School of São Carlos, University of São Paulo, São Paulo, 2016.

Considering the importance of financial factors and financial constraints in firm's investment decisions, financial sector show up as important source of funds providers to the viability of industry investments. Because of this connection, a possible transmission channel in which the financial intermediaries affect firm's growth and risk is from the dependence on external financial funds, so the risk and return of firms should be affected by the difficulties and vagaries of financial sector. In accordance to this circumstance this study aim's to verify the effects of the financial sector risk spillover and contagion to the real economy in constrained, and unconstrained, firms' investment decisions. To achieve this goal, we use financial data and stock returns of publicly traded companies in Brazil from 1997 to 2015. The risk spillover is estimated by a VAR-GARCH process, and financial contagion by an index called conditional coexceedance. These variables are included in a modified neoclassical accelerator model of investment, splitting the observations into groups of constrained and unconstrained firms, classified by $\mathrm{KZ}$ and $\mathrm{WW}$ indexes. The estimation of the investment model is performed by GMM system, and the results show that the level of financial sector risk spillover negatively impact investment rates of constrained companies, both by the KZ and WW segregations. This study contributes to the national literature using a microeconomic approach to the risk spillover and conditional co-exceedances addressing it to the investment model.
\end{abstract}

Keywords: Investment decisions. Risk spillover. Financial constraints. Financial contagion. 


\section{LISTA DE GRÁFICOS}

Gráfico 1 - Retorno diário da carteira do setor financeiro 44

Gráfico 2 - Variação do PIB real trimestral 45

Gráfico 3 - Histograma do retorno diário da carteira do setor financeiro 46

Gráfico 4 - Indicador de retornos extremos e desvio-padrão 47

Gráfico 5 - Dispersão da média do índice CEC 48

Gráfico 6 - Média do índice CEC de todas as empresas por trimestre 49

Gráfico 7 - Média da dummy p-valor do coeficiente gama por trimestre 51

Gráfico 8 - Média do coeficiente gama por trimestre 51 


\section{LISTA DE TABELAS}

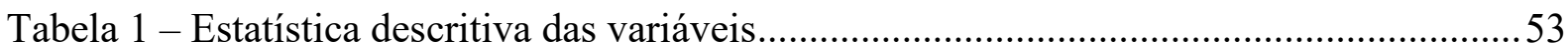

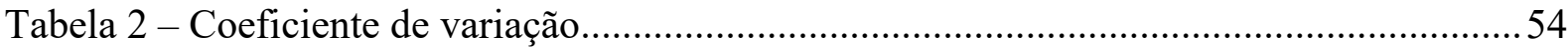

Tabela 3 - Estimativa do investimento pelo system GMM..................................................55

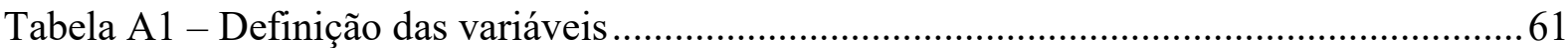

Tabela B1 - Estatísticas descritivas das empresas do setor financeiro ...................................62

Tabela B2 - Estatísticas descritivas das empresas na economia real .....................................64 64

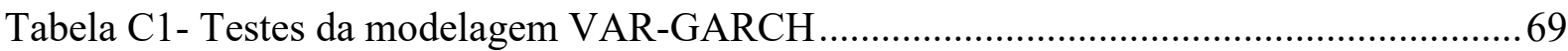

Tabela C2 - Correlação das variáveis do modelo de investimento .......................................... 73 


\section{LISTA DE SIGLAS}

ADR: American Depositary Receipts (certificado de depósito de valores mobiliários) ARCH: Autoregressive Conditional Heterocedasticity

BM\&FBOVESPA: Bolsa de Valores, Mercadorias e Futuros de São Paulo ETF: Exchange Traded Funds (fundos de índice)

GARCH: Generalized Autoregressive Conditional Heteroskedasticity

KZ: Índice KZ de restrição financeira da firma

GMM: Generalized method of moments

IPCA: Índice Nacional de Preços ao Consumidor Amplo

NAICS: North American Industry Classification System

VAR: Vetor auto-regressivo

WW: Índice WW de restrição financeira da firma 


\section{SUMÁRIO}

1 INTRODUÇÃ

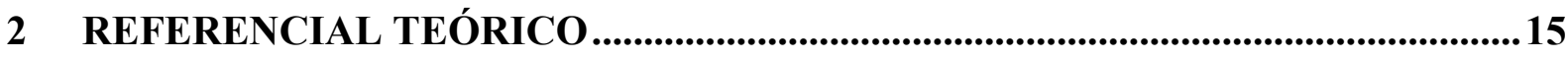

2.1 Decisão de investimento e restrição financeira.................................................... 15

2.2 Alastramento de risco e contágio financeiro......................................................22

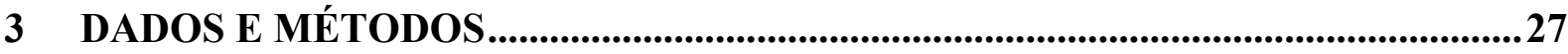

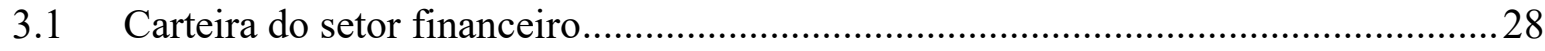

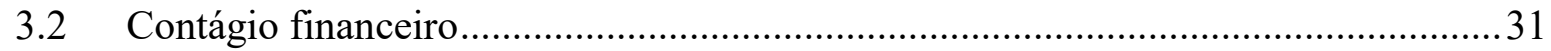

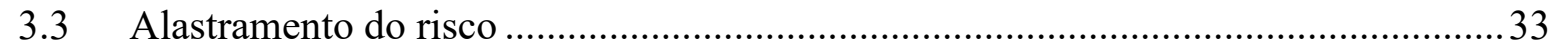

3.4 Modelo de investimento e restrição financeira ..................................................... 36

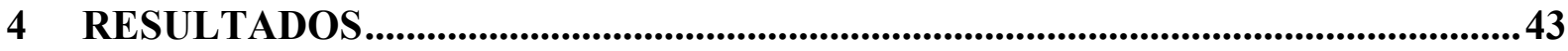

4.1 Formulação da carteira do setor financeiro........................................................ 43

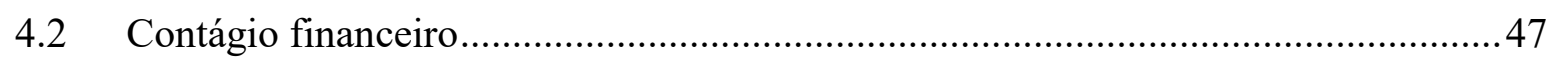

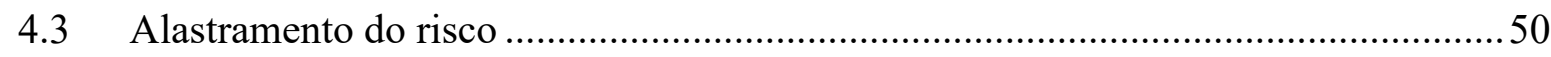

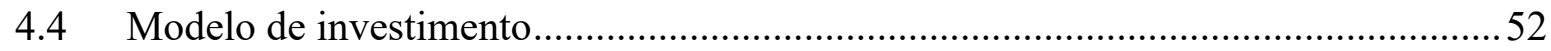

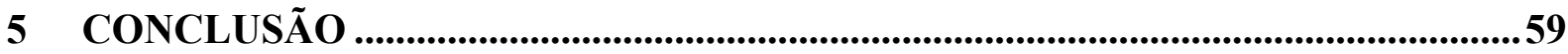

APÊNDICE A - DEFINIÇÃO DAS VARIÁVEIS ....................................................61

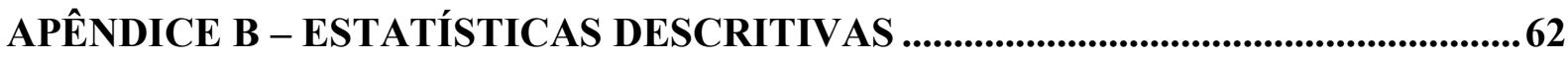

APÊNDICE C - ESTATÍSTICAS DOS MODELOS DE REGRESSÃO .......................... 69

REFERÊNCIAS BIBLIOGRÁFICAS ...........................................................................75 


\section{INTRODUÇÃo}

Estudos de imperfeições no mercado de capitais, principalmente no aspecto da assimetria de informações, mostram a importância dos fatores financeiros nas decisões de investimento no qual os custos de financiamento interno e externo não possuem a característica de substitutos perfeitos. Portanto, os fundos externos apresentam-se relevantes para os gastos com investimento das firmas restritas financeiramente (BERNANKE, 1983; BLINDER, 1987; FAZZARI et al., 1988; FAZZARI; PETERSEN, 1993; SCHALLER, 1993).

Segundo Kaplan e Zingales (1997) se o investimento de uma firma é limitado pelo custo ou disponibilidade de financiamento externo de tal forma que o investimento seria realizado caso possuísse recursos internos a firma é restrita financeiramente. Os custos e indisponibilidade de investimentos podem surgir de diversas formas, considerando as imperfeições do mercado, assimetria de informação e custo de agencia, essas podem gerar custos adicionais nas taxas de captação dos recursos externos ou até mesmo a falta desses, nos quais suscitam entraves nas decisões de investimentos das firmas e, por conseguinte, ineficiências na conjuntura econômica de um estado.

Da ligação do setor financeiro com as firmas faz-se perceber que um possível canal de transmissão no qual o setor financeiro afeta o crescimento e risco das empresas é pela dependência financeira, portanto, o risco e retorno das firmas devem ser afetados pelas oscilações negativas das entidades financeiras, e choques no retorno dessas entidades podem alastrar-se a grandes choques na economia real. Desta relação que o presente estudo foi motivado, objetivando verificar na economia brasileira os efeitos do alastramento de risco do setor financeiro para a economia real nas decisões de investimentos das firmas, as quais perpassam por conjunturas de restrição financeira.

A propagação de uma crise de uma economia para outra recebeu foco de atenção nas pesquisas a partir da crise asiática de 1997, pois originou-se de economias que até então eram consideradas exemplares pela suas trajetórias de desenvolvimento econômico iniciados na década de $60 \mathrm{~A}$ crise propagou-se para o leste asiático, atingindo até países mais ricos como os Estados Unidos da América (CLAESSENS; FORBES, 2004). A partir de então o termo contágio passou a ser amplamente utilizado para referir-se aos movimentos de crises financeiras.

$\mathrm{Na}$ análise do alastramento do risco este estudo utiliza dois elementos. Um primeiro que refere-se ao contágio do risco do setor financeiro para as empresas, no qual está ligado a 
movimentos de retornos extremos no mercado de ações, e para isso assumindo uma definição de contágio financeiro menos restrita, onde os eventos de propagação que ocorrem em economias com relações comercias intensas, e em uma mesma região geográfica, também são consideradas contágio. E um segundo elemento no qual o alastramento do risco ocorre não só em eventos extremos, mas por qualquer transmissão de volatilidade dos retornos do setor financeiro para as firmas da economia real.

Para a medida do contágio financeiro, utilizou-se os co-excessos condicionais proposto por Chiu, Peña e Wang (2015). E o alastramento do risco foi estimado por um processo VARGARCH. Essas estimativas foram realizadas com os retornos diários das ações das empresas de capital aberto listadas na bolsa de valores de São Paulo no período de 1997 a 2015.

Os índices de transmissão de risco e contágio são implementados em um modelo acelerador de investimento estimado pelo system GMM (ARELLANO; BOVER, 1995; BLUNDELL; BOND, 1998) com o objetivo de obter evidencias do efeito desses fenômenos nas decisões da firma. Para comparar os efeitos nas firmas restritas e não restritas segregou-se a amostra de acordo com os índices de restrição financeira KZ (LAMONT; POLK; SAAREQUEJO, 2001) e WW (WHITED; WU, 2006).

Com isso este trabalho procura contribuir para a literatura nacional utilizando um enfoque microeconômico do alastramento do risco e dos co-excessos condicionais analisando suas relações com as decisões das firmas restritas e não restritas financeiramente.

No capítulo seguinte são apresentadas as produções cientificas relevantes para esse estudo, com respeito ao investimento, restrição financeira e contágio financeiro. No tópico 3 a exposição da metodologia utilizada para estruturar as análises, no tópico 4 os resultados encontrados e finalizando no tópico 5 com a conclusão. 


\section{REFERENCIAL TEÓRICO}

2.1 Decisão de investimento e restrição financeira

Os estudos sobre investimento tomam a atenção de pesquisas há muitos anos. Keynes (1936) foi um dos pioneiros que se popularizou em tratar as decisões de investimento como uma variável endógena, o que a partir de então muitos estudos empíricos e modelos surgiram sobre o tema, entre eles o modelo de interação do multiplicador e acelerador (SAMUELSON, 1939), o modelo acelerador neoclássico de Jorgenson em meados dos anos 60 (HALL; JORGENSON, 1967; JORGENSON, 1963) e o modelo Q de Tobin no final dos anos 60 (TOBIN, 1969).

Segundo Keynes (1936), as decisões de investimento são fundamentadas na relação entre a eficiência marginal do capital (ou taxa de retorno do investimento) e o custo de oportunidade deste capital a ser investido. Formalmente o investimento $(I)$ é uma função da taxa de retorno do investimento $(i)$ e do custo de oportunidade $(c): I=f(i, c)$.

Portanto as decisões de investimento são realizadas em um ambiente de incerteza, pois requerem suposições sobre o custo de capital e retornos futuros esperados. Este conceito foi importante para o desenvolvimento posterior de teorias econômicas do investimento e grande parte dos modelos incorporam ou partem das ideias da teoria de Keynes.

O conceito do multiplicador de Keynes afirma que conforme o investimento aumenta, o aumento da renda ocorre proporcionalmente a um multiplicador do investimento. Porém nas teorias de ciclos e crescimento econômico existe o princípio acelerador que postula o inverso do multiplicador de Keynes, quando a renda ou consumo aumenta, o investimento que irá aumentar por um multiplicador. Este conceito desenvolvido antes de Keynes por Carver (1903), Aftalion (1909), Clark (1917) e Bickerdike (1914), porém popularizado após a teoria de Keynes, postula que quando a renda das pessoas aumenta, o consumo também aumenta e mais produtos devem ser produzidos. Se o nível de capital estiver totalmente em uso, mais capital será necessário para o aumento produtivo. Portanto os investimentos feitos pelas empresas aumentam quando a renda ou demanda aumentam. Neste caso o investimento é induzido por mudanças na renda e no consumo ou ainda quando há um aumento na demanda levando ao seu excesso, a teoria sugere que existem duas maneiras de as empresas equilibrarem esta diferença: 
ou reduzindo a demanda com um aumento de preços, ou aumentando os investimentos para suprir o excesso.

O princípio do modelo acelerador pressupõe que um aumento no produto $(Y)$, requer um aumento proporcional no estoque de capital $(K)$, a fim de manter uma relação proporcional constante $(\lambda)$ entre capital e produto, portanto o estoque de capital ótimo é uma proporção constante do capital e produto, o qual em qualquer período $t$ é igual a:

$$
K_{t}=\lambda Y_{t}
$$

Onde $K_{t}$ é o estoque de capital ótimo no período $t ; \lambda$ é uma constante positiva (chamado de acelerador); e $Y_{t}$ é o produto no período $t$. Mudanças no produto induzem a mudanças no estoque de capital, sendo assim:

$$
\begin{gathered}
K_{t}-K_{t-1}=\lambda\left(Y_{t}-Y_{t-1}\right) \\
I_{t}=\lambda\left(Y_{t}-Y_{t-1}\right)
\end{gathered}
$$

Sendo o investimento líquido no período $t\left(I_{t}\right)$ igual a variação do estoque de capital $\left(K_{t}-K_{t-1}\right), \lambda$ reflete a relação $K / Y$ na equação (2). O investimento líquido é proporcional às mudanças do produto, de forma que, se o produto permanecer constante $(\Delta Y=0)$, o investimento deve ser igual a zero.

Em geral o investimento no período $t$ ajusta parcialmente o estoque de capital no mesmo período para o nível ótimo, portanto o nível atual depende do nível anterior. A partir disso, surgiu um contexto de críticas do modelo acelerador devido a possibilidade de correlação serial do investimento, o modelo não considera defasagens do estoque de capital (KOYCK, 1954). Se ocorrer um aumento na demanda, para suprir este aumento as firmas primeiro utilizam os estoques disponíveis, em seguida intensificam o uso do estoque de capital e se o aumento na demanda for suficientemente grande e persistente realizam o investimento (I). Como o financiamento não é abundante e prontamente disponível no mercado de capitais, existe um atraso financeiro em efetuar o levantamento de recursos para comprar o capital necessário (realizar o investimento), e ainda um atraso devido ao intervalo de tempo no processo da tomada de decisão, do capital financeiro estar disponível (realização do pedido dos itens), e em deixar o novo capital físico pronto para utilização. 
Consequentemente novos modelos passaram a incorporar variáveis defasadas no modelo inicial da equação (2), surgindo o modelo acelerador flexível (ou modelo de ajuste de estoque de capital).

Nos modelos apresentados, a ausência de preços do custo do capital induziu estudos a respeito dos efeitos dos preços relativos sobre a aquisição de capital (ou investimento), o que deu início ao modelo acelerador neoclássico, intensificando as pesquisas dos determinantes do investimento (CHIRINKO, 1993). Jorgenson (1963), a partir da função de produção CobbDouglas, com pressupostos de retornos constantes de escala e mercados competitivos, define o nível de capital ótimo $\left(K^{*}\right)$ como:

$$
K^{*}=\alpha \frac{Y}{C_{K}}
$$

Onde $\alpha$ é a parcela de capital na função Cobb-Douglas, $C_{K}$ o custo de utilização do capital $(K)$ e $Y$ a demanda da firma que pode ser expressa em termos das vendas $(S)$. Do mesmo modo que o modelo flexível anterior, este foi modificado para incorporar a correlação serial do investimento, originando o modelo acelerador neoclássico flexível (HALL; JORGENSON, 1967). No âmbito microeconômico o modelo pode ser definido como:

$$
I=\lambda\left[\left(\alpha \frac{S}{C_{K}}\right)-K_{t-1}\right]
$$

Onde $\lambda$ representa a velocidade de ajustamento do estoque de capital, assumindo valores entre 0 e $1(0<\lambda<1)$. A formulação deste modelo considera o teorema de Modigliani e Miller $(1958,1963)$ de que os fundos internos e externos são substitutos perfeitos, portanto a estrutura de capital das empresas não afeta suas decisões de investimento, sendo os aspectos que direcionam as decisões apenas mercadológicos, explicado por variáveis reais, como preços relativos dos fatores de produção, produtividade, demanda e desenvolvimentos tecnológicos, sob o pressuposto de um mercado competitivo e sem assimetria de informação. Essa abordagem torna o modelo independente do uso de variáveis financeiras.

Posteriormente os estudos de imperfeições no mercado de capitais, principalmente no aspecto da assimetria de informações (AKERLOF, 1970; STIGLITZ; WEISS, 1981), trouxeram uma nova abordagem para os modelos de investimento, incorporando fatores financeiros (BERNANKE, 1983; BLINDER, 1987; FAZZARI et al., 1988; FAZZARI; 
PETERSEN, 1993; SCHALLER, 1993). A importância dos fatores financeiros nas decisões de investimentos não consideradas nos modelos empíricos neoclássicos poderiam estar subestimando os resultados das estimativas das vendas da firma, por absorver outros efeitos (financeiros) ignorados.

A contestação da teoria de Modigliani e Miller $(1958,1963)$ resulta na relevância dos fundos externos para os gastos com investimentos e no tratamento das características das firmas quanto à restrição financeira, abordagem que será adotada nesse estudo.

Fazzari, Hubbard e Petersen (1988) fazem uma análise da relação das variáveis financeiras com as decisões de investimento das empresas, utilizando o fluxo de caixa como variável de liquidez interna para testar a existência de restrição financeira. Buscam também fundamentar a ligação da estrutura da dívida com o gasto real com investimento pela identificação das razões pelas quais o financiamento interno e externo não serem substitutos perfeitos como apontado por Modigliani e Miller (1958).

Devido a esses aspectos, a observância da existência de mercados imperfeitos e assimetria de informação causam divergências no que diz respeito ao custo de capital próprio e de terceiros, motivando mais estudos da relação de variáveis financeiras com as decisões de investimento e dos entraves da restrição financeira das firmas.

Devereux e Schiantarelli (1990) verificaram a sensibilidade do investimento com fluxo de caixa das empresas, confirmando os resultados obtidos de Fazzari, Hubbard e Petersen (1988), apontando a significância do fluxo de caixa no modelo.

Como nos trabalhos citados anteriormente, Carpenter et al. (1994) classificaram as empresas analisadas por tamanho e a partir do agrupamento avaliaram as fontes internas das firmas como recurso para realização dos investimentos. Os resultados mostraram que os fundos internos de financiamento dos investimentos estão altamente relacionados com os investimentos para todas as empresas, principalmente para as menores em períodos de contração econômica.

Hsiao e Tahmiscioglu (1997) utilizaram modelo de regressão em painel com efeitos fixos e aleatórios para verificar a relação do fluxo de caixa e investimento. Porém com a hipótese de que as empresas mais intensivas em capital tenham os investimentos mais sensíveis à liquidez (pois incorrem de altos custos fixos e maior necessidade de capital) agruparam a amostra de acordo a intensidade do capital.

Outro enfoque está na decisão dos gestores com os investimentos quando estão inseridos em um ambiente de assimetria de informação com os acionistas. Os fundos gerados internamente nas empresas, principalmente as com baixo nível de distribuição de dividendos e 
capital pulverizado, pode acarretar num comportamento arbitrário nos investimentos por parte dos administradores, podendo efetuar investimentos que não agregam valor a empresa, acarretando em uma maior sensibilidade dos investimentos ao caixa devido à assimetria de informação (VOGT, 1994).

A utilização do fluxo de caixa utilizada como liquidez para identificar a restrição financeira gerou debates no que cerne a validade da variável para explicar as decisões de investimentos. As principais contestações estão na proposição do fluxo de caixa estar altamente relacionado com outras variáveis financeiras esperadas das quais também possam explicar as decisões de investimentos. Assim pode-se entender que algumas empresas com altos níveis relativos de fluxo de caixa aumentam seus investimentos devido à expectativa de lucratividade e de outras variáveis esperadas do que propriamente da ausência de restrição financeira e baixos custos de captação.

Kaplan e Zingales (1997) investigam a sensibilidade do investimento com o fluxo de caixa e os resultados não corroboraram com trabalhos anteriores. Utilizando a mesma amostra de Fazzari, Hubbard e Petersen (1988) identificam que a maior parte das empresas consideradas como restritas não deveriam ser pois aumentaram seus investimentos a partir de recursos externos ou saldos de caixa. Além disso os resultados também divergiram quanto à sensibilidade ao fluxo de caixa, as empresas menos restritas em Fazzari, Hubbard e Petersen (1988) apresentaram uma sensibilidade maior que as mais restritas na qual uma possível explicação apresentada seja que a sensibilidade do investimento das firmas restritas não vêm de problemas de liquidez. Para os autores uma empresa é restrita financeiramente se os investimentos são limitados pelos custos ou disponibilidade de financiamento externo sendo que aqueles seriam realizados caso houvesse recursos internos.

Esse trabalho gerou uma importante discussão e a necessidade de controlar as oportunidades de investimento e isolar os efeitos da liquidez. Fazzari, Hubbard e Petersen (2000), contrapondo os pontos de Kaplan e Zingales (1997), argumentaram que as evidências obtidas para as críticas realizadas não podem ser sustentadas devido a possíveis problemas de vieses nas conclusões devido ao tamanho da amostra utilizada, na qual empresas classificadas como restritas podem fazer reservas de caixa para precaverem-se expectativas de restrições financeiras.

Posteriormente, Cleary (1999), analisa a sensibilidade da decisão de investimento com a situação de liquidez em uma amostra de 1.317 empresas norte americanas de 1988 a 1994 e utilizam uma metodologia de classificação financeira (restritas ou não) das firmas que permite elas mudarem de estado de situação financeira de um período para outro. Os resultados obtidos 
suportam os resultados de Kaplan e Zingales (1997), o investimento é mais sensível ao fluxo de caixa quando uma empresa é menos restrita financeiramente.

Algumas discussões também foram levantadas a respeito da utilização do $Q$ de Tobin para controlar a lucratividade e oportunidades de investimentos, no qual o fluxo de caixa pode ser um representante mais robusto para o potencial de lucratividade. Erickson e Whited (ERICKSON; WHITED, 2000) utilizaram o método dos momentos generalizados (GMM) para incorporar no modelo de investimento o erro de medida da variável $Q$ de Tobin (para 737 empresas de 1992 a 1995). Os resultados indicaram que o fluxo de caixa não se apresentou significativo para explicar os investimentos quando incorporado o erro de medida do $Q$ de Tobin.

A classificação das firmas entre restritas e não restritas financeiramente tem tomado grandes esforços de pesquisa, grande parte da dificuldade surge devido à esta característica não ser diretamente observada, levando à escolha de critérios subjetivos para realizar tal tarefa.

Lamont, Polk e Saá-Requejo (2001) a partir dos coeficientes da regressão de Kaplan e Zingales (1997) construíram o índice KZ de classificação do nível de restrição financeira das firmas, e testaram se o impacto das restrições no valor da empresa pode ser observado no retorno das ações. As evidências encontradas foram que restrições financeiras afetam o valor da firma, sendo que os níveis das restrições variam no tempo, e as firmas mais restritas obtêm menor retorno que as menos restritas.

Whited e Wu (2006) construíram um índice de restrição financeira, chamado de índice WW, a partir da equação de investimento de Euler utilizando a estimação pelo GMM a partir de dados de frequência trimestral. Testaram a validade do índice com análises de séries temporais dos retornos das ações das firmas consideradas restritas financeiramente, resultando em uma covariância positiva nos retornos e contrastaram o índice $\mathrm{KZ}$ argumentando que as firmas consideradas como restritas pelo $\mathrm{KZ}$ eram grandes e com excessos de investimentos.

Hadlock e Pierce (2010) analisaram os fatores relevantes para a condição da restrição financeira coletando informações qualitativas reportadas em demonstrativos realizados pelos administradores das firmas e estimaram um modelo logit ordenado prevendo o nível de restrição como função de variáveis quantitativas. Os resultados das análises mostraram que os fatores tamanho e idade são altamente significativos na classificação da restrição financeira, em consequência propuseram um indicador baseado nestas duas variáveis, chamado de SA.

O uso desses 3 indicadores tornou-se muito popular, aplicados como medida do nível de restrição financeira da firma e amplamente utilizados até os dias atuais. Porém alguns estudos tiveram dificuldades em obter resultados robustos quando utilizado os 3 índices para agrupar 
as empresas, historicamente o KZ não é correlacionado com o WW e SZ (AKTAS; DE BODT; ROLL, 2013; AMORE; SCHNEIDER; ŽALDOKAS, 2013; HANN; OGNEVA; OZBAS, 2013; YUNG; NAFAR, 2014).

Apesar de escassos, alguns trabalhos também foram endereçados para a economia brasileira. Terra (2003) fazendo uso do modelo acelerador dos investimentos verificou a presença de restrição financeira nas firmas brasileiras no período de 1986 a 1997, os resultados mostraram que empresas multinacionais são menos restritas que as locais. Kalatzis e Azzoni (2009) utilizam uma abordagem econométrica bayesiana para verificar a restrição financeira no mesmo período do estudo de Terra (2003), os resultados evidenciam que as empresas mais intensivas em capital são mais restritas. Em um estudo posterior, utilizando o período de 1997 a 2004, Bassetto e Kalatzis (2011) fazem a classificação da firmas restritas usando a metodologia de cluster e com estimação econométrica bayesiana corroboram os resultados anteriores de que as firmas mais intensivas em capitais possuem um grau maior de restrição financeira. Kirch, Procianoy e Terra (2014) abordando o multiplicador de crédito proposto por Almeida e Campello (2007), analisam a relação da restrição com o investimento das firmas brasileiras, e os resultados mostram que as firmas restritas se comportam como estabelecido no modelo neoclássico. No geral as pesquisas neste tema buscaram verificar a existência e a essência da restrição financeira, relacionando com os determinantes dos investimentos, e as características das firmas restritas e não restritas. Assim como legitimar e/ou propor métodos de identificação dos níveis de restrição.

Os impasses nas pesquisas dos determinantes do investimento da firma no que cerne as questões da restrição financeira e a lacuna de publicações dirigidas ao cenário brasileiro foram os combustíveis motivacionais deste estudo. Considerando a importância dos fatores financeiros nas decisões de investimento e as restrições financeiras das firmas, os intermediários financeiros mostram-se como importantes provedores de fonte de recursos para a viabilização dos investimentos. Devido a esta ligação, um possível canal de transmissão no qual o setor financeiro afeta o crescimento e risco das empresas ocorre pela dependência de recursos financeiros externos, portanto, o risco e retorno das firmas devem ser afetados pelas dificuldades e descomedimentos das entidades financeiras. Atentando a esta circunstância vêse importante o estudo do alastramento do risco do setor financeiro para economia real, tema da próxima seção. 
2.2 Alastramento de risco e contágio financeiro

A propagação de uma crise de uma economia para um mercado ou grupo de mercados tomou grande atenção de pesquisas na década de 90, principalmente após a crise asiática de 1997-1998, na qual o colapso monetário tailandês propagou-se para o leste asiático, atingindo em pouco tempo Rússia e Brasil, chegando até economias mais desenvolvidas como a norteamericana e europeia (CLAESSENS; FORBES, 2004). A atenção recebida ocorreu especialmente pela crise originar e atingir diretamente um conjunto de países considerados até então arquétipos pelas suas trajetórias de desenvolvimento econômico, iniciados na década de 60.

O termo contágio passou então a ser muito utilizado para referir-se aos movimentos de propagação de crises financeiras ${ }^{1}$, e as investigações deste fenômeno passaram a levantar pontos importantes, não só de entender as causas da crise, mas também o porquê de a crise ter se espalhado e o que pode ser feito para limitar propagações de crises futuras. Uma questão de destaque a respeito do conceito de contágio financeiro é, se o fator fundamental que levou a essas oscilações e transmissões foi realmente um efeito de contágio, e em caso positivo por quais mecanismos operava de forma tão intensa.

Não existe atualmente uma definição uniforme do que constitui o contágio financeiro, e o conceito adotado é importante pois baliza as abordagens metodológicas das pesquisas. Alguns trabalhos procuraram debater o conceito. Primeiramente, como apresentado em trabalhos que abordam a definição conceitual (CLAESSENS; DJANKOV; LANG, 2000; CLAESSENS; DORNBUSCH; PARK, 2001; CLAESSENS; FORBES, 2004), pode-se ilustrar a questão com o caso da desvalorização da moeda russa em 1998, no qual sucedeu uma desvalorização no mercado acionário brasileiro em mais de 50\%. Pode-se chegar a uma concordância, sem muitas definições prévias, que essa propagação foi um contágio financeiro. Além disso, sucedendo o mesmo evento Russo, o zloti polonês caiu cerca de $11 \%$, no entanto, esse constitui um contágio? Ou até mesmo em movimentos com menor expressão é constituído contágio?

Por um lado, tem-se uma definição mais restrita de contágio (comumente designada de shift-contagion para diferenciá-la) na qual caracteriza-se pelo aumento significativo das

\footnotetext{
${ }^{1}$ Segundo Claessens e Forbes (2004) a empresa Lexis-Nexis fez uma pesquisa das publicações nos maiores jornais e revistas até 1997 e não encontrou quase nenhum uso do termo contágio relacionado com mercados financeiros internacionais. Já uma mesma pesquisa feita a partir de meados de 1997, resultou que a maioria dos artigos usou o termo contágio referindo-se à propagação da perturbação dos mercados financeiros entre os países.
} 
ligações entre os mercados de duas economias, ou de uma economia individual para um grupo, que estão localizadas em regiões geográficas distintas, possuem diferentes estruturas, e sem supostas ligações comerciais. Neste cenário, a propagação da crise de uma economia para outra é definida como contágio financeiro. Por outro lado, há uma definição mais ampla em que as economias podem estar localizadas em uma mesma região geográfica, com muitas similaridades em termos de estrutura de mercado, com fortes relações comerciais e financeiras. Logo, tendem a estar conectadas tanto em períodos de estabilidade como em períodos de crise. Portanto, a transmissão de um choque econômico durante uma crise em uma dessas economias configura-se como uma extensão desta mesma ligação (ou interdependência) entre os mercados nos períodos de estabilidade (CLAESSENS; FORBES, 2004).

Segundo Claessens, Dornbusch e Park (2001) o contágio financeiro ainda pode ocorrer por diferentes motivos, os quais pode-se, de forma geral, dividi-los conceitualmente em duas categorias: (i) causas fundamentais (tais como, choques comuns, ligações comerciais e desvalorização competitiva, ligações financeiras); e (ii) comportamento dos investidores (tais como: liquidez e problemas de incentivo, assimetria de informação e coordenação de problemas, equilibro múltiplo, mudanças nas regras do “jogo”).

Trabalhos, como de Friedman e Schwartz (1963), Bernanke (1983) e Bernanke e Gertler (1989), argumentam que os deslocamentos no setor financeiro são causas de flutuações econômica. Crises financeiras causam aumentos no custo da intermediação financeira e restringe o crédito, por conseguinte contrai o nível de atividade econômica e pode levar a períodos de baixo crescimento e até recessão econômica.

O contágio financeiro pode ser modelado como um fenômeno de equilíbrio, pequenos choques (poucas instituições ou região particular da economia) são propagados para o setor financeiro e em sequência levados ao resto da economia, portanto pequenos choques podem levar a grandes efeitos no sentido de contágio financeiro (ALLEN; GALE, 2000).

Diversos esforços acadêmicos têm sido feitos no tema de contágio financeiro com enfoques particulares. Os principais estão na mensuração da propagação dos distúrbios de mercado de um país para outro na forma de movimentos conjuntos no câmbio, preços de ações, risco país, fluxo de capitais e também no estudo dos canais que a propagação ocorre ${ }^{2}$. A partir de evidencias empíricas, surge um questionamento se o contágio financeiro internacional existe ou, analisando os movimentos conjuntos da década de 90 , a propagação em si pode não ter sido grande o suficiente considerando o ambiente do mercado de capitais e a economia internacional.

\footnotetext{
${ }^{2}$ Alguns exemplos podem ser vistos em Allen e Gale (2000), Bae, Karolyi e Stulz (2003), Forbes e Rigobon (2002, 2001), Fry-Mckibbin, Martin e Tang (2014), Kodres e Pritsker (2002), Patton (2006) e Pericolli e Sbracia (2003).
} 
Assim sendo, a magnitude e a volatilidade dos movimentos podem não estar diretamente ligados com a instabilidade financeira e sim, em grande parte, ser um indício do efeito manada ${ }^{3}$ (KAROLYI, 2003).

Além da discussão conceitual, estudos empíricos foram realizados para entender o efeito de propagação, como identificação, canais de ocorrência, impacto e formas de prevenção. Por certa influência de pesquisas de analises epidemiológicas de doenças contagiosas que utilizavam modelos de regressão logística multinomial, Bae, Karolyn e Stulz (2003) adotaram o mesmo método na área financeira para modelar ocorrências de altos retornos, no qual é referido como "exceedance" (excessos). A medida de contágio adotada capta a coincidência de choques de retornos extremos entre os países de uma mesma região e entre as regiões. Caracterizaram também o grau de contágio, sua importância econômica, e seus determinantes. O resultado empírico da análise de países emergentes foi que o contágio é previsível e depende das taxas de juros regionais, mudanças nas taxas de câmbio, e volatilidade condicional do retorno das ações.

Segundo Karolyi (2003), as abordagens utilizadas até então para modelar o contágio financeiro apresentam uma limitação importante, em geral devido a muitas enfatizarem o retorno extremo dos ativos, não fazem controle dos fundamentos econômicos. Apontam também as vantagens de utilizar modelos de regressão logística multinomial, utilizada em Bae, Karolyn e Stulz (2003), para modelar as ocorrências dos co-excessos.

Com a mesma abordagem, Christiansen e Ranaldo (2009) analisam a integração financeira de membros da União Europeia (EU), antes e depois da entrada de novos países no ano de 2004, e utilizam o modelo de regressão logística multinomial para avaliar como as variáveis persistência, classe de ativos e volatilidade estão relacionadas com a variável coexcessos (coexceedance) num determinado período entre países. Os resultados forneceram evidencias que existe uma forte persistência dos co-excessos nos dados analisados.

Chui, Peña e Wang (2015) buscaram fazer a ligação entre o risco do setor financeiro e da economia real (indústria e comércio) analisaram o contágio financeiro a partir dos retornos dos setores da economia e propuseram uma nova medida para os co-excessos de Bae, Karolyn e Stulz (2003), chamado por eles de conditional coexceedance, a fim de captar o alastramento do risco de cauda do setor financeiro para cada setor do mercado. Os resultados mostraram a ocorrência do contágio financeiro e que o nível do alastramento do risco de cauda é relacionado

\footnotetext{
${ }^{3} \mathrm{Na}$ área das finanças comportamentais, Banerjee (1992) define o efeito manada como sendo: cada um fazendo o que todo mundo está fazendo, até mesmo se sua informação individual sugere fazer algo completamente diferente.
} 
com características da indústria: o financiamento da dívida liquida com vínculo positivo com o nível do contágio, e o spread do investimento e o valuation com vínculos negativos.

Outros trabalhos foram publicados envolvendo a análise do contágio financeiro utilizando o mercado acionário com abordagens metodológicas distintas. King e Wadhwani (1990) examinaram equilíbrio de mercado utilizando expectativas racionais e assimetria de informação com modelo de regressão de múltiplos para identificar a transmissão da volatilidade entre mercados acionários. Os resultados mostraram que não houve tendência de aumento de correlações entre os mercados analisados, porém não se descartou a hipótese da ocorrência da transmissão. Forbes e Rigobon (2002) usam um modelo de vetor autorregressivo (VAR) nos dados das crises das décadas de 80 e 90 e concluíram que as propagações das crises de 1987 nos EUA, 1994 no México e 1997 na Ásia foram efeitos de interdependência entre as economias e não efeito de contágio.

Caporale, Cipollini e Spagnolo (2005) verificaram a hipótese de interdependência ou contágio por meio da análise de correlação condicional. Observaram que durante a crise asiática ocorreu um aumento no co-movimento das ações dos países afetados.

Krozner, Laeven e Klingebiel (2007), investigam o impacto do crescimento de crises bancárias nas firmas com diferentes níveis de dependência no financiamento externo. Os resultados foram que os setores que são altamente dependentes de financiamento externo tendem a ter uma maior contração do valor adicionado durante uma crise em países com sistema financeiro mais desenvolvido que de países com sistema financeiro menos desenvolvidos. No entanto, não houve evidencias que as firmas mais dependentes de financiamentos externos são prejudicadas em locais com sistemas financeiros menos desenvolvidos.

Quanto aos estudos nacionais, em grande parte tratam da crise e desvalorização cambial de 1998-1999 e da crise internacional do subprime de 2008. Carvalho e Chiann (2013) verificaram a existência de contágio financeiro no período de 1996 a 2009 pelos índices de mercado do Brasil, Argentina, México, EUA, Malásia e Rússia. Empregando uma abordagem de redes bayesianas e análise sequencial os resultados mostraram grande interligação entre os mercados em períodos de crise. Perobelli, Vidal e Securato (2013) testam o efeito de contágio comparando as teorias propostas por Forbes e Rigobon (2002) e Corsetti, Pericoli e Sbracia (2005), com uma amostra de 16 países, verificam oito episódios de crises financeiras, de 1997 a 2008. Os resultados da aplicação da metodologia de Forbes e Rigobon (2002) exibiram que para 15 países não houve evidencias de contágio em nenhum dos episódios de crise, já utilizando o método de Corsetti, Pericoli e Sbracia (2005) o efeito do contágio só não foi evidenciado na crise russa de 1998, argentina de 2001, e brasileira de 2002. 
Como apresentado, grande parte dos estudos sobre identificação do contágio financeiro analisam a propagação de crises entre países. Já o presente estudo amplia a literatura nacional utilizando um enfoque microeconômico, no qual analisa-se a transmissão de risco do setor financeiro para as firmas da economia real. Para tanto, adota-se uma definição menos restrita de contágio financeiro, na qual o fenômeno pode existir pela propagação de eventos extremos entre economias com ligações comerciais e em uma mesma região geográfica, no caso deste trabalho, entre o setor financeiro e empresas, e em qualquer período.

Com o objetivo de verificar os efeitos do alastramento de risco do setor financeiro para a economia real nas decisões de investimentos das firmas, as quais perpassam por conjunturas de restrição financeira, testa-se as seguintes hipóteses para a economia brasileira: (a) o efeito de contágio financeiro do setor financeiro para a economia real afeta as decisões de investimentos das firmas restritas e não restritas financeiramente?; e (b) o efeito do alastramento de risco do setor financeiro para a economia real afeta as decisões de investimentos das firmas restritas e não restritas financeiramente?. A hipótese do contágio financeiro está ligada a eventos de perdas extremas, já o alastramento da volatilidade abriga a propagação de risco como um todo. As questões metodológicas e dados utilizados para atingir tais objetivos são apresentados no capítulo a seguir. 


\section{DADOS E MÉTODOS}

Na identificação do contágio financeiro e alastramento de risco, assume-se o risco sendo a medida da incerteza global da firma. Nesse estudo o risco é calculado como o desvio padrão dos retornos dos preços das ações das firmas de capital aberto negociadas na bolsa de valores BMF\&BOVESPA, no período de 1997 a 2015.

A fim de selecionar as séries que representam as oscilações de mercado de cada empresa foram considerados apenas as classes de ações ordinárias e preferenciais ( $\mathrm{ON}$ e PN), excluindo ADRs, ETFs, ações nominativas, ações fracionadas, etc. Com os preços de fechamento obtevese os retornos diários discretos e considerando que o preço da ação não se alterou nos dias que houveram dados ausentes (missing values), estes foram preenchidos com a informação da última cotação disponível, ou seja, retorno igual a zero.

Realizou-se uma limpeza na base de dados dos retornos das ações com o objetivo de considerar apenas as que apresentaram liquidez no período, as observações de cada empresa foram analisadas e excluiu-se as séries que apresentaram baixa liquidez ou muitas observações do retorno iguais a zero ${ }^{4}$. Para representar o risco do setor financeiro foi construído uma carteira e a partir do retorno desta carteira obteve-se o desvio padrão do setor.

$\mathrm{Na}$ análise do investimento utiliza-se os dados divulgados nos demonstrativos financeiros trimestrais das mesmas empresas. Tanto os dados de cotações e retorno, quanto os dados contábeis foram ajustados pelo índice de inflação IPCA na data base 31/12/2015. Os dados foram obtidos na base de dados Economática ${ }^{\circledR}{ }^{5}$.

Com o risco da firma e do setor financeiro realizam-se as análises de contágio financeiro e alastramento do risco. Os indicadores de contágio e alastramento foram agrupados em períodos trimestrais a fim de coincidir com a frequência dos dados contábeis, formando uma única base de dados contendo as variáveis do modelo de investimento.

Nas próximas seções deste capítulo são apresentados os métodos utilizados com os dados expostos, partindo da formação da carteira do setor financeiro, formação dos índices de contágio financeiro e alastramento do risco até o modelo de investimento e sua estimação.

\footnotetext{
${ }^{4}$ Excluiu-se as séries nos períodos em que mais de um terço dos retornos foram iguais a zero.

5 Base de dados Economática - Tools for Investment Analysis (maio/2016), disponível em https://economatica.com/
} 
3.1 Carteira do setor financeiro

Construiu-se uma carteira dinâmica de mínima variância com ajuste diário do setor financeiro utilizando os momentos dos retornos (média, desvio-padrão e covariância) das ações das empresas pertencentes à classificação NAICS no nível de três dígitos: 521 a 525 e 531 a 535.

Define-se o retorno da ação $i$ no período $t$ como:

$$
\begin{gathered}
r_{i, t}=\frac{P_{i, t}-P_{i, t-1}}{P_{i, t-1}} \\
R_{(i \times 1)}=\left[\begin{array}{c}
r_{1} \\
r_{2} \\
\vdots \\
r_{i}
\end{array}\right]
\end{gathered}
$$

Onde $P$ representa o preço de fechamento ajustado pela inflação na data base de 31/12/2015. Devido ao propósito deste estudo assumiu-se que não existem vendas a descoberto (short sales) e alavancagem das ações ${ }^{6}$, sendo assim tem-se que:

$$
W_{(i \times 1)}=\left[\begin{array}{c}
w_{1} \\
w_{2} \\
\vdots \\
w_{i}
\end{array}\right]
$$

Sujeito a:

$$
\begin{gathered}
0 \leq w_{i} \\
W^{\prime}(1)_{(i \times 1)}=1
\end{gathered}
$$

Onde $w_{i}$ é a proporção da ação $i$ na carteira; o sobrescrito ' indica a transposição da matriz; e $(1)_{(i \times 1)}$ é o vetor de uns de tamanho $i$. Define-se o retorno da carteira do setor e a matriz de variância e covariância, respectivamente, como:

\footnotetext{
${ }^{6} \mathrm{O}$ propósito é estimar uma média de retorno e desvio-padrão de mercado para o setor financeiro, portanto foi feito a restrição de não existir vendas a descoberto $\left(w_{F I N} i, t \geq 0\right)$ e não existir alavancagem na carteira $\left(w_{F I N} i, t \leq\right.$ 1). A prática de vendas a descoberto também é prevenida em bolsas de valores para alguns ativos e requer qualificações substanciais de crédito quando realizadas.
} 


$$
\begin{gathered}
r_{F I N}=W^{\prime} \cdot R \\
\Sigma_{(i \times i)}=\left[\begin{array}{ccc}
\sigma_{1}^{2} & \cdots & \sigma_{1, i} \\
\vdots & \ddots & \vdots \\
\sigma_{i, 1} & \cdots & \sigma_{i}^{2}
\end{array}\right]
\end{gathered}
$$

Segundo Markowitz (1952), a variância de uma carteira pode ser mensurada pela soma das variâncias individuais com os pares de covariâncias, representada pela matriz $\Sigma$, e ponderadas pelo peso de cada ativo (vetor $W$ ), portanto, a variância da carteira pode ser representada pela expressão a seguir:

$$
\sigma_{F I N}^{2}=W^{\prime} \Sigma W
$$

Carteiras eficientes são as que possuem o maior retorno esperado para um dado nível de risco, o qual pode ser mensurado pelo desvio-padrão da carteira (MARKOWITZ, 1952). Para implementar a otimização de Markowitz é necessário conhecer a distribuição dos retornos e estimar os retornos esperados. Já a carteira de mínima variância global é uma carteira eficiente de ações da qual as proporções dos ativos não dependem diretamente dos retornos esperados (JORION, 1985; MERTON, 1980). Portanto, aplica-se o algoritmo de Markowitz para obterse a carteira de mínima variância global com a restrição de não existirem vendas a descoberto e alavancagem. O problema de otimização é definido como:

$$
\begin{gathered}
\min _{w} \sigma_{F I N}^{2}=\min _{w} W^{\prime} \Sigma W \\
\text { sujeito a: } 0 \leq w_{i} ; W^{\prime}(1)=1
\end{gathered}
$$

Na aplicação da otimização utiliza-se programação quadrática por permitir restrições com desigualdade (RUPPERT; MATTESON, 2015). São utilizadas para minimizar funções objetivas quadráticas sujeitas a restrições lineares, deste modo a função objetiva no problema da seleção dos pesos da carteira apresentado é a variância do retorno da carteira do setor financeiro, equação (13). Para empregar a otimização modifica-se função da variância, para tanto considere: 


$$
\begin{gathered}
D=2 \Sigma \\
d_{(i \times 1)}=(0 \ldots 0)^{\prime}
\end{gathered}
$$

Onde $d$ é um vetor de zeros de tamanho $i$, reescrevendo a função de mínima variância da carteira (equação (12)) com os termos definidos na equação (14), tem-se:

$$
\sigma_{F I N}^{2}=W^{\prime} \Sigma W=\frac{1}{2} w^{\prime} D w-d^{\prime} w
$$

O problema de otimização passa a ser em função da variância da carteira modificada:

$$
\min _{w} \sigma_{F I N}^{2}=\min _{w} \frac{1}{2} w^{\prime} D w-d^{\prime} w
$$

A seguir é definido as matrizes das restrições do problema em três etapas: primeiro define-se as matrizes referentes a restrição de igualdade (identificadas pelo subscrito $E Q$ ); segundo, as matrizes para a restrição de desigualdade (identificadas pelo subscrito $n E Q$ ); por fim a união das matrizes destas duas matrizes.

A restrição de igualdade, $w^{\prime} 1=1$, passa a ser escrita como:

$$
\begin{gathered}
D_{E Q_{(1 \times i)}}^{\prime}=1_{(1 \times i)}^{\prime} \\
s_{E Q_{(1 \times 1)}}=1 \\
D_{E Q}^{\prime} w=1^{\prime} w=1=s_{E Q}
\end{gathered}
$$

A restrição de desigualdade, $w \geq 0$, passa a ser escrita como:

$$
\begin{gathered}
D_{n E Q_{(i \times i)}}^{\prime}=I_{i} \\
s_{n E Q_{(i \times 1)}}=\left(\begin{array}{c}
0 \\
\vdots \\
0
\end{array}\right) \\
D_{n E Q}^{\prime} W=I_{i} w=w \geq 0_{(i \times 1)}=s_{n E Q}
\end{gathered}
$$

Unindo as matrizes de restrição temos a restrição global a sujeitar a função objetiva: 


$$
D^{\prime}=\left(\begin{array}{c}
D_{E Q}^{\prime} \\
D_{n E Q}^{\prime}
\end{array}\right)=\left(\begin{array}{c}
1_{(1 \times i)}^{\prime} \\
I_{i}
\end{array}\right) ; s=\left(\begin{array}{c}
s_{E Q} \\
s_{n E Q}
\end{array}\right)=\left(\begin{array}{c}
1 \\
0_{(i \times 1)}
\end{array}\right)
$$

Com isso aplica-se a otimização diariamente, os resultados são os pesos para cada dia e para cada ação, $w_{i, t}$. Para existir solução no conjunto dos números reais no problema de otimização, a matriz de covariância, $\Sigma$, deve ser positiva definida. Quando $\Sigma$ não se apresentou positiva definida aplicou-se um estimador de encolhimento do tipo James-Stein, cujos métodos de implementação utilizados são os apresentados em Opgen-Rhein e Strimmer (2007), o modelo da estatística de encolhimento apresentado pelos autores é derivado de um conjunto quasi-empírico bayesiano e não necessita de especificações dos parâmetros e das distribuições de probabilidade ${ }^{7}$. Com isso sempre se tem uma matriz de covariância positiva definida que a partir dela calcula-se os retornos e desvio padrão da carteira que representa neste estudo os movimentos do setor financeiro.

\subsection{Contágio financeiro}

De acordo com a abordagem de Allen e Gale (2000), pequenos choques de retorno propagam-se a grandes choques na presença de contágio financeiro. O pressuposto do enfoque utilizado é que o contágio financeiro é um fenômeno associado a grandes retornos (BAE; KAROLYI; STULZ, 2003), assim sendo, a abordagem deste estudo também estará nos retornos extremos.

Bae, Karolyn e Stulz (2003) afirmam que a medida dos excessos de retorno como indicador da presença de contágio é melhor que o coeficiente de correlação se existe comportamento de mercado não linear, pois a medida dos excessos não é restrita a descrever comportamentos mercadológicos lineares. Como consequência escolheu-se utilizar o apuramento de coincidências de retornos extremos em vez de correlações de retornos extremos conjuntos como indicador do contágio financeiro.

\footnotetext{
${ }^{7}$ Segundo Opgen-Rhein e Strimmer (2007) a abordagem é tanto computacional quanto estatisticamente eficientes, e a inversa da matriz pode ser eficientemente computada.
} 
O contágio será captado pelo risco de cauda financeiro ${ }^{8}$, aplicando o índice proposto no trabalho de Chiu, Peña e Wang (2015), fundamentados em Bae, Karolyn e Stulz (2003), no qual utiliza-se um indicador representativo chamado de co-excessos condicionais (CEC). O CEC mede a frequência dos retornos extremamente negativos e simultâneos entre o setor financeiro e as ações das firmas da economia real.

O retorno extremo negativo, ou excesso negativo, é definido como o retorno que se encontra abaixo do $\alpha$-ésimo percentil da distribuição do retorno marginal. $\mathrm{O}$ excesso negativo para a empresa $i$ no tempo $t$ é definido como:

$$
C_{i, t}(e)=\left\{\begin{array}{c}
1, \text { se } r_{i, t} \in e, t=1, \ldots, T \\
0, \text { caso contrário }
\end{array}\right.
$$

No qual $C_{i, t}$ é a função característica que se iguala a 1 quando o retorno da firma $i$ no período $t, r_{i, t}$, pertence ao conjunto $e$ e 0 caso contrário. Como o interesse está nos retornos negativos, o limiar para definir os retornos extremos é definido como o $5^{\circ}$ percentil da distribuição dos retornos diários, e o conjunto $e$ é o conjunto dos retornos diários localizados abaixo deste limiar.

Concentrando na ocorrência de retornos negativos extremos simultâneos como principal elemento do contágio, a medida CEC, para a firma (não financeira) $i$ no período $t$ é definida como:

$$
C E C_{i, t}=C_{i, t}(e) \times C_{F I N, t}(e), \quad t=1, \ldots, T
$$

No qual $C E C_{i, t}$ iguala-se a 1 se ambos, a firma $i$ e o setor financeiro $(F I N)$, tenham excessos no momento $t$ e 0 caso contrário. Com essa medida obtêm-se as frequências observadas do CEC para a firma $i$ para cada trimestre somando os CEC diários. A intuição deste indicador é que quanto mais elevado a medida, maior a exposição ao movimento conjunto do risco de cauda (adotado como indicador de contágio). O resultado de Chiu, Peña e Wang (2015) ao testarem o indicador foi que em períodos de crise os episódios de extrema volatilidade iniciam-se no setor financeiro e propagam para a economia real.

\footnotetext{
${ }^{8}$ Risco de cauda (tail risk) é o risco de um ativo ou carteira de ativos moverem-se mais que um dado limiar que divide o de centro de uma distribuição de sua cauda. Em particular, a maioria dos agentes estão apenas interessados no risco de queda, ou seja, mover-se abaixo do limiar (cauda esquerda).
} 


\subsection{Alastramento do risco}

Para mais evidencias da ocorrência de propagação do risco verifica-se o alastramento não só pelos movimentos do contágio financeiro, mas também o sucedido de toda a distribuição de probabilidade dos retornos do setor financeiro e das firmas. Sendo assim, estuda-se a transmissão do risco como um todo, não se firmando apenas nos retornos negativos extremos.

A análise do alastramento do risco é realizada a partir da adaptação do método aplicado por Liu e Pan (1997). Ajusta-se a autocorrelação das séries de retornos de cada firma e do setor financeiro pelo modelo de vetores autorregressivos (VAR), em seguida normaliza-se os resíduos do VAR da série do setor financeiro pela média do processo "Generalized Autoregressive Conditional Heteroskedasticity" - GARCH, e em um segundo estágio realizase a avaliação do alastramento da volatilidade pela modelagem de regressão multivariada na qual a variável explicada é a variância da firma $i$ e o parâmetro de interesse estimado é da variável explicativa obtida da série normalizada pelo processo GARCH. Assim, existe um alastramento do risco do setor financeiro para a firma se o parâmetro de interesse for significativamente positivo.

Sims (1980) desenvolveu seu modelo VAR induzido pelo teste de causalidade de Granger (1969). A aplicação do modelo nesse estudo consiste em estimar as séries dos retornos de cada firma e do setor financeiro:

$$
\begin{aligned}
r_{t}^{i} & =\sum_{j=1}^{k} \beta_{j} r_{t-j}^{i}+\sum_{j=1}^{k} \phi_{j} r_{t-j}^{F I N}+u_{t}^{i} \\
r_{t}^{F I N} & =\sum_{j=1}^{k} \theta_{j} r_{t-j}^{F I N}+\sum_{j=1}^{k} \delta_{j} r_{t-j}^{i}+u_{t}^{F I N}
\end{aligned}
$$

Onde $r_{t}^{F I N}$ representa o retorno do setor financeiro $(F I N)$ no período $t$, e $r_{t}^{i}$ o retorno da firma $i$ pertencente ao setor não financeiro, procedendo com um modelo para cada firma $i$. $O$ termo de choque (erro estocástico ou impulso) $u_{t}^{i}$ e $u_{t}^{F I N}$ são normalizados pelo processo GARCH. Porém antes deve-se resolver uma questão empírica, o comprimento das defasagens: $k$.

Com a finalidade de obter um modelo parcimonioso são utilizados os critérios de informação de Akaike e de Schwarz para decidir o tamanho de $k$, para o modelo de cada 
empresa, utilizando o que apresenta menor valor das defasagens, a fim de evitar muitos graus de liberdade e possíveis problemas de multicolinearidade. Ademais para validar o modelo realiza-se a verificação de estacionariedade com os testes Dickey-Fuller aumentado - ADF (DICKEY; FULLER, 1979, 1981) utilizando a estatística tau de Mackinnon (1991) e o teste não paramétrico Phillips-Perron (PHILLIPS; PERRON, 1988), e os testes padrão t e F para a significância individual e conjunta dos parâmetros estimados. Com isso o resíduo $u_{t}^{F I N}$, com distribuição $N\left(0, \sigma_{F I N, t}^{2}\right)$, é normalizado com a média do processo GARCH.

O modelo GARCH proposto por Bollerslev (1986) fornece uma estrutura de atraso mais flexível que os modelos "Auto-Regressive Conditional Heterocedasticity" - ARCH (ENGLE, 1982), adicionando variâncias estimadas passadas no modelo. Esses modelos são comumente utilizados em trabalhos de finanças com o intuito de avaliar o risco obtido da variação da série de retornos de um ativo. A variabilidade desses ativos financeiros observada no mercado financeiro com uma variância não constante, pode ser entendida como a variância condicional nos modelos denominados heterocedásticos condicionais.

Considerando que os retornos podem não ser correlacionados serialmente, mas a variância condicional possui uma relação quadrática com os retornos passados, os modelos ARCH tratam esta heterocedasticidade como um ponto a ser modelado.

A ideia do modelo ARCH está na questão da variância do termo de erro $u_{t}^{F I N}$ ser dependente de $\left(u_{t-1}^{F I N}\right)^{2}$ e com uma distribuição $N\left[0,\left(\sigma_{F I N, t}^{2}=\alpha^{F I N}+\lambda^{F I N}\left(u_{t-1}^{F I N}\right)^{2}\right)\right]$. Portanto, a variância $\left(\sigma_{F I N, t}^{2}\right)$ é delineada pelo quadrado da variância defasada e dos parâmetros $\alpha^{F I N} \mathrm{e}$ $\lambda^{F I N}$. Pelo fato deste modelo inicial ter apenas uma defasagem da variância condicional é escrito como $\operatorname{ARCH}(1)$, generalizando o modelo para $q$ defasagens, $\operatorname{ARCH}(q)$ :

$$
\sigma_{F I N, t}^{2}=\alpha^{F I N}+\sum_{l=1}^{q} \lambda_{l}^{F I N}\left(u_{t-q}^{F I N}\right)^{2}
$$

Com o objetivo de estender o conjunto de informação e diminuir o número de parâmetros dos modelos $\operatorname{ARCH}(q)$, Bollerslev (1986) introduz no modelo $\mathrm{ARCH}$ variâncias estimadas passadas, $\sigma_{F I N, t-p}^{2}$ :

$$
\sigma_{F I N, t}^{2}=\alpha^{F I N}+\sum_{l=1}^{q} \omega_{l}^{F I N}\left(u_{t-q}^{F I N}\right)^{2}+\sum_{m=1}^{p} \lambda_{m}^{F I N} \sigma_{F I N, t-p}^{2}
$$


Originando o modelo $\operatorname{GARCH}(p, q)$, onde as restrições para que esta variância seja positiva e fracamente estacionária são:

$$
\begin{gathered}
\alpha^{F I N}>0 \\
\omega_{l}^{F I N}, \lambda_{m}^{F I N} \geq 0 \\
0 \leq \sum_{\substack{m=1 \\
l=1}}^{p, q}\left(\omega_{l}^{F I N}+\lambda_{m}^{F I N}\right)<1
\end{gathered}
$$

Neste estudo é aplicado o GARCH(1,1), de forma que:

$$
\sigma_{F I N, t}^{2}=\alpha^{F I N}+\omega^{F I N}\left(u_{t-1}^{F I N}\right)^{2}+\lambda^{F I N} \sigma_{F I N, t-1}^{2}
$$

No qual a série dos retornos do setor financeiro normalizada é:

$$
\eta_{t}^{F I N}=\frac{u_{t}^{F I N}}{\sigma_{F I N, t}^{2}} \sim N(0,1)
$$

Finalmente é estimado o alastramento da volatilidade com o modelo multivariado:

$$
\sigma_{i, t}^{2}=\rho^{i}+\xi^{i}\left(u_{t-1}^{i}\right)^{2}+\varphi^{i} \sigma_{i, t-1}^{2}+\gamma^{i}\left(\eta_{t-1}^{F I N}\right)^{2}
$$

Onde o coeficiente $\gamma^{i}$ estimado é definido por $\hat{\gamma}_{i}$, e representa o impacto do risco ajustado do setor financeiro no risco da firma $i$. Portanto, se este coeficiente é significante estatisticamente tem-se evidência do alastramento do risco do setor financeiro para a economia real.

Ambos os indicadores, de movimentos conjuntos dos retornos extremos negativos $(C E C)$ e o de alastramento do risco $\hat{\gamma}_{i}$, serão testados no modelo de investimento para as firmas restritas e não restritas financeiramente. 
3.4 Modelo de investimento e restrição financeira

Após a teoria de Modigliani e Miller $(1958,1963)$ diversos trabalho empíricos emergiram com o intuito de rever efeitos financeiros no investimento e a importância dos fundos internos no crescimento das firmas sucedido principalmente das imperfeições no mercado de capitais implicando neste caso na restrição. Sendo assim, em mercados imperfeitos de capitais, os fundos internos não são substitutos perfeitos dos financiamentos externos nas decisões de investimento das firmas, a partir deste pressuposto, advém a importância do estudo da restrição financeira e da relação com as instituições financeiras. Dessa forma, este trabalho busca contribuir com a literatura incorporando a análise do alastramento do risco do setor financeiro para a economia real nas decisões de investimento das firmas restritas e não restritas financeiramente.

Para tanto faz-se uso do indicador dos co-excessos condicionais $(C E C)$ e do alastramento do risco $\left(\hat{\gamma}_{i}\right)$ no modelo de investimento, segregando as firmas entre restrita e não restritas financeiramente por meio dos indicadores de restrição KZ e WW (LAMONT; POLK; SAAREQUEJO, 2001; WHITED; WU, 2006). O modelo de investimento empregado é o neoclássico acelerador do investimentos flexível originado de Jorgenson (1963), e adaptado a fim de incorporar os índices $C E C$ e $\hat{\gamma}_{i}$. Utiliza-se o modelo na sua versão flexível por possibilitar a correlação serial do investimento e o processo de ajustamento a mudanças dependente do tempo, portanto, o ajuste da taxa corrente de investimento depende de seu nível anterior, resultando em um modelo dinâmico. O proposto neste trabalho é definido por:

$$
\begin{aligned}
\frac{I_{i, t}}{K_{i, t-1}}=\alpha_{i}+ & \beta_{1}\left(\frac{I_{i, t}}{K_{i, t-1}}\right)_{i, t-1}+\beta_{2}\left(\frac{I_{i, t}}{K_{i, t-1}}\right)_{i, t-1}^{2}+\beta_{3} \frac{C F_{i, t}}{K_{i, t-1}}+\beta_{4} \frac{D_{i, t}}{K_{t-1}}+\beta_{5} \frac{S_{i, t}}{K_{t-1}} \\
& +\beta_{6} C E C_{i, t}+\beta_{7} \hat{\gamma}_{i, t}+\varepsilon_{i t}
\end{aligned}
$$

Onde os subscritos $i$ e $t$ representam a firma e o trimestre respectivamente; $K$ o estoque de capital em ativos imobilizados; $I$ o investimento da firma, definido como a variação do estoque de capital $K$ ajustado pelos movimentos de vendas de imobilizado (baixas), depreciação e impairment de cada período; $C F$ o fluxo de caixa; $D$ a dívida definida como a soma dos passivos onerosos do balanço patrimonial; $S$ as vendas líquidas de tributo e comissão sobre venda; CEC o indicador de co-excessos condicionais, e $\hat{\gamma}$ o indicador do alastramento do risco 
calculado do processo VAR-GARCH e $\varepsilon_{i, t}$ o termo de erro da estimação. A Tabela A1 do apêndice A contém uma apresentação completa das variáveis.

A variável investimento $(I)$ objetiva captar apenas as aquisições na conta contábil do ativo imobilizado líquido, portanto, na variação entre os períodos do ativo fixo é retirado os movimentos de vendas, depreciação e impairment, $I_{i, t}$ é definido como $K_{i, t}-K_{i, t-1}+K S_{i, t}+$ $D E P_{i, t}+I M P_{i, t}$, onde $K S$ são as vendas líquidas das baixas do ativo imobilizado no trimestre, $D E P$ a depreciação do trimestre, e IMP o impairment registrado no trimestre.

A utilização do investimento como razão do estoque de capital $\left(I_{i, t} / K_{i, t-1}\right)$ garante que a taxa de crescimento do capital físico $\left(\frac{K_{i, t}}{K_{i, t-1}}-1\right)$ independe da sua escala. A utilização da variável dependente defasada e quadrática busca proporcionar ao modelo um aspecto não linear e dinâmico no qual espera-se um efeito marginal decrescente, ou seja, $\beta_{1}>0$ e $\beta_{2}<0$.

Modigliani e Miller (1963) assinalam o benefício da dívida devido à redução da base de cálculo para apuração de tributos sobre o lucro, portanto, a variável $\left(D_{i, t} / K_{t-1}\right)$ capta a alavancagem da empresa e o possível benefício fiscal devido à despesa com juros, podendo levar a um aumento no valor da empresa, assim, o valor esperado do coeficiente $\beta_{4}$ é maior que zero, e mais sensível nas empresas não restritas.

A proporção de geração de caixa referente ao capital da firma $\left(C F_{i, t} / K_{t-1}\right)$ procura incluir a geração da disponibilidade interna de recursos, e considerado como uma fonte de financiamento de baixo custo, será significativo para as firmas das quais os financiamentos interno e externo não são substitutos perfeitos. Pode-se interpretá-la como possível restrição financeira nas decisões de investimento, as firmas restritas possivelmente terão uma sensibilidade maior à esta variável. Já a inclusão da variável taxa de vendas $\left(S_{i, t} / K_{i, t-1}\right)$ procura controlar a relação da lucratividade futura na taxa de investimento permitindo a separação deste efeito do fluxo de caixa, portanto espera-se um efeito positivo do coeficiente $\beta_{5}$.

A variável $C E C_{i, t}$ procura inserir o componente dos co-excessos condicionais no modelo, onde capta a relação dos movimentos conjuntos dos retornos extremos negativos do setor financeiro para a firma, usado como um indicador do contágio financeiro. Níveis mais elevados desta variável significam uma alta frequência de retornos extremos negativos conjuntos entre o setor financeiro e a firma, ou um possível efeito de contágio maior.

Já o índice $\hat{\gamma}_{i, t}$ procura captar o efeito da intensidade do alastramento do risco do setor financeiro para a firma $i$ medido pela estimação do parâmetro $\gamma^{i}$ da equação (29). Maiores valores do índice indicam um maior impacto do risco do setor financeiro no risco da firma, ou 
um maior alastramento do risco, causando uma dispersão maior no retorno esperado das firmas advindos das variações do retorno do setor financeiro levando a um maior custo de oportunidade do capital próprio sobre os investimentos. Considerando que as firmas não restritas podem substituir o capital próprio por capital de terceiros com uma elasticidade próxima de 1, os efeitos do alastramento do risco nos investimentos possivelmente são menores que nas firmas restritas financeiramente.

Para estimar os parâmetros da função de investimento proposta utiliza-se modelos de regressão linear aplicados a dados em painel. Devido ao modelo ser dinâmico, a inclusão da variável $\left(I_{i, t} / K_{i, t-1}\right)$ defasada como explicativa causa o chamado "dynamic panel bias" (NICKELL, 1981), no qual o termo defasado da taxa de investimento é correlacionado com os efeitos fixos do termo de erro, portanto esta variável caracteriza-se como endógena no modelo. Outra variável endógena é a $\left(D_{i, t} / K_{i, t-1}\right)$ dado que seus valores dependem das decisões e habilidades dos gestores das firmas. Ao empregar estas variáveis no modelo a estimação por mínimos quadrados ordinários (OLS) torna-se inconsistente, pois ele amplia as estimativas dos coeficientes das variáveis endógenas por atribuir poder preditivo a elas na qual pertence ao efeito fixo da firma. Na estimativa por efeito fixo o problema poderia ser suprimido para uma amostra suficientemente grande, tal que $T \rightarrow \infty$, porém a amostra neste estudo tem $T=80$ trimestres e 193 empresas.

Para contornar a endogeneidade neste modelo, instrumentaliza-se a variável $I_{i, t} / K_{i, t-1}$ defasada e as demais variáveis endógenas utilizando a estratégia proposta por Arellano e Bover (1995) e Blundell e Bond (1998), estimando o modelo pelo método dos momentos generalizados (GMM) utilizando equações em nível e diferenças defasadas das variáveis endógenas como instrumentos, fazendo uso de um sistema tanto de equações em nível quanto em diferença no processo de estimação, conhecido como system GMM.

Devido a utilização de equações em nível, o efeito fixo da firma $\left(\alpha_{i}\right)$ permanece no modelo e pode estar correlacionado com os regressores, portanto assume-se que a correlação é constante no tempo:

$$
E\left(Z_{i, t-p} \alpha_{i}\right)=E\left(Z_{i, t+q} \alpha_{i}\right)
$$

Onde $Z$ representa a matriz das variáveis endógenas, assim as variáveis em diferença não são correlacionadas com o efeito específico, e as diferenças defasadas tornam-se instrumentos válidos para as variáveis endógenas em nível e tem-se a condição de ortogonalidade: 


$$
E\left[\Delta X_{i, t-1}\left(\alpha_{i}+\varepsilon_{i, t}\right)\right]=0, \text { para } t=3, \ldots, T
$$

Onde $X$ representa a matriz dos instrumentos. Esta configuração gera um sistema de duas equações, a equação original e a transformada. Outra condição de ortogonalidade que deve ser observada na estimação é definida por:

$$
E\left(X_{i, t-s} \Delta \varepsilon_{i, t}\right)=0, \text { para } s \geq 2 \text { e } t=3, \ldots, T
$$

Essa condição advém da ideia do modelo proposto por Arellano e Bond (1991), permitindo o uso de níveis defasados da variável endógena como instrumento da variável endógena em diferença, ou seja, utilizar $\left(I_{i} / K_{i, t-1}\right)_{i, t-s}$ para $s \geq 2$ como instrumento de $\Delta\left(I_{i} / K_{i, t-1}\right)_{i, t-1}$.

O processo de estimação implementado neste estudo possui 2 estágios (twostep system GMM). No qual no primeiro estágio admite-se o pressuposto que os erros são homocedásticos, tanto entre as firmas $i$ quanto ao longo dos trimestres $t$. No segundo estágio retira-se a hipótese de homocedasticidade, e com os resíduos da estimação do primeiro estágio é formada a matriz de variância e covariância de Windmeijer (2005), otimizando a ponderação para a estimação pelo GMM. Estimar duas equações em um system GMM reduz o viés e a imprecisão associados com o estimador GMM somente de primeiras diferenças (ARELLANO; BOVER, 1995; BLUNDELL; BOND, 1998).

As demais variáveis são consideradas como exógenas no modelo, já que não podem ser determinadas dentro do próprio modelo proposto e seus níveis independem das decisões dos gestores das firmas.

Como apresentado em Arellano e Bond (1991), Arellano e Bover (1995) e Blundell e Bond (1998), dois testes de especificação são implementados. O teste de Sargan/Hansen de sobreidentificação verifica a validade geral dos instrumentos, com a hipótese nula que todos os instrumentos conjuntos são exógenos, com um grande p-valor do teste a hipótese nula não é rejeitada. Um segundo teste consiste em verificar a hipótese nula que o termo de erro das equações em diferença não são serialmente correlacionadas de segunda ordem, aplicando um modelo AR(2). Portanto, para a validação do modelo não se deve rejeitar a hipótese nula.

Para ter uma amostra mais homogênea e poder tirar conclusões da situação financeira das firmas com relação aos parâmetros utilizados, os dados serão agrupados conforme o índice KZ 
e WW, em firmas restritas e não restritas. O objetivo é identificar a situação financeira das empresas (se restritas financeiramente ou não).

Considerando que a restrição é um importante fator nas decisões de investimento, é importante identificar a situação financeira e agrupá-las segundo este critério para homogeneizar a amostra.

Lamont, Polk e Saá-Requejo (2001) utilizaram os coeficientes da regressão do modelo de Kaplan e Zingales (1997), e construíram o índice KZ, formado pela combinação linear de cinco indicadores contábeis. O índice identifica o grau de restrição financeira das empresas, no qual quanto maior (menor) o índice KZ, maior (menor) o nível de restrição financeira. Este estudo faz uso do mesmo índice KZ, utilizando dados contábeis trimestrais das firmas do setor não financeiro, o modelo é especificado como:

$$
\begin{aligned}
K Z_{i, t}=-1,001909 \frac{C F_{i, t}}{K_{i, t-1}}+0,2826389 Q_{i, t}+3,139193 \frac{D_{i, t}}{T C_{i, t}}-39,3678 \frac{D I V_{i, t}}{K_{i, t-1}} \\
-1,314759 \frac{C S H_{i, t}}{K_{i, t-1}}
\end{aligned}
$$

Onde A variável $C F$ é o fluxo de caixa, $K$ o estoque de capital em ativo fixo, $Q$ o 'q' de Tobin, $D$ a dívida, $T C$ o capital total (soma do patrimônio líquido e dívida), DIV os dividendos (pagamentos às ações ordinárias e preferenciais) e $C S H$ o caixa e equivalentes de caixa (investimentos de curto prazo de alta liquidez).

Para entender a classificação das empresas em restritas e não restritas classifica-se as firmas também utilizando o índice WW de Whited e Wu (2006), definido como:

$$
\begin{aligned}
W W_{i, t}= & -0,091 \frac{C F_{i, t}}{T A_{i, t}}-0,062 \mathrm{dDIV}_{i, t}+0,021 \frac{D L T_{i, t}}{A T_{i, t}}-0,044 \text { size }_{\mathrm{i}, \mathrm{t}} \\
& +0,102 \mathrm{SGI}_{\mathrm{i}, \mathrm{t}}-0,035 \mathrm{SG}_{\mathrm{i}, \mathrm{t}}
\end{aligned}
$$

Onde $C F$ é o fluxo de caixa; $T A$ é o ativo total; $d D I V$ é uma dummy que assume valor 1 caso tenha ocorrido a distribuição de dividendos e 0 caso contrário; DLT é a dívida de longo prazo; size o tamanho da empresa medida pela capitalização de mercado; SGI é a taxa de crescimento das vendas do setor da empresa; e $S G$ a taxa de crescimento das vendas da empresa.

Tanto o índice KZ, quanto o índice WW foram construídos de forma que quanto maior o valor associado a eles, maior a restrição financeira da firma, e para classificar as firmas em 
restritas e não restritas a amostra é dividida em tercis de acordo com os valores de cada índice, sendo o primeiro tercil constituído pelas firmas não restritas e o terceiro tercil pelas restritas.

Realiza-se a mensuração de cada índice das empresas por período assim como em Cleary (1999), as empresas assumem uma posição dinâmica na classificação da restrição financeira, permitindo a transição de cada uma entre os grupos de restritas, não restritas e indefinido (segundo tercil). No capítulo seguinte serão apresentados os resultados dos métodos exibidos neste capítulo. 


\section{RESULTADOS}

Este capítulo apresenta os resultados das estimativas referentes ao risco da carteira do setor financeiro e do alastramento do risco e contágio deste setor para a economia real, figurando-se como base para a análise deste fenômeno nas decisões de investimentos das firmas restritas e não restritas. $\mathrm{O}$ agrupamento das firmas pelo grau de restrição financeira tem por objetivo homogeneizar a amostra e possibilitar a análise de possíveis diferenças nas decisões de investimento entre esses dois grupos.

A classificação das firmas foi possibilitada pelo emprego de dois índices específicos na literatura de restrição financeira, o índice KZ e o índice WW. Também são apresentados neste capítulo as características descritivas das variáveis financeiras, os índices de co-excessos condicionais e de alastramento do risco, e os resultados das estimações pelo método dos momentos generalizados dos parâmetros de interesse da função de investimento.

\subsection{Formulação da carteira do setor financeiro}

A Tabela B1 do apêndice B exibe as empresas participantes na formação da carteira do setor financeiro, com os códigos das ações negociadas na bolsa de valores e as estatísticas descritivas de cada uma. Utilizou-se 74 cotações diferentes para um total de 57 empresas, os valores variam de acordo com o período de análise na formação da carteira, carecido da ação estar ativa para negociação na bolsa, isto justifica a variação da quantidade de observações de cada cotação.

O peso de cada ação é uma média dos pesos diários durante o período em que foi utilizada, e apesar de alguns ativos apresentarem uma relação da média de retorno sobre o desvio-padrão elevado (como por exemplo o BMEB3), ou seja, retorno média por unidade de risco elevado, a determinação do peso na carteira de cada ativo depende da sua covariância com os demais ativos e de sua contribuição para a variância da carteira.

A seguir é apresentado o comportamento do retorno diário resultante da carteira do setor financeiro elaborada pelo método da mínima variância global. 
Gráfico 1 - Retorno diário da carteira do setor financeiro

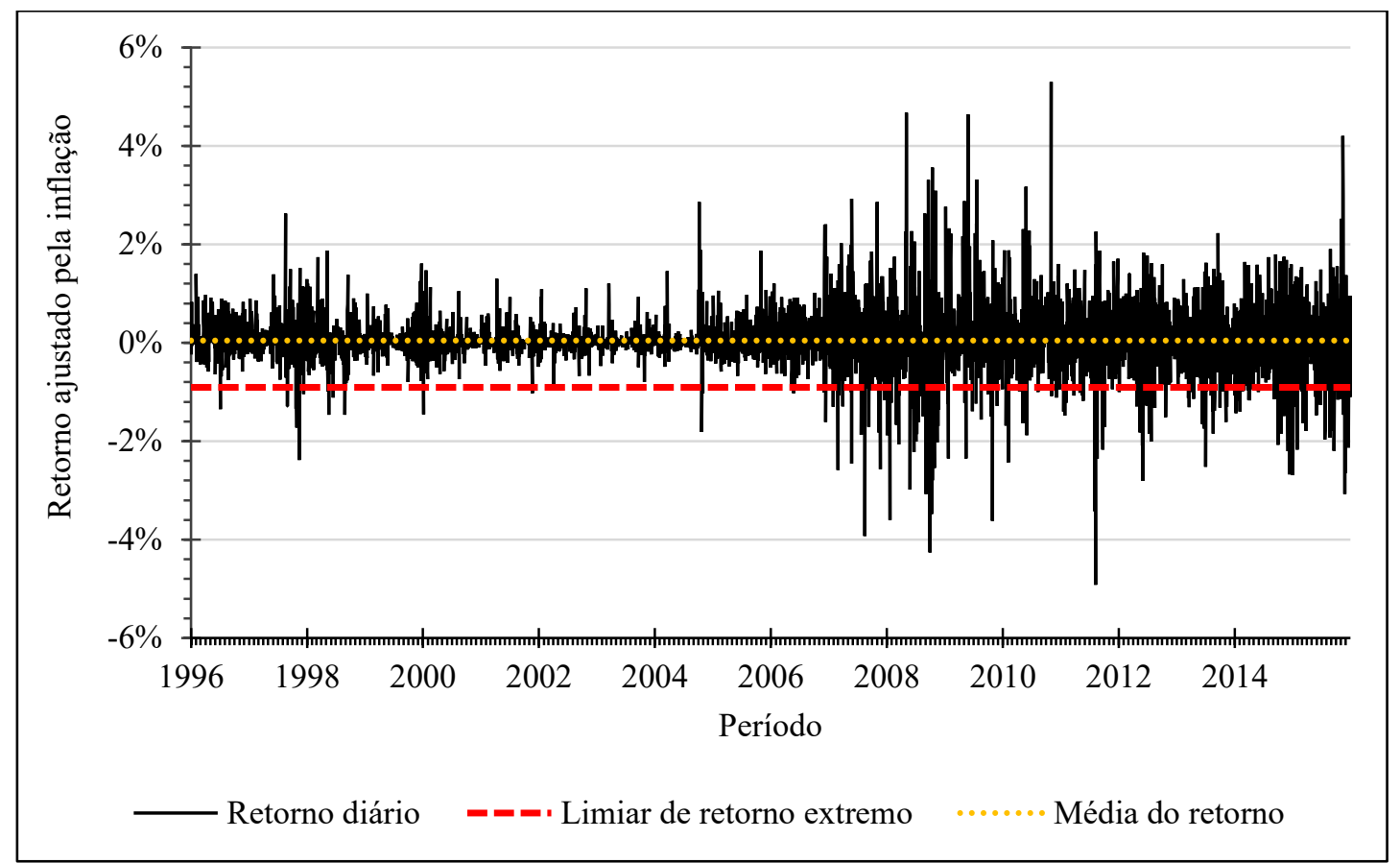

Elaborado pelo autor.

O resultado é condizente com o esperado desta carteira. A série possui 5.218 observações diárias, com média próxima de zero e desvio padrão de 0,006 , apresenta uma concentração de volatilidades pouco mais elevadas no final de 1997 e 1998, e uma elevação expressiva a partir de 2007 com grandes movimentos concentrados no final de 2008 e início de 2009. Houveram dois episódios de crises nesses períodos, a crise russa de 1998 e a denominada crise do subprime respectivamente, cujas flutuações do setor financeiro podem estar atreladas.

A partir de 2007, apesar dos picos da crise do subprime de 2008, observa-se que a série exibe um significativo aumento nas oscilações, tanto positivas quanto negativas, que persistem até o final de 2015. Consequentemente ocasiona um aumento da volatilidade, ao segregar a série em duas partes, antes e depois de 2006, os valores dos desvios padrões são de 0,3399\% e $0,8382 \%$ respectivamente, um aumento de quase 2,5 vezes. Porém, junto com o aumento do desvio padrão ocorreu uma redução de $36 \%$ na média do retorno diário.

A crise financeira internacional de 2008 provocou uma severa retração na economia mundial. Adicionada a outros fatores internos e externos, o sucedido na economia brasileira não foi diferente e é tema de pesquisas até os dias atuais (DAMODARAN, 2016).

Como exposto no Gráfico 2, a taxa de variação do PIB real brasileiro (comparado com o mesmo trimestre do ano anterior) mostrou-se negativo nos últimos anos e quando plotada a 
tendência exponencial da série, apesar do desempenho positivo do ano de 2010, nota-se o decrescimento médio a partir de 2006.

Gráfico 2 - Variação do PIB real trimestral

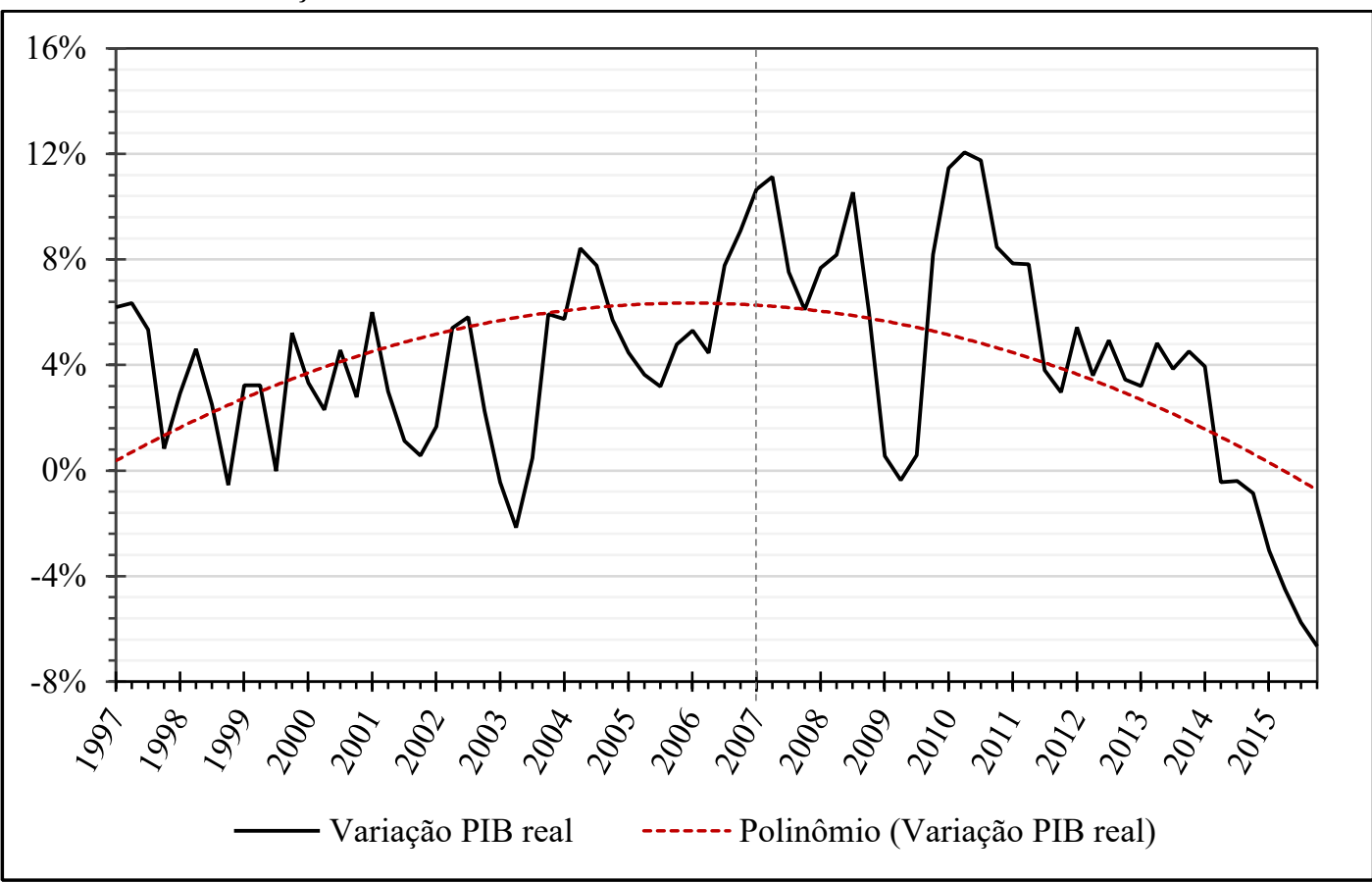

Fonte: Instituto Brasileiro de Geografia e Estatística (IBGE).

Elaborado pelo autor.

A característica de aumento da volatilidade e redução do retorno médio do retorno da carteira do setor financeiro, observada a partir de 2006, em parte pode ser apoiada nos fatores de retração econômica advindos, da crise financeira mundial e de seus posteriores agravos no volume de negócios dos preços internacionais das commidities, e de outros fatores internos no país.

Quanto à distribuição dos dados de retorno da carteira, utiliza-se o histograma exibido no Gráfico 3 com o objetivo de fornecer mais um elemento para uma análise mais concisa das informações do comportamento da série por meio da observação das frequências dos retornos. 
Gráfico 3 - Histograma do retorno diário da carteira do setor financeiro

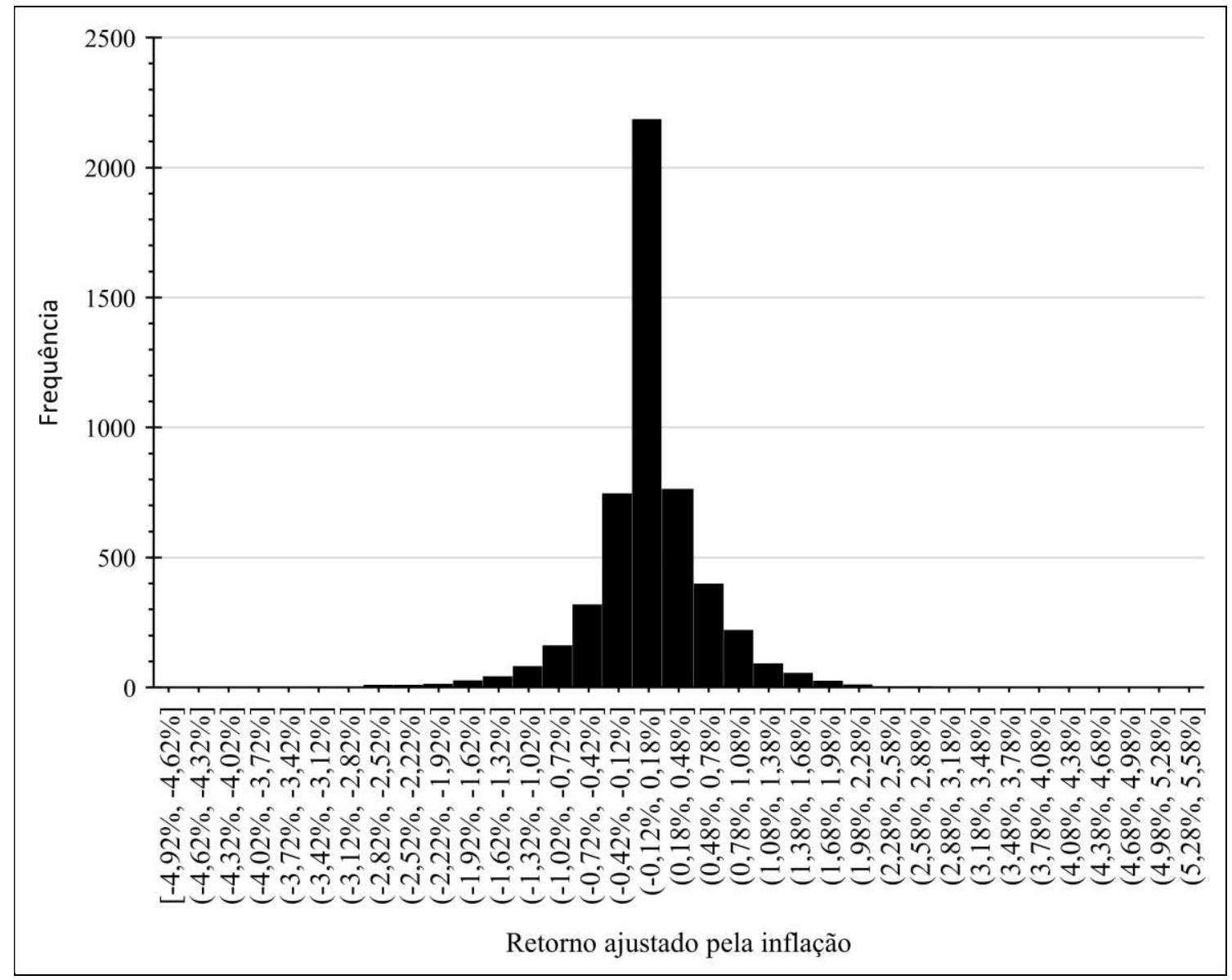

Elaborado pelo autor.

A série aparentemente assemelha-se com uma distribuição normal padrão, porém ao analisar as estatísticas de ordem maiores que 2 vê-se algumas diferenças. A assimetria amostral é negativa, no valor de $-0,064$, calculada pelo terceiro momento da série. O excesso de curtose é de 8,49 (leptocúrtica), com caudas mais achatadas. Parcialmente, esta característica surge da metodologia aplicada para criação da carteira. Ajustando a carteira diariamente pela mínima variância reduz-se o risco global da carteira que, neste caso, resultou em caudas mais achatadas, leptocúrtica com assimetria negativa, por outro lado esta característica foi possível pela própria natureza dos retornos do conjunto de ações. Portanto, o risco e retorno representativo do setor financeiro para este estudo advém de uma alocação de capital nas ações do setor financeiro de modo a minimizar a variância global da carteira, e esta será utilizada para mensurar os movimentos de retornos negativos extremos e alastramento da volatilidade para as empresas do setor não financeiro. 


\subsection{Contágio financeiro}

$\mathrm{Na}$ identificação do contágio financeiro, este estudo adota o indicador de co-excessos condicionais $(C E C)$, no qual identifica os retornos conjuntos da firma e do setor financeiro que ultrapassam um limiar de corte entre cauda esquerda e centro da distribuição amostral da série. O limiar do retorno extremo negativo foi determinado pelo $5^{\circ}$ percentil da amostra de cada empresa e do setor financeiro. Com o Gráfico 1 apresentado na seção 4.1 pode-se ver a dinâmica de seleção dos retornos extremos pelo setor financeiro, todos os retornos abaixo do limiar são selecionados para compor o indicador de excesso $\left(C_{t}^{i}\right)$, de cada empresa $i$ no período $t$, que assume valor 1 se o retorno for abaixo do limiar e zero caso contrário.

Pela limitação de espaço para apresentação de todos indicadores $C_{t}^{i}$, optou-se em apresentar graficamente (Gráfico 4) os dados agregados por trimestre somente do setor financeiro, o indicador é comparado com o mesmo de cada empresa $i$ para formação do índice CEC.

Gráfico 4 - Indicador de retornos extremos e desvio-padrão

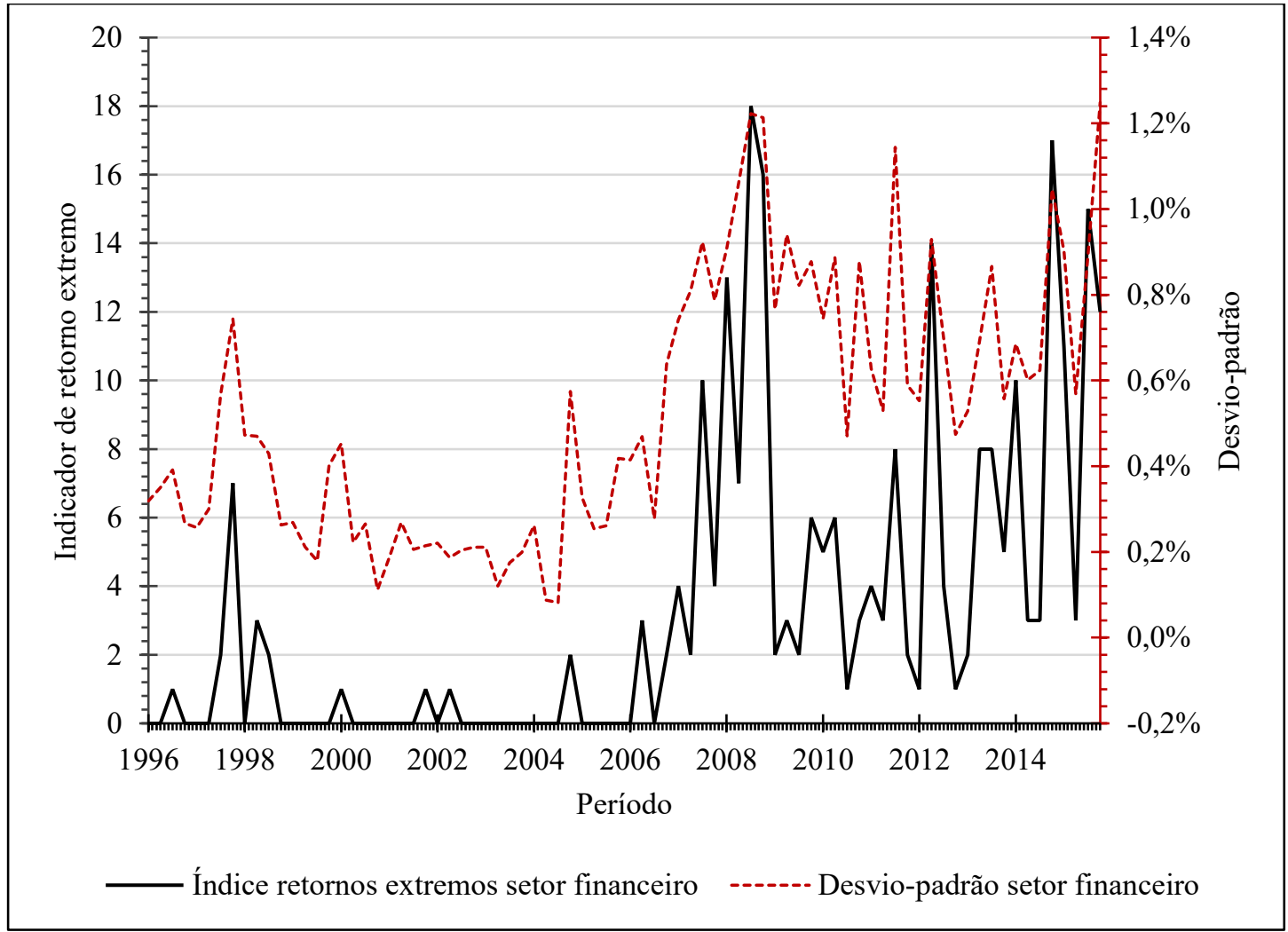

Elaborado pelo autor. 
Como o indicador possui uma alta correlação com o desvio-padrão, nota-se um aumento de observações extremas a partir de meados de 2007, ligada à intensificação da volatilidade conforme apresentado na série de retorno do setor na seção anterior (Gráfico 1). A apuração do indicador para cada empresa segue a mesma dinâmica e compara-se cada um, diariamente, com o indicador do setor no qual os resultados são reunidos por trimestre decorrendo no índice trimestral de co-excessos condicionais de cada empresa $i$ do setor não financeiro, $C E C_{t}^{i}$. $\mathrm{O}$ índice $C E C$, junto com a frequência do $C E C$ (proporção dos dias no trimestre em que o $C E C$ foi igual a 1, indicado pelo código $P b$ ), são apresentados em termos da média de cada empresa na Tabela B2 do apêndice B.

A média geral do $C E C$ é de 0,6 e o desvio padrão 1,39 , a média de cada empresa é demonstrada no Gráfico 5, sendo que algumas expõem valores médios acima da média geral, porém nenhuma apresenta-se muito dispersa (mais de 1 ou 2 desvios-padrão da amostra toda). Ao analisar as empresas com maiores médias observa-se que todas têm cotações na amostra iniciadas a partir do ano de 2007. A empresa Ultrapar apresenta maior indicador médio no valor de 1,67, a empresa teve a série das cotações iniciada em outubro/2011. Ainda todas as empresas com média igual a zero $(0,000)$ apresentaram data máxima de cotação anterior ao segundo semestre de 2006.

Gráfico 5 - Dispersão da média do índice CEC

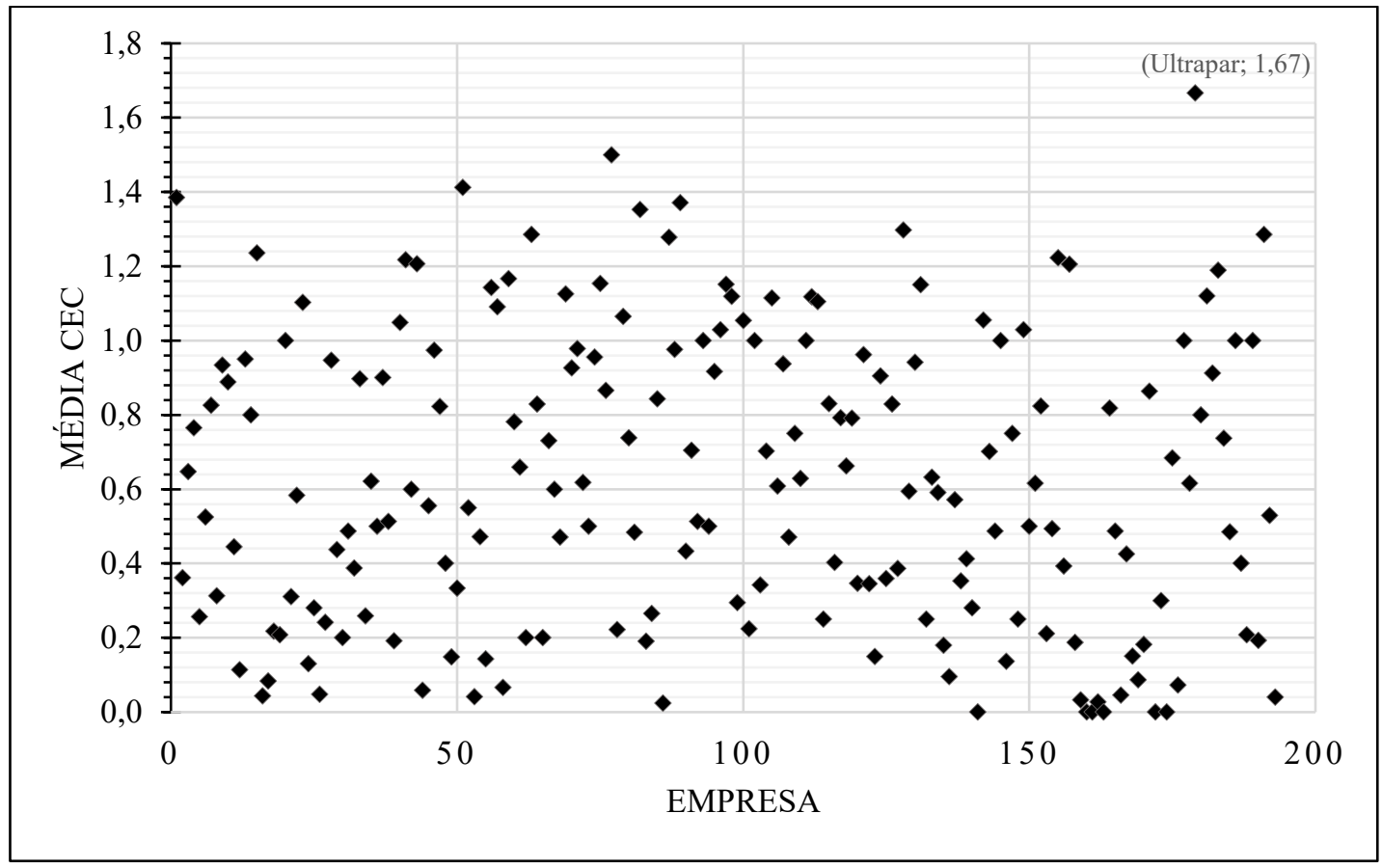

Elaborado pelo autor. 
Portanto, além de fatores econômicos que influenciam a relação entre os movimentos conjuntos dos retornos extremos, o período em que a observação da firma se inicia e termina na amostra é um fator relevante para o tamanho do valor médio do indicador $C E C$. Se a empresa possuir apenas observações de retorno em período de alta volatilidade do setor financeiro a probabilidade de uma queda extrema movimentar-se junto com uma queda extrema do setor financeiro é maior do que em períodos dos quais o setor financeiro apresenta volatilidade menor. Por conseguinte, viu-se necessário a análise da média do indicador por trimestre.

Gráfico 6 - Média do índice CEC de todas as empresas por trimestre

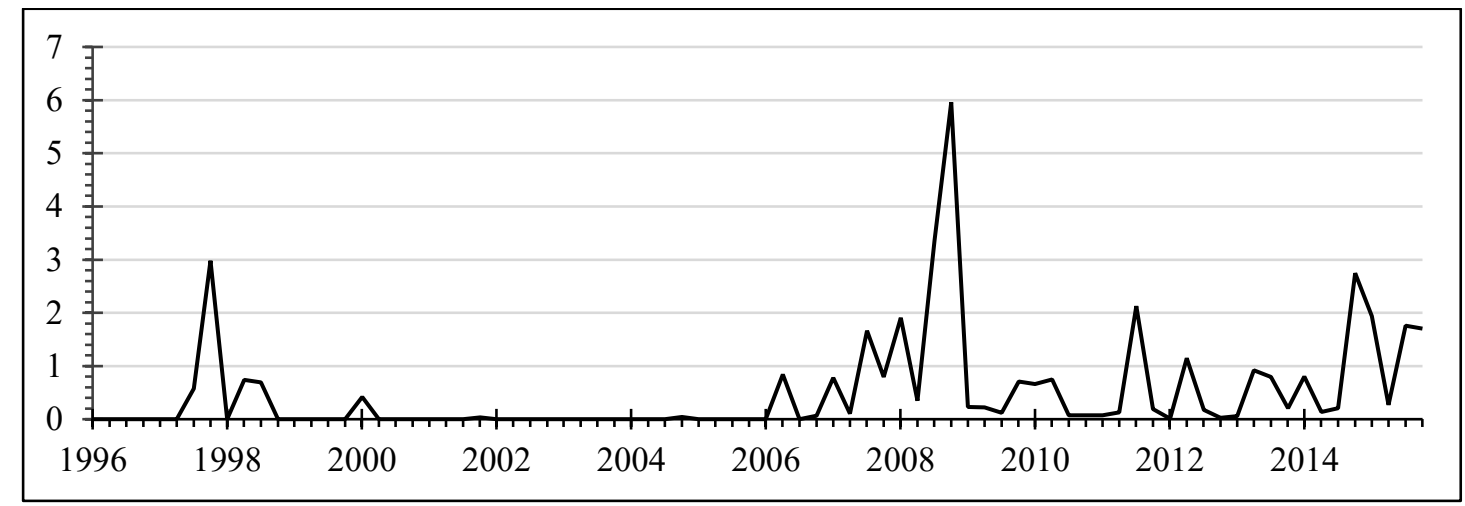

Elaborado pelo autor.

Para ilustrar os movimentos do índice $C E C$ por período, elaborou-se o Gráfico 6. Com a média do indicador das empresas por trimestre exibe-se sua evolução no tempo. O resultado é condizente com as análises realizadas do desvio-padrão e do indicador de perda extrema do setor financeiro. Elevações nos anos de 1997 a 1999, e uma intensificação de valores mais altos a partir de 2006 com um pico no último trimestre de 2008.

Apesar dos resultados serem condizentes com o cenário econômico, o efeito de contágio não pode ser apoiado com segurança, pois os movimentos conjuntos podem incorrer de efeitos de feedback entre as firmas e as empresas do setor financeiro. Mesmo com os resultados obtidos por Chiu, Peña e Wang (2015) evidenciar um efeito de contágio originado do setor financeiro para a econômica real em momentos de crise, o mesmo não pode ser afirmado nessa pesquisa, pois, faz jus a outro cenário econômico como objeto de estudo. Sendo assim, os resultados desta variável são tratados simplesmente como movimentos conjuntos extremos negativos entre o setor financeiro e as firmas. 
4.3 Alastramento do risco

Com a série de retornos do setor financeiro foi implementado a modelagem VAR para cada uma das empresas da amostra, portanto, foram processadas 193 regressões para a relação do setor financeiro e de cada firma e mais 193 regressões para o caso inverso. A Tabela C1 do apêndice $\mathrm{C}$ apresenta uma síntese dos resultados da modelagem.

Os resultados dos testes de estacionariedade foram satisfatórios. No teste de raiz unitária ADF todas as séries apresentaram uma estatística 'tau' suficientemente grande para rejeitar a hipótese de não estacionariedade ao nível de significância de $1 \%$. No teste não paramétrico Phillips-Perron os resultados foram os mesmos, todas as séries exibiram p-valores menores que $1 \%$. Portanto assume-se que todas as séries de retorno são estacionárias.

A escolha das defasagens para o modelo de cada firma foi realizada pelo Critério Bayesiano de Schwarz (BIC), pois apresentou menores defasagens que o AIC, utilizando 1 ou 2 defasagens apenas.

A apresentação dos resultados do modelo VAR é realizada na Tabela C2 do apêndice C. Os p-valores representam significância estatística ao nível de 1\% para o teste conjunto (teste F) dos coeficientes da equação em que o retorno do setor financeiro é a variável explicada. A maior parte das empresas, $89 \%$ do total, apresentaram significância dos parâmetros estimados ao nível de $10 \%$. Quando a significância é reduzida para $5 \%$ o total de empresas passa a ser de $83 \%$ do total com coeficientes estatisticamente significantes. Portanto, na maioria dos casos, o modelo VAR apresentou resultados significativos.

Em seguida, é realizado a normalização dos resíduos das funções da série do retorno do setor financeiro pela média do processo $\operatorname{GARCH}(1,1)$. A Tabela $\mathrm{C} 2$ do apêndice $\mathrm{C}$ demonstra os p-valores do teste Ljung-Box para autocorrelações dos resíduos padronizados, em que 98\% das empresas apresentaram erros independentes e identicamente distribuídos ao nível de significância 5\%.

Sendo assim, as firmas que apresentaram resultados adequados aos testes aplicados obtiveram resíduos do modelo VAR normalizados pela média do processo GARCH e a equação (29) foi estimada, resultando nos coeficientes $\gamma_{t-1}^{i}$ para cada trimestre e para cada empresa. Como objetivo de representar os resultados construiu-se o Gráfico 7 e o Gráfico 8.

A significância estatística do parâmetro $\gamma_{t-1}^{i}$ estimado, $\hat{\gamma}_{i, t}$, representa a propagação do risco do setor financeiro para a firma $i$, no trimestre $t$. Com os resultados das estatísticas $t$ de 
student foi elaborada uma variável dummy que assume valor 1 caso o p-valor da estatística $t$ seja menor ou igual a $5 \%$ e o coeficiente $\hat{\gamma}_{i, t}$ seja positivo e 0 caso contrário. A média desta variável por trimestre, de todas as empresas, foi utilizada para ilustrar os movimentos da propagação de risco na economia real, apresentada no Gráfico 7. Como o resultado é uma média da variável dummy, o gráfico representa a proporção das firmas que apresentaram um efeito positivo de alastramento de risco, como por exemplo no terceiro trimestre de $2009,26,3 \%$ das empresas suportaram o efeito.

Gráfico 7 - Média da dummy p-valor do coeficiente gama por trimestre

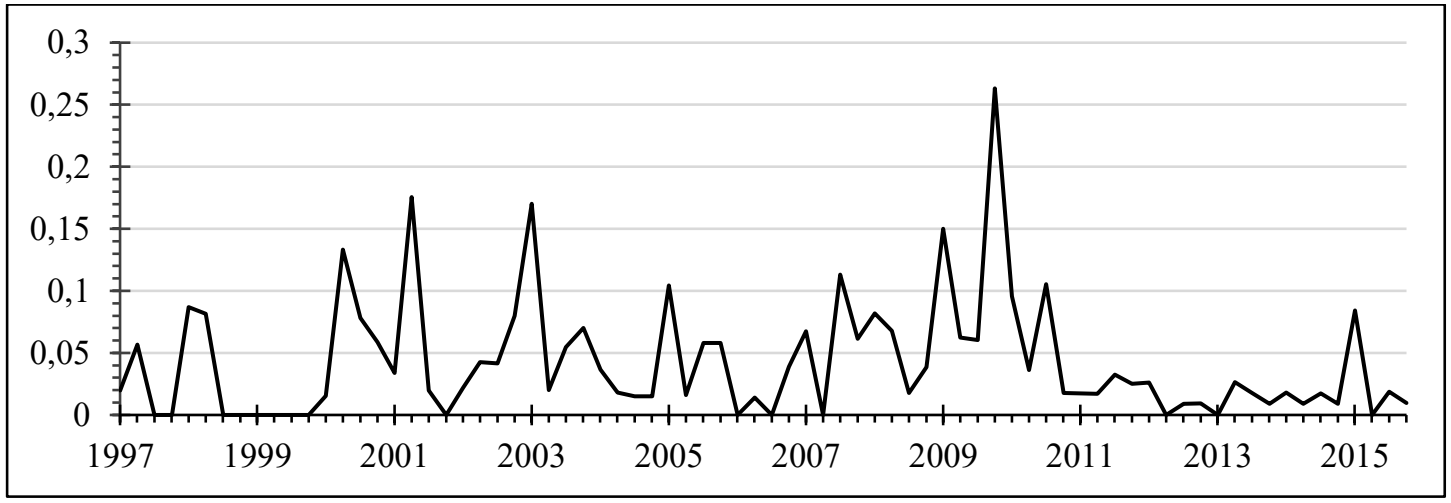

Elaborado pelo autor.

Ademais, para uma representação da magnitude do efeito dos resultados das médias do Gráfico 7, calcula-se as médias dos parâmetros gamas estimados, $\hat{\gamma}_{i, t}$, nos quais os resultados foram positivos e significativos a um nível de 5\%. As médias trimestrais agrupando todas as empresas são exibidas no Gráfico 8.

Gráfico 8 - Média do coeficiente gama por trimestre

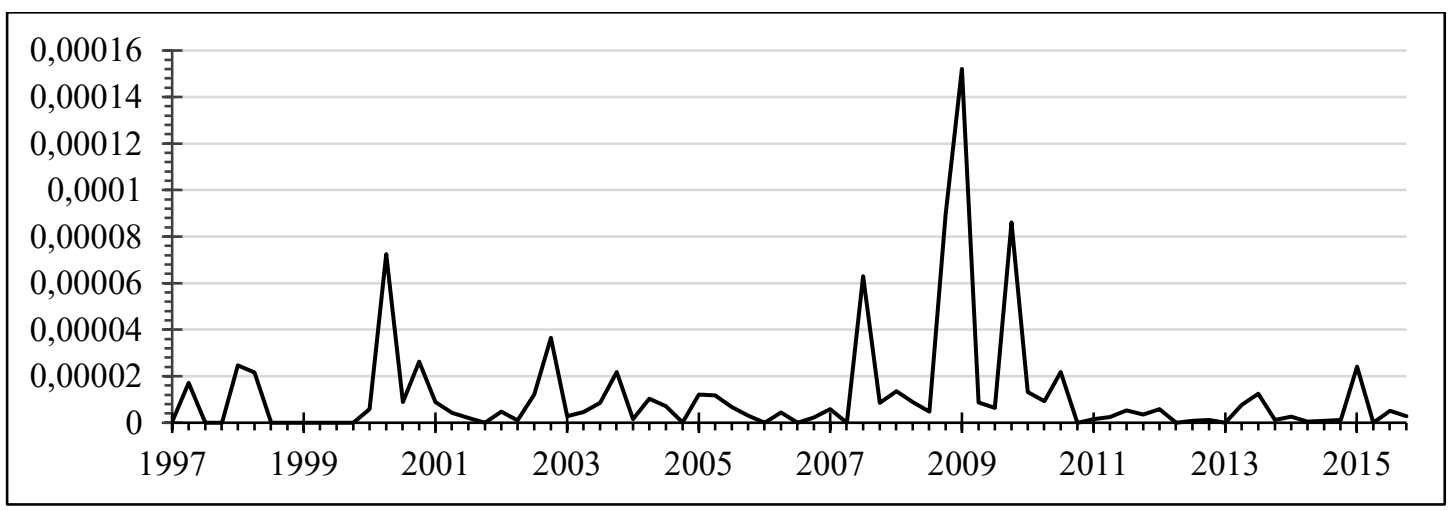

Elaborado pelo autor. 
Apesar dos efeitos na proporção das firmas afetadas pelo alastramento do risco do setor financeiro apresentar-se com uma intensidade que oscila em torno de uma média aproximadamente constante do ano 2000 a 2008, e com uma elevação no ano de 2009 (Gráfíco 7), ao analisar em conjunto com o coeficiente gama médio (Gráfico 8), observa-se que o alastramento do risco ocorreu de forma mais intensa no $2^{\circ}$ trimestre de $2000,3^{\circ}$ trimestre de 2007 e em 2009.

Comparando o alastramento do risco do setor financeiro para a indústria $\left(\hat{\gamma}_{i, t}\right)$ e os coexcessos condicionais $(C E C)$, observa-se grandes elevações no índice CEC de 1 a 2 períodos anteriores às elevações do coeficiente gama. Ainda uma redução no impacto médio do $\hat{\gamma}_{i, t}$ a partir de 2011, efeito contrário do CEC, que apresentou uma elevação média a partir de 2008 .

\subsection{Modelo de investimento}

$\mathrm{Na}$ análise das decisões de investimento foram empregadas as variáveis da equação (30) segregando a amostra em firmas restritas e não restritas segundo os índices KZ e WW. Esta seção apresenta os aspectos das estatísticas descritivas das variáveis e dos resultados da estimação do modelo de regressão utilizando as variáveis explicativas de co-excessos condicionais e alastramento da volatilidade do setor financeiro para a economia real.

A Tabela 1 exibe a média e desvio-padrão de cada variável microeconômica, destacando as estatísticas na amostra segregada pela restrição financeira. $\mathrm{O}$ agrupamento de acordo com os indicadores $\mathrm{KZ}$ e WW permite uma homogeneização das características das empresas e a utilização de mais de um indicador fornece uma robustez na análise entre os grupos de firmas.

Ao analisar as médias das variáveis, as firmas não restritas apresentam, em geral, maiores níveis que as não restritas, seja pela segregação KZ, seja pela segregação WW. A proporção da dívida ao capital das firmas restritas em média é menor que das não restritas, apoiando o conceito que a restrição financeira é definida pelas empresas deixarem de efetuar investimentos devido à indisponibilidade de recursos internos e à restrição de recursos financeiros externos (KAPLAN; ZINGALES, 1997). Conceito que é corroborado com as médias das taxas de investimentos maiores das firmas não restritas frente às restritas.

Uma interpretação da variável fluxo de caixa aporta-se em indicar a disponibilidade interna de recursos, maiores níveis desta variável indica menores níveis de restrição financeira. 
Sendo assim, a divisão das firmas pelos índices KZ e WW estão de acordo com a interpretação indicada, a variável $\left(C F_{i, t} / K_{i, t-1}\right)$ apresenta médias maiores para as empresas não restritas.

Tabela 1 - Estatística descritiva das variáveis

\begin{tabular}{|c|c|c|c|c|c|c|c|c|c|c|}
\hline \multirow{3}{*}{ Variáveis } & \multirow{2}{*}{\multicolumn{2}{|c|}{$\underline{\text { Geral }}$}} & \multicolumn{4}{|c|}{ Índice KZ } & \multicolumn{4}{|c|}{ Índice WW } \\
\hline & & & \multicolumn{2}{|c|}{$\underline{\text { Não restritas }}$} & \multicolumn{2}{|c|}{$\underline{\text { Restritas }}$} & \multicolumn{2}{|c|}{ Não restritas } & \multicolumn{2}{|c|}{$\underline{\text { Restritas }}$} \\
\hline & Média & Desvio & Média & Desvio & Média & Desvio & Média & Desvio & Média & Desvio \\
\hline$I_{i, t} / K_{i, t-1}$ & 0,05 & 0,32 & 0,10 & 0,51 & 0,02 & 0,13 & 0,07 & 0,34 & 0,03 & 0,39 \\
\hline$D_{i, t} / K_{i, t-1}$ & 0,85 & 3,38 & 1,40 & 5,42 & 0,75 & 2,05 & 1,09 & 4,49 & 0,63 & 1,52 \\
\hline$C F_{i, t} / K_{i, t-1}$ & 0,01 & 0,72 & 0,09 & 1,15 & $-0,05$ & 0,47 & 0,02 & 0,45 & $-0,02$ & 0,83 \\
\hline$S_{i, t} / K_{i, t-1}$ & 1,27 & 3,07 & 2,29 & 4,47 & 0,74 & 1,94 & 0,86 & 1,90 & 1,61 & 4,17 \\
\hline$C E C_{i, t}$ & 0,71 & 1,50 & 0,83 & 1,62 & 0,69 & 1,48 & 0,79 & 1,62 & 0,66 & 1,40 \\
\hline$\hat{\gamma}_{i, t}$ & 0,012 & 0,193 & 0,011 & 0,084 & 0,018 & 0,320 & 0,012 & 0,131 & 0,020 & 0,322 \\
\hline Observações & \multicolumn{2}{|c|}{5.275} & \multicolumn{2}{|c|}{1.762} & \multicolumn{2}{|c|}{1.762} & \multicolumn{2}{|c|}{1.737} & \multicolumn{2}{|c|}{1.737} \\
\hline
\end{tabular}

Elaborado pelo autor.

A variável $\hat{\gamma}_{i, t}$ foi multiplicada por $10^{3}$ para a apresentação em nível maior. A descrição completa das variáveis se encontra na Tabela A1 do apêndice A.

A taxa de vendas $\left(S_{i, t} / K_{i, t-1}\right)$, diferentemente da separação pelo $\mathrm{KZ}$, as firmas WW restritas mostram maiores níveis que as WW não restritas. Ao considerar que esta variável capta as oportunidades de crescimento e a rentabilidade das decisões de investimento, as firmas WW restritas possuem, em média, maiores expectativas de rentabilidade futura que as WW não restritas. Contudo, a variabilidade desta variável medida pelo desvio-padrão mostra-se significantemente maior para as firmas WW restritas com uma mediana de 0,67, assim, algumas observações da amostra deste grupo possuem altos valores ocasionando uma elevação da média.

A média dos co-excessos condicionais $(C E C)$ apresenta-se maior para o grupo de firmas não restritas. Algumas interpretações podem surgir deste resultado, como as firmas não restritas exibem um grau de alavancagem superior, a ligação com o setor financeiro é maior, consequentemente, possibilitando maior suscetibilidade de apresentarem movimentos conjuntos de perdas (retornos negativos) extremas, ou co-excessos condicionais $(C E C)$ dos retornos maiores que as firmas restritas financeiramente. Por outro lado, a variável $\hat{\gamma}_{i, t}$ apresenta uma média menor para as firmas não restritas, portanto as empresas restritas, na média, suportam um impacto maior da propagação da volatilidade do setor financeiro.

$\mathrm{Na}$ comparação entre as médias das variáveis entre os índices $\mathrm{KZ}$ e WW, as firmas $\mathrm{KZ}$ não restritas apresentam médias das variáveis microeconômicas e do $C E C$ maiores que as WW não restritas e um $\hat{\gamma}_{i, t}$ médio menor. Já para as firmas restritas as médias para o grupo KZ são maiores somente para as variáveis $D_{i, t} / K_{i, t-1}$ e $C E C_{i, t}$. 
As dispersões das observações são apresentadas pelo coeficiente de variação na Tabela 2, comparando as firmas restritas e não restritas financeiramente. Com exceção da variável dívida, em geral as firmas restritas mostram uma dispersão relativa maior nas demais variáveis. Ademais, as firmas não restritas possuem maior variabilidade em relação à média na proporção da dívida em relação ao capital. Este resultado é consistente com o agrupamento das firmas pela restrição financeira, dado que as firmas não restritas têm acesso aos créditos externos, suas movimentações da dívida apresentam maior variabilidade em comparação com as firmas restritas.

Tabela 2 - Coeficiente de variação

\begin{tabular}{lcccc}
\hline \multirow{2}{*}{ Variáveis } & \multicolumn{2}{c}{ Índice KZ } & \multicolumn{2}{c}{ Índice WW } \\
\cline { 2 - 4 } & Não restritas & $\underline{\text { Restritas }}$ & Não restritas & $\underline{\text { Restritas }}$ \\
\hline$I_{i, t} / K_{i, t-1}$ & 5,23 & 5,93 & 5,26 & 13,71 \\
$D_{i, t} / K_{i, t-1}$ & 3,87 & 2,73 & 4,11 & 2,41 \\
$C F_{i, t} / K_{i, t-1}$ & 13,29 & $-8,66$ & 24,05 & $-40,60$ \\
$S_{i, t} / K_{i, t-1}$ & 1,95 & 2,62 & 2,21 & 2,59 \\
$C E C_{i, t}$ & 1,94 & 2,16 & 2,06 & 2,11 \\
$\hat{\gamma}_{i, t}$ & 7,377 & 17,994 & 10,532 & 15,921 \\
\hline
\end{tabular}

Elaborado pelo autor.

Coeficiente de variação de Pearson mede a dispersão relativa no qual o desvio padrão é expresso em unidades da média.

Visto o apresentado das variáveis aplicadas no estudo das decisões de investimento, os resultados das estatísticas descritivas indicam uma consistência das médias da amostra para os grupos de firmas restritas e não restritas financeiramente. Quanto às variáveis de risco CEC e $\gamma$, os resultados demonstram que as empresas não restritas possuem maiores co-excessos condicionais de retorno extremo (cauda esquerda da distribuição de probabilidades) das firmas com o setor financeiro, e ao analisar o alastramento da volatilidade, que considera o centro da distribuição dos retornos, as firmas restritas em média suportam maiores propagações de risco advindas do setor financeiro. Para maiores evidências e interpretações emprega-se a abordagem econométrica para dados em painel utilizando o estimador system GMM.

Na Tabela C2 do apêndice C são apresentadas as correlações das variáveis explicativas do modelo de investimento. O resultado mostra baixos índices de correlação das variáveis, na qual não há existência de relação linear perfeita entre elas e devido à baixa correlação assumese que não existe colinearidade, possibilitando as inferências baseadas no modelo de regressão.

A Tabela 3 mostra os resultados das estimações dos parâmetros do modelo da equação (30) para as firmas restritas e não restritas financeiramente classificadas pelos índices $\mathrm{KZ}$ e WW. Primeiramente é feita uma análise dos coeficientes das variáveis microeconômicas 
indicativas do investimento e, em seguida, das principais variáveis de interesse dos movimentos do setor financeiro e da economia real.

As variáveis taxa de investimento defasada e defasada quadrática, $\left(I_{i, t} / K_{i, t-1}\right)_{i, t-1} \mathrm{e}$ $\left(I_{i, t} / K_{i, t-1}\right)_{i, t-1}^{2}$, possuem estimativas significativas em todos os modelos, mostrando que apesar da taxa de investimento passada explicar a contemporânea, existe uma relação não linear no ajuste de capital e como esperado, $\beta_{1}>0$ e $\beta_{2}<0$, o efeito é marginal decrescente e igual a:

$$
\frac{\partial I_{i, t} / K_{i, t-1}}{\partial\left(I_{i, t} / K_{i, t-1}\right)_{i, t-1}}=\beta_{1}+2 \beta_{2}\left(I_{i, t} / K_{i, t-1}\right)_{i, t-1}
$$

Comparando a um mesmo nível de taxa de investimento, as empresas $\mathrm{KZ}$ não restritas financeiramente possuem em efeito marginal da taxa de investimento defasada maior que as restritas.

Tabela 3 - Estimativa do investimento pelo system GMM

\begin{tabular}{|c|c|c|c|c|c|}
\hline \multirow{2}{*}{ Variáveis } & \multicolumn{2}{|c|}{ Índice KZ } & \multicolumn{2}{|c|}{ Índice WW } & \multirow{2}{*}{ Geral } \\
\hline & Não restritas & Restritas & Não restritas & Restritas & \\
\hline$\left(I_{i, t} / K_{i, t-1}\right)_{i, t-1}$ & $0,261 * * *$ & $0,077 * * *$ & $0,269 * * *$ & $0,202 * * *$ & $0,128 * * *$ \\
\hline$\left(I_{i, t} / K_{i, t-1}\right)_{i, t-1}^{2}$ & $-0,039 * * *$ & $-0,064 * * *$ & $-0,076^{* * *}$ & $-0,029 * * *$ & $-0,014 * * *$ \\
\hline$D_{i, t} / K_{i, t-1}$ & $0,026^{* * *}$ & $0,003 * * *$ & $0,015 * * *$ & $-0,004 * * *$ & $0,015 * * *$ \\
\hline$C F_{i, t} / K_{i, t-1}$ & $-0,014 * * *$ & $0,017 * * *$ & $0,056^{* * *}$ & $-0,027 * * *$ & $0,043 * * *$ \\
\hline$S_{i, t} / K_{i, t-1}$ & $0,001 * * *$ & $0,019 * * *$ & $0,039 * * *$ & $0,003 * * *$ & $0,016^{* * *}$ \\
\hline$C E C_{i, t}$ & $0,013 * * *$ & $0,003 * * *$ & $0,006^{* * *}$ & $0,024 * * *$ & $0,007 * * *$ \\
\hline$\hat{\gamma}_{i, t}$ & $-0,187$ & $-0,082 * * *$ & $-0,199$ & $-0,031 * * *$ & $-0,276$ \\
\hline Teste AR(2) (p-valor) & 0,484 & 0,338 & 0,085 & 0,491 & 0,26 \\
\hline Teste Hansen ( $\mathrm{p}$-valor) & 0,999 & 0,999 & 0,999 & 0,999 & 0,999 \\
\hline
\end{tabular}


A variável taxa da dívida resultou no sinal do parâmetro estimado esperado, quanto maior a alavancagem, maior o impacto na taxa de investimento das firmas não restritas. As firmas restritas apresentaram coeficientes menores que os das firmas não restritas, e no caso do WW restritas, parâmetro negativo.

A variável taxa de vendas apresentou-se significante em todos os modelos com sinal positivo como esperado. Porém com diferentes efeitos nos grupos das firmas restritas e não restritas quando comparado a segregação pelo KZ e pelo WW.

Já a variável fluxo de caixa exibiu resultados ambíguos na comparação das firmas agrupadas pelo KZ e WW. As firmas KZ restritas apresentaram sensibilidade maior à esta variável do que as $\mathrm{KZ}$ não restritas, no caso da divisão pelo índice WW o resultado foi inverso, as WW não restritas que apresentaram sensibilidade maior.

Quanto à variável de retornos extremos negativos simultâneos $(C E C)$, ao contrário do esperado, os coeficientes estimados obtidos sugerem uma relação positiva com a taxa de investimento. Maiores retornos extremos simultâneos entre o setor financeiro e a firma implicam em maiores taxas de investimento das firmas. Maiores valores desta variável podem estar associados a uma maior ligação entre o setor financeiro e a empresa ao invés do efeito de contágio devido a um efeito de feedback entre o setor financeiro e a firma nos movimentos de retornos extremos, o que sugere que as empresas que tenham maiores índices CEC também possuam maiores alavancagens para realizar os investimentos. Com as estatísticas descritivas da Tabela 1, têm-se que as maiores médias da taxa da dívida $\left(D_{i, t} / K_{i, t-1}\right)$ são das empresas classificadas como não restritas financeiramente, o mesmo pode ser visto para as médias do $C E C$. Assim é esperado que as firmas não restritas tenham um coeficiente $\beta_{6}$ maior que as não restritas, o que é verificado pelo agrupamento do índice $\mathrm{KZ}$, porém, os resultados segundo o índice WW mostram que o coeficiente é maior para as firmas restritas financeiramente.

A propagação do risco medida pela variável $\gamma$ apresenta significância estatística somente quando a amostra é dividida pelos índices de restrição financeira, não mostrando significância para o modelo geral utilizando todas as empresas da amostra, impossibilitando inferências a respeito desta variável nas decisões de investimento caso o agrupamento não fosse realizado.

O alastramento do risco é significante somente para as firmas restritas, e resulta em uma relação negativa com a taxa de investimento. Sendo assim, as firmas restritas que apresentam maior alastramento de risco do setor financeiro, em um cenário ceteris paribus, têm as taxas de investimento reduzidas. Adotando o risco do retorno da carteira do setor como representativo do risco global do setor, sob o pressuposto que os preços das ações incorporam o risco global 
da firma, em um cenário de aumento do risco das empresas financeiras as empresas da economia real que têm seus riscos afetados de forma mais intensiva devido ao efeito propagativo, têm suas taxas de investimento reduzidas.

A inserção da variável de alastramento do risco em conjunto com o $C E C$ aumentou a eficiência da estimativa do modelo de investimento em todas as estimações apresentadas. Comparado com outros resultados de estudos endereçados ao cenário brasileiro (KALATZIS; AZZONI, 2009; KIRCH; PROCIANOY; TERRA, 2014; TERRA, 2003), o modelo apresentou significância estatística na maior parte dos parâmetros estimados. Os resultados das estimativas dos coeficientes da taxa de investimento dinâmico defasado e quadrático corroboram com a literatura apresentada. 


\section{CONCLUSÃO}

Este estudo teve o objetivo de verificar o impacto do contágio financeiro e do alastramento do risco do setor financeiro para a firma nas decisões de investimento das empresas restritas e não restritas financeiramente na economia brasileira. Para tanto utilizou-se informações de empresas de capital aberto durante os anos de 1997 a 2015. Os riscos e retornos do setor financeiro foram medidos com uma carteira de mínima variância global das empresas integrantes dessa esfera econômica.

Para fazer inferências a respeito do alastramento do risco e contágio do setor financeiro utilizou-se as séries dos retornos das ações das empresas para mensurar dois indicadores. Para o alastramento do risco foi utilizado uma modelagem VAR-GARCH e estimou-se o parâmetro de efeito do risco normalizado do setor financeiro no risco da firma. Os resultados mostraram que houve um maior número de firmas afetadas, assim como uma maior intensidade, no ano de 2009.

O indicador de contágio foi medido pelo proposto por Chui, Peña e Wang (2015), designado como uma medida de movimentos negativos conjuntos e extremos dos retornos, nesse estudo foi aplicado ao retorno da carteira do setor financeiro e das firmas. O indicador apresentou um aumento no nível médio no final de 1997 e início de 1998 e uma tendência de crescimento após 2008. Porém não foi apoiado que os movimentos desse indicador representam a ocorrência de contágio financeiro devido a um possível efeito de feedback entre a volatilidade dos retornos do setor financeiro e das firmas, portanto o índice foi tratado apenas como movimentos negativos extremos conjuntos.

Os dois indicadores foram empregados em um modelo acelerador de investimentos dinâmico a fim de investigar seus efeitos no modelo. Para dirigir os impactos nas firmas restritas e não restritas a amostra foi dividida em grupos de acordo com os índices de restrição financeira KZ e WW.

O modelo de investimento foi estimado pelo system GMM. Além do uso da variável dependente defasada como explicativa, empregou-se a mesma variável na forma quadrática para adicionar uma dinâmica não linear, no qual resultou em um efeito marginal decrescente. O uso das variáveis dívida e vendas mostraram-se condizentes com o esperado, os parâmetros da variável taxa de vendas foram significativos em todos os modelos e com efeito positivo, o impacto da dívida no investimento mostrou-se ser maior para as firmas não restritas financeiramente. 
Com a intenção de obter evidencias dos efeitos da restrição financeira, foi empregado a variável fluxo de caixa para estimar o modelo de investimento. Considerando que ela capta a disponibilidade de recursos internos e de baixo custo, as empresas não restritas deveriam ter coeficientes não significantes ou muito reduzidos desta variável, pois, possuem outra fonte substituta de recursos, os empréstimos de terceiros. Para reduzir o viés de inflar as estimativas foi introduzido a variável taxa de vendas com o intuito de controlar a expectativa de rentabilidade futura que pode estar associada ao fluxo de caixa. Os resultados dos parâmetros estimados foram contraditórios para as empresas WW não restritas e esta variável pode não estar representando de forma eficiente a restrição financeira nesta classificação.

A introdução dos indicadores de alastramento do risco e de movimentos negativos extremos conjuntos aumentou a eficiência na estimação dos parâmetros do modelo de investimento. Os movimentos negativos extremos conjuntos obtiveram parâmetros positivos e significativos em todos os modelos, uma possível explicação é que esta variável esteja captando o nível de ligação das firmas com o setor financeiro. O coeficiente da variável de alastramento do risco somente mostrou-se significativo quando a amostra foi segregada em empresas restritas e não restritas. A significância ocorreu apenas nos parâmetros das firmas restritas, tanto no modelo KZ restritas, quanto no WW restritas, mostrando uma maior consistência dos resultados, nos quais apresentaram parâmetros negativos.

Estes resultados contribuem para a literatura abordando a questão do alastramento do risco no modelo de investimento e a significância do parâmetro estimado exibe evidencias de sua importância para os movimentos de ajustes de capitais das firmas.

Mesmo apresentando alguns resultados significativos este estudo limita-se ao uso dos indicadores de restrição financeiro. A classificação das firmas entre restritas e não restritas passam por critérios subjetivos, sendo alvo de críticas quanto ao método adotado. Mesmo adotando dois indicadores amplamente estudados na literatura com o objetivo de maior robustez nos resultados, o índice KZ possui uma baixa correlação com o índice WW. Outras limitações estão nas variáveis de alastramento de risco e contágio financeiro, nas quais podem representar efeitos de feedback, onde mais indicadores e testes aparecem necessários para ampliar os resultados obtidos. 


\section{APÊNDICE A - DEFINIÇÃO DAS VARIÁVEIS}

Tabela A1 - Definição das variáveis

\begin{tabular}{lll}
\hline Variável & Descrição & Procedimento de mensuração \\
\hline$I$ & Investimento no ativo & Aquisições de ativo imobilizado calculado como: $K_{i, t}-K_{i, t-1}+$ \\
& imobilizado & $K S_{i, t}+D E P_{i, t}+I M P_{i, t}$ \\
$K$ & Estoque de capital & Ativo imobilizado líquido no balanço patrimonial \\
$C F$ & Fluxo de caixa & Variação do saldo de caixa e equivalentes de caixa \\
$D$ & Dívida & Total do passivo oneroso de longo prazo \\
$S$ & Vendas & Receita líquida de tributos e comissões sobre vendas \\
$C E C$ & Co-excessos condicionais & Índice de movimentos conjuntos de retornos extremos negativos \\
$\hat{\gamma}$ & Parâmetro do modelo de & Estimado pela equação (29) \\
& alastramento de risco & \\
$K S$ & Vendas líquidas do ativo & Total das baixas líquidas do ativo imobilizado no período \\
& imobilizado & \\
$D E P$ & Depreciação & Total da depreciação do período \\
$I M P$ & Impairment & Redução do valor recuperável do ativo imobilizado no período \\
$Q$ & Q de Tobin & Utilizado o 'q' médio, pela proporção do valor de mercado e \\
& & contábil do patrimônio líquido \\
$T C$ & Capital total & Total do patrimônio líquido e do passivo oneroso \\
$D I V$ & Dividendos & Total de dividendos distribuídos \\
$C S H$ & Caixa total & Saldo de caixa e equivalentes de caixa \\
$D L T$ & Dívida de longo prazo & Passivo oneroso de longo prazo \\
Size & Tamanho da empresa & Total da capitalização de mercado \\
$S G I$ & Taxa de crescimento das vendas & Taxa de variação da receita líquida de tributos e comissões sobre \\
& & vendas
\end{tabular}




\section{APÊNDICE B - ESTATÍSTICAS DESCRITIVAS}

Tabela B1 - Estatísticas descritivas das empresas do setor financeiro

\begin{tabular}{|c|c|c|c|c|c|c|c|}
\hline Empresa & $\begin{array}{l}\text { Código } \\
\text { de } \\
\text { cotação }\end{array}$ & $\begin{array}{l}\text { Média } \\
\text { peso na } \\
\text { carteira }\end{array}$ & $\begin{array}{l}\text { Média } \\
\text { do } \\
\text { retorno }\end{array}$ & $\begin{array}{c}\text { Desvio- } \\
\text { padrão }\end{array}$ & $\begin{array}{c}\text { Data mínima } \\
\text { na carteira* }\end{array}$ & $\begin{array}{c}\text { Data } \\
\text { máxima na } \\
\text { carteira* }\end{array}$ & Observações \\
\hline Abc Brasil & $\mathrm{ABCB} 4$ & $0,56 \%$ & $0,01 \%$ & $2,53 \%$ & $26 / 09 / 2007$ & $30 / 12 / 2015$ & 2.040 \\
\hline Aliansce & ALSC3 & $6,88 \%$ & $0,01 \%$ & $1,49 \%$ & $29 / 01 / 2010$ & $30 / 12 / 2015$ & 1.466 \\
\hline America do Sul & BASU5 & $4,63 \%$ & $-0,01 \%$ & $2,23 \%$ & 01/01/1996 & $31 / 12 / 1999$ & 531 \\
\hline Amazonia & BAZA3 & $0,72 \%$ & $0,14 \%$ & $4,76 \%$ & 01/07/1996 & $30 / 12 / 2015$ & 2.297 \\
\hline Banco do Brasil & BBAS3 & $0,16 \%$ & $0,07 \%$ & $4,44 \%$ & 01/01/1996 & $30 / 12 / 2015$ & 4.912 \\
\hline Banco do Brasil & BBAS4 & $0,10 \%$ & $0,07 \%$ & $3,17 \%$ & 01/01/1996 & $30 / 08 / 2002$ & 1.633 \\
\hline Bandeirantes & BBCM4 & $3,77 \%$ & $-0,06 \%$ & $1,45 \%$ & 03/06/1996 & $29 / 02 / 2000$ & 422 \\
\hline Bradesco & $\mathrm{BBDC} 3$ & $0,10 \%$ & $0,08 \%$ & $3,64 \%$ & 01/01/1996 & $30 / 12 / 2015$ & 4.946 \\
\hline Bradesco & BBDC4 & $0,03 \%$ & $0,08 \%$ & $3,81 \%$ & 01/01/1996 & $30 / 12 / 2015$ & 4.950 \\
\hline BR Brokers & BBRK3 & $1,17 \%$ & $-0,05 \%$ & $3,31 \%$ & $01 / 11 / 2007$ & $30 / 12 / 2015$ & 1.987 \\
\hline BBSeguridade & BBSE3 & $13,60 \%$ & $0,06 \%$ & $1,11 \%$ & $29 / 04 / 2013$ & $30 / 12 / 2015$ & 663 \\
\hline Btg Pactual & BBTG11 & $13,79 \%$ & $-0,07 \%$ & $1,44 \%$ & $26 / 04 / 2012$ & $30 / 12 / 2015$ & 909 \\
\hline $\mathrm{BCN}$ & BCNA4 & $0,50 \%$ & $0,31 \%$ & $1,82 \%$ & 01/01/1996 & 26/06/1998 & 580 \\
\hline Banestes & BEES3 & $0,18 \%$ & $0,15 \%$ & $5,62 \%$ & 01/08/1997 & $30 / 12 / 2015$ & 2.112 \\
\hline Banestes & BEES4 & $3,59 \%$ & $0,28 \%$ & $2,78 \%$ & $27 / 05 / 2008$ & $30 / 12 / 2015$ & 724 \\
\hline Bemge & BEMG4 & $0,55 \%$ & $1,04 \%$ & $3,78 \%$ & 02/06/1997 & $31 / 07 / 2000$ & 359 \\
\hline Banespa & BESP3 & $0,75 \%$ & $0,37 \%$ & $4,16 \%$ & 01/01/1996 & $30 / 03 / 2007$ & 1.738 \\
\hline Banespa & BESP4 & $0,00 \%$ & $0,21 \%$ & $4,45 \%$ & 01/01/1996 & $30 / 03 / 2007$ & 2.551 \\
\hline Sudameris & BFIT3 & $1,79 \%$ & $0,16 \%$ & $2,67 \%$ & 01/01/1996 & $31 / 01 / 2007$ & 1.267 \\
\hline Banese & BGIP4 & $0,82 \%$ & $0,35 \%$ & $4,27 \%$ & 01/09/1997 & $30 / 11 / 2015$ & 1.152 \\
\hline Bicbanco & BICB4 & $1,04 \%$ & $0,01 \%$ & $2,63 \%$ & 29/10/2007 & $30 / 09 / 2015$ & 1.954 \\
\hline Merc S Paulo & BMCT4 & $4,38 \%$ & $1,07 \%$ & $2,05 \%$ & 01/01/1996 & $30 / 04 / 2003$ & 303 \\
\hline Merc Brasil & BMEB3 & $10,92 \%$ & $0,85 \%$ & $1,42 \%$ & $01 / 05 / 2007$ & $31 / 01 / 2012$ & 271 \\
\hline Merc Brasil & BMEB4 & $2,06 \%$ & $0,16 \%$ & $2,59 \%$ & 01/11/1996 & $29 / 12 / 2015$ & 1.440 \\
\hline Merc Invest & BMIN4 & $0,15 \%$ & $0,14 \%$ & $4,54 \%$ & $01 / 12 / 2006$ & $30 / 09 / 2014$ & 1.198 \\
\hline Nord Brasil & BNBR3 & $1,22 \%$ & $0,70 \%$ & $2,36 \%$ & 01/02/1996 & $31 / 01 / 2011$ & 207 \\
\hline Nord Brasil & BNBR4 & $2,31 \%$ & $0,44 \%$ & $2,99 \%$ & 01/05/1997 & $30 / 04 / 2013$ & 392 \\
\hline Nossa Caixa & BNCA3 & $2,23 \%$ & $0,11 \%$ & $2,19 \%$ & $28 / 10 / 2005$ & $31 / 03 / 2010$ & 1.085 \\
\hline Santander Noroeste & BNET4 & $2,40 \%$ & $0,31 \%$ & $1,89 \%$ & 01/03/1996 & $31 / 05 / 1999$ & 400 \\
\hline Banco Pan & BPAN4 & $0,58 \%$ & $-0,07 \%$ & $2,90 \%$ & $19 / 11 / 2007$ & $30 / 12 / 2015$ & 2.004 \\
\hline BR Insurance & BRIN3 & $6,04 \%$ & $-0,14 \%$ & $2,93 \%$ & $01 / 11 / 2010$ & $30 / 12 / 2015$ & 1.268 \\
\hline Alfa Invest & BRIV3 & $4,93 \%$ & $0,17 \%$ & $1,58 \%$ & 01/04/1996 & $31 / 10 / 2012$ & 945 \\
\hline Alfa Invest & BRIV4 & $2,48 \%$ & $0,18 \%$ & $2,50 \%$ & 01/01/1996 & $31 / 08 / 2015$ & 1.769 \\
\hline BR Malls Par & BRML3 & $0,42 \%$ & $0,04 \%$ & $3,04 \%$ & $05 / 04 / 2007$ & $30 / 12 / 2015$ & 2.160 \\
\hline BR Propert & BRPR3 & $6,27 \%$ & $0,01 \%$ & $1,65 \%$ & $09 / 03 / 2010$ & $30 / 12 / 2015$ & 1.441 \\
\hline Banrisul & BRSR3 & $3,85 \%$ & $0,91 \%$ & $2,01 \%$ & 01/11/1996 & $30 / 11 / 2015$ & 139 \\
\hline Banrisul & BRSR5 & $1,61 \%$ & $0,53 \%$ & $2,55 \%$ & 01/08/1996 & $31 / 12 / 2010$ & 283 \\
\hline Banrisul & BRSR6 & $0,30 \%$ & $0,01 \%$ & $2,82 \%$ & $04 / 09 / 2007$ & $30 / 12 / 2015$ & 2.056 \\
\hline Besc & BSCT6 & $0,94 \%$ & $0,51 \%$ & $5,76 \%$ & 01/08/1996 & $28 / 11 / 2008$ & 811 \\
\hline BmfBovespa & BVMF3 & $0,35 \%$ & $0,03 \%$ & $2,74 \%$ & $21 / 08 / 2008$ & $30 / 12 / 2015$ & 1.821 \\
\hline Cyre Com-Ccp & CCPR3 & $0,81 \%$ & $0,05 \%$ & $2,19 \%$ & $10 / 08 / 2007$ & $31 / 07 / 2015$ & 1.401 \\
\hline Alfa Financ & CRIV3 & $3,69 \%$ & $0,22 \%$ & $2,00 \%$ & 01/09/1997 & $30 / 05 / 2014$ & 559 \\
\hline Alfa Financ & CRIV4 & $2,95 \%$ & $0,12 \%$ & $2,27 \%$ & 01/03/1996 & $31 / 08 / 2015$ & 1.706 \\
\hline $\begin{array}{l}\text { Cetip } \\
\text { (continua) }\end{array}$ & CTIP3 & $7,21 \%$ & $0,07 \%$ & $1,53 \%$ & $28 / 10 / 2009$ & $30 / 12 / 2015$ & 1.526 \\
\hline
\end{tabular}


(conclusão)

\begin{tabular}{|c|c|c|c|c|c|c|c|}
\hline Empresa & $\begin{array}{l}\text { Código } \\
\text { de } \\
\text { cotação }\end{array}$ & $\begin{array}{l}\text { Média } \\
\text { peso na } \\
\text { carteira }\end{array}$ & $\begin{array}{l}\text { Média } \\
\text { do } \\
\text { retorno }\end{array}$ & $\begin{array}{l}\text { Desvio- } \\
\text { padrão }\end{array}$ & $\begin{array}{l}\text { Data mínima } \\
\text { na carteira* }\end{array}$ & $\begin{array}{c}\text { Data } \\
\text { máxima na } \\
\text { carteira* }\end{array}$ & Observações \\
\hline Cruzeiro Sul & CZRS4 & $1,58 \%$ & $-0,06 \%$ & $2,73 \%$ & $26 / 06 / 2007$ & $31 / 08 / 2012$ & 1.227 \\
\hline Daycoval & DAYC4 & $0,29 \%$ & $0,00 \%$ & $2,62 \%$ & 29/06/2007 & $30 / 12 / 2015$ & 2.073 \\
\hline Generalshopp & GSHP3 & $2,27 \%$ & $-0,04 \%$ & $3,12 \%$ & 01/08/2007 & $30 / 12 / 2015$ & 2.031 \\
\hline Indusval & IDVL4 & $4,70 \%$ & $-0,05 \%$ & $2,82 \%$ & $26 / 07 / 2007$ & $30 / 12 / 2015$ & 1.765 \\
\hline Iguatemi & IGTA3 & $0,85 \%$ & $0,02 \%$ & $2,24 \%$ & 07/02/2007 & $30 / 12 / 2015$ & 2.199 \\
\hline ItauUnibanco & ITUB3 & $1,21 \%$ & $0,13 \%$ & $3,02 \%$ & 01/01/1996 & $30 / 12 / 2015$ & 3.835 \\
\hline ItauUnibanco & ITUB4 & $0,03 \%$ & $0,09 \%$ & $3,85 \%$ & 01/01/1996 & $30 / 12 / 2015$ & 4.950 \\
\hline Locamerica & LCAM3 & $10,60 \%$ & $-0,08 \%$ & $1,78 \%$ & 23/04/2012 & $30 / 12 / 2015$ & 902 \\
\hline Lopes Brasil & LPSB3 & $1,26 \%$ & $-0,04 \%$ & $2,95 \%$ & $18 / 12 / 2006$ & $30 / 12 / 2015$ & 2.232 \\
\hline Multiplan & MULT3 & $0,22 \%$ & $0,03 \%$ & $2,38 \%$ & $27 / 07 / 2007$ & $30 / 12 / 2015$ & 2.083 \\
\hline Pine & PINE4 & $0,43 \%$ & $-0,02 \%$ & $2,46 \%$ & $02 / 04 / 2007$ & $30 / 11 / 2015$ & 2.141 \\
\hline Parana & PRBC4 & $1,67 \%$ & $0,02 \%$ & $2,41 \%$ & 03/07/2007 & $30 / 12 / 2015$ & 2.018 \\
\hline Porto Seguro & PSSA3 & $2,22 \%$ & $0,07 \%$ & $2,24 \%$ & $22 / 11 / 2004$ & $30 / 12 / 2015$ & 2.747 \\
\hline Real & REAL3 & $2,36 \%$ & $0,08 \%$ & $1,84 \%$ & 01/01/1996 & $28 / 01 / 2000$ & 499 \\
\hline Real & REAL4 & $1,39 \%$ & $0,19 \%$ & $1,93 \%$ & 01/01/1996 & $28 / 01 / 2000$ & 848 \\
\hline Localiza & RENT3 & $1,10 \%$ & $0,10 \%$ & $3,07 \%$ & 01/06/2005 & $30 / 12 / 2015$ & 2.618 \\
\hline Santander BR & SANB11 & $4,70 \%$ & $0,00 \%$ & $1,81 \%$ & 08/10/2009 & $30 / 12 / 2015$ & 1.539 \\
\hline Santander BR & SANB3 & $2,73 \%$ & $0,19 \%$ & $3,08 \%$ & 04/04/2007 & $30 / 12 / 2015$ & 983 \\
\hline Santander BR & SANB4 & $0,76 \%$ & $0,21 \%$ & $3,83 \%$ & 01/10/2004 & $30 / 12 / 2015$ & 1.281 \\
\hline Sul Amer Nac & SASG3 & $1,17 \%$ & $0,00 \%$ & $1,98 \%$ & $01 / 12 / 2006$ & $30 / 04 / 2008$ & 341 \\
\hline Sao Carlos & SCAR3 & $1,47 \%$ & $0,14 \%$ & $3,04 \%$ & 28/09/1999 & $30 / 12 / 2015$ & 2.275 \\
\hline Sao Carlos & SCAR4 & $4,43 \%$ & $0,58 \%$ & $2,36 \%$ & 22/09/1999 & $22 / 08 / 2006$ & 382 \\
\hline Sofisa & SFSA4 & $0,69 \%$ & $-0,01 \%$ & $2,63 \%$ & $02 / 05 / 2007$ & $30 / 11 / 2015$ & 1.691 \\
\hline Sierrabrasil & SSBR3 & $11,11 \%$ & $-0,02 \%$ & $1,38 \%$ & 03/02/2011 & $30 / 12 / 2015$ & 1.213 \\
\hline Sul America & SULA11 & $1,19 \%$ & $0,05 \%$ & $2,20 \%$ & 05/10/2007 & $30 / 12 / 2015$ & 2.034 \\
\hline Tig Ltd & TARP11 & $8,13 \%$ & $0,10 \%$ & $1,13 \%$ & $31 / 05 / 2007$ & $31 / 08 / 2010$ & 468 \\
\hline Tarpon Inv & TRPN3 & $3,02 \%$ & $0,17 \%$ & $2,89 \%$ & $27 / 05 / 2009$ & $30 / 12 / 2015$ & 1.380 \\
\hline Unibanco & UBBR11 & $0,80 \%$ & $0,19 \%$ & $3,86 \%$ & 26/08/1997 & $30 / 03 / 2009$ & 2.633 \\
\hline Unibanco & UBBR3 & $2,37 \%$ & $0,26 \%$ & $3,67 \%$ & 01/02/1996 & $30 / 03 / 2009$ & 1.847 \\
\hline Unibanco & UBBR4 & $0,67 \%$ & $0,13 \%$ & $3,49 \%$ & 01/01/1996 & $30 / 03 / 2009$ & 3.141 \\
\hline Total Seto & & & & & $03 / 07 / 1995$ & $30 / 12 / 2015$ & 119.754 \\
\hline
\end{tabular}

Fonte: Economática ${ }^{\circledR}$.

Elaborado pelo autor.

* As datas: mínima e máxima referem-se ao início e fim das observações utilizadas das cotações para formação da carteira do setor, como a carteira é dinâmica com ajustes diários houveram ações que em determinados dias apresentaram peso igual a zero. 
Tabela B2 - Estatísticas descritivas das empresas na economia real

\begin{tabular}{|c|c|c|c|c|c|c|c|c|}
\hline Empresa & Média & Mediana & $\begin{array}{c}\text { Desvio- } \\
\text { padrão }\end{array}$ & $\begin{array}{c}\text { Data } \\
\text { Mínima }\end{array}$ & $\begin{array}{c}\text { Data } \\
\text { Máxima }\end{array}$ & Observações & $\begin{array}{c}\text { Média } \\
C E C\end{array}$ & $\begin{array}{l}\text { Média } \\
\hat{\gamma} \cdot 10^{3}\end{array}$ \\
\hline Abyara & $-0,04 \%$ & $-0,22 \%$ & $4,84 \%$ & $01 / 02 / 2007$ & $30 / 12 / 2009$ & 719 & 1,385 & 0,0000 \\
\hline Aco Altona & $0,10 \%$ & $0,00 \%$ & $2,77 \%$ & $02 / 04 / 2007$ & $26 / 11 / 2014$ & 1052 & 0,361 & 0,0000 \\
\hline Acos Vill & $0,21 \%$ & $0,00 \%$ & $3,03 \%$ & $01 / 04 / 2004$ & $30 / 12 / 2010$ & 1439 & 0,647 & 0,0000 \\
\hline All Amer Lat & $-0,02 \%$ & $-0,11 \%$ & $2,89 \%$ & $02 / 10 / 2006$ & $31 / 03 / 2015$ & 1244 & 0,765 & 0,0000 \\
\hline Alpargatas & $0,20 \%$ & $0,00 \%$ & $3,11 \%$ & $02 / 01 / 2007$ & $30 / 12 / 2015$ & 720 & 0,256 & 0,0011 \\
\hline Ambev S/A & $0,14 \%$ & $0,00 \%$ & $1,96 \%$ & 02/01/1997 & $30 / 12 / 2015$ & 4191 & 0,525 & 0,0034 \\
\hline Amil & $0,08 \%$ & $0,00 \%$ & $2,74 \%$ & $29 / 10 / 2007$ & $28 / 03 / 2013$ & 1336 & 0,826 & 0,0015 \\
\hline Ampla Energ & $0,25 \%$ & $0,00 \%$ & $4,80 \%$ & 03/07/1995 & $30 / 03 / 2012$ & 2305 & 0,313 & 0,0000 \\
\hline Anhanguera & $0,05 \%$ & $0,00 \%$ & $2,52 \%$ & $03 / 01 / 2011$ & $30 / 06 / 2014$ & 864 & 0,933 & 0,0000 \\
\hline Anima & $-0,02 \%$ & $-0,05 \%$ & $3,56 \%$ & $28 / 10 / 2013$ & $30 / 12 / 2015$ & 536 & 0,889 & 0,0000 \\
\hline Aracruz & $0,15 \%$ & $0,00 \%$ & $5,09 \%$ & 04/10/1999 & $30 / 09 / 2009$ & 799 & 0,444 & 0,0000 \\
\hline Arcelor BR & $0,26 \%$ & $0,00 \%$ & $2,87 \%$ & 03/07/1995 & $31 / 05 / 2007$ & 1640 & 0,114 & 0,0000 \\
\hline Arezzo Co & $0,02 \%$ & $0,00 \%$ & $2,42 \%$ & $02 / 02 / 2011$ & $30 / 12 / 2015$ & 1216 & 0,950 & 0,0000 \\
\hline Autometal & $0,04 \%$ & $0,00 \%$ & $1,95 \%$ & $07 / 02 / 2011$ & $30 / 09 / 2014$ & 905 & 0,800 & 0,0000 \\
\hline B2W Digital & $-0,03 \%$ & $-0,15 \%$ & $3,80 \%$ & $09 / 08 / 2007$ & $30 / 12 / 2015$ & 2074 & 1,235 & 0,0136 \\
\hline Bahia Sul & $0,18 \%$ & $0,00 \%$ & $2,58 \%$ & 01/10/1999 & $23 / 06 / 2004$ & 1022 & 0,043 & 0,0000 \\
\hline Bandeirante Energ & $-0,06 \%$ & $0,00 \%$ & $4,83 \%$ & 01/04/1998 & $29 / 09 / 2000$ & 590 & 0,083 & 0,0000 \\
\hline Bardella & $0,25 \%$ & $0,00 \%$ & $2,73 \%$ & 02/01/1997 & $30 / 09 / 2014$ & 2162 & 0,217 & 0,0000 \\
\hline Bombril & $0,03 \%$ & $0,00 \%$ & $3,48 \%$ & 03/07/1995 & $24 / 09 / 2014$ & 3588 & 0,208 & 0,0000 \\
\hline BR Pharma & $-0,36 \%$ & $-0,08 \%$ & $3,42 \%$ & 01/07/2011 & $30 / 12 / 2015$ & 1077 & 1,000 & 0,0097 \\
\hline Brasil T Par & $0,11 \%$ & $0,00 \%$ & $3,41 \%$ & 02/10/1998 & $30 / 09 / 2009$ & 2717 & 0,311 & 0,0015 \\
\hline Braskem & $0,12 \%$ & $0,00 \%$ & $2,77 \%$ & $04 / 08 / 2004$ & $30 / 12 / 2015$ & 2286 & 0,583 & 0,0000 \\
\hline BRF SA & $0,08 \%$ & $0,00 \%$ & $2,30 \%$ & $02 / 05 / 2006$ & $30 / 12 / 2015$ & 2390 & 1,103 & 0,0103 \\
\hline Bunge Alimentos & $0,10 \%$ & $0,00 \%$ & $3,75 \%$ & 03/07/1995 & $26 / 06 / 2001$ & 1046 & 0,130 & 0,0047 \\
\hline Bunge Fertilizantes & $0,18 \%$ & $0,00 \%$ & $3,97 \%$ & 07/08/1995 & $28 / 12 / 2001$ & 1387 & 0,280 & 0,1071 \\
\hline Caemi & $0,26 \%$ & $0,00 \%$ & $2,94 \%$ & 03/07/1995 & $31 / 03 / 2006$ & 2187 & 0,048 & 0,0000 \\
\hline Cambuci & $0,43 \%$ & $0,00 \%$ & $4,56 \%$ & $04 / 05 / 2009$ & $30 / 06 / 2015$ & 746 & 0,241 & 0,0000 \\
\hline CCR SA & $0,13 \%$ & $0,04 \%$ & $2,38 \%$ & $01 / 10 / 2002$ & $30 / 12 / 2015$ & 3236 & 0,946 & 0,0023 \\
\hline Celesc & $0,03 \%$ & $0,00 \%$ & $2,78 \%$ & $01 / 02 / 1996$ & $30 / 12 / 2015$ & 4826 & 0,438 & 0,0005 \\
\hline Celpe & $0,56 \%$ & $0,00 \%$ & $4,36 \%$ & 08/01/1997 & $24 / 08 / 2007$ & 364 & 0,200 & 0,0000 \\
\hline Cemig & $0,08 \%$ & $0,00 \%$ & $2,80 \%$ & 03/07/1995 & $30 / 12 / 2015$ & 5033 & 0,488 & 0,0014 \\
\hline Cesp & $0,06 \%$ & $0,00 \%$ & $3,30 \%$ & 03/07/1995 & $30 / 12 / 2015$ & 4540 & 0,388 & 0,0006 \\
\hline Cia Hering & $0,14 \%$ & $0,00 \%$ & $2,81 \%$ & $01 / 02 / 2007$ & $30 / 12 / 2015$ & 2183 & 0,897 & 0,0000 \\
\hline Coelba & $0,17 \%$ & $0,00 \%$ & $3,43 \%$ & 04/10/1996 & $30 / 09 / 1999$ & 590 & 0,259 & 0,0000 \\
\hline Confab & $0,15 \%$ & $0,00 \%$ & $2,78 \%$ & 01/04/1996 & $30 / 03 / 2012$ & 3957 & 0,621 & 0,0106 \\
\hline Contax & $0,05 \%$ & $0,00 \%$ & $3,77 \%$ & $03 / 10 / 2005$ & $30 / 12 / 2015$ & 1325 & 0,500 & 0,0000 \\
\hline Copasa & $0,01 \%$ & $0,00 \%$ & $2,48 \%$ & $08 / 02 / 2006$ & $30 / 12 / 2015$ & 2444 & 0,900 & 0,0019 \\
\hline Copel & $0,06 \%$ & $0,00 \%$ & $2,76 \%$ & 03/07/1995 & $30 / 12 / 2015$ & 4789 & 0,513 & 0,0596 \\
\hline Copesul & $0,16 \%$ & $0,00 \%$ & $2,47 \%$ & 03/07/1995 & $28 / 09 / 2007$ & 2757 & 0,191 & 0,0046 \\
\hline Cosan & $0,05 \%$ & $0,00 \%$ & $2,91 \%$ & $18 / 11 / 2005$ & $30 / 12 / 2015$ & 2500 & 1,049 & 0,0011 \\
\hline CPFL Energia & $0,04 \%$ & $0,00 \%$ & $1,92 \%$ & $01 / 10 / 2004$ & $30 / 12 / 2015$ & 2780 & 1,217 & 0,0000 \\
\hline CPFL Renovav & $-0,04 \%$ & $0,00 \%$ & $1,37 \%$ & $19 / 07 / 2013$ & $30 / 12 / 2015$ & 601 & 0,600 & 0,0000 \\
\hline Cremer & $0,05 \%$ & $0,00 \%$ & $2,25 \%$ & $30 / 04 / 2007$ & $30 / 06 / 2014$ & 1717 & 1,207 & 0,0061 \\
\hline Crt Celular & $0,14 \%$ & $0,00 \%$ & $4,36 \%$ & $06 / 04 / 2001$ & $28 / 03 / 2006$ & 370 & 0,059 & 0,0000 \\
\hline Crt Ciargtelec & $0,14 \%$ & $0,00 \%$ & $4,29 \%$ & $12 / 11 / 1996$ & $28 / 02 / 2001$ & 1054 & 0,556 & 0,0000 \\
\hline Csu Cardsyst & $-0,05 \%$ & $0,00 \%$ & $2,82 \%$ & $02 / 05 / 2006$ & $30 / 12 / 2015$ & 2390 & 0,974 & 0,0000 \\
\hline Dasa & $0,03 \%$ & $0,00 \%$ & $2,45 \%$ & $03 / 01 / 2005$ & $30 / 12 / 2015$ & 2719 & 0,822 & 0,0032 \\
\hline Dimed & $0,33 \%$ & $0,14 \%$ & $2,54 \%$ & 01/07/2009 & $30 / 12 / 2015$ & 686 & 0,400 & 0,0036 \\
\hline Dixie Toga & $0,18 \%$ & $0,00 \%$ & $3,56 \%$ & 01/07/1997 & $31 / 03 / 2010$ & 447 & 0,148 & 0,0000 \\
\hline Doc Imbituba & $0,24 \%$ & $0,00 \%$ & $6,20 \%$ & $03 / 01 / 2005$ & $30 / 09 / 2013$ & 1772 & 0,333 & 0,0000 \\
\hline
\end{tabular}

(continua) 
(continuação)

\begin{tabular}{|c|c|c|c|c|c|c|c|c|}
\hline Empresa & Média & Mediana & $\begin{array}{l}\text { Desvio- } \\
\text { padrão }\end{array}$ & $\begin{array}{c}\text { Data } \\
\text { Mínima }\end{array}$ & $\begin{array}{l}\text { Data } \\
\text { Máxima }\end{array}$ & Observações & $\begin{array}{l}\text { Média } \\
C E C\end{array}$ & $\begin{array}{l}\text { Média } \\
\hat{\gamma} .10^{3}\end{array}$ \\
\hline $\begin{array}{l}\text { Duratex } \\
\text { nat }\end{array}$ & $0,00 \%$ & $0,00 \%$ & $2,61 \%$ & $01 / 10 / 2007$ & $30 / 12 / 2015$ & 2034 & 1,412 & 0,0125 \\
\hline Eletrobras & $0,03 \%$ & $0,00 \%$ & $3,12 \%$ & 03/07/1995 & $30 / 12 / 2015$ & 5074 & 0,550 & 0,0064 \\
\hline Eleva & $0,44 \%$ & $0,00 \%$ & $3,32 \%$ & 03/07/1995 & $28 / 12 / 2007$ & 1271 & 0,042 & 0,0000 \\
\hline Embraer & $0,11 \%$ & $0,00 \%$ & $2,75 \%$ & 05/04/1999 & $30 / 12 / 2015$ & 4137 & 0,471 & 0,0106 \\
\hline Embratel Part & $0,13 \%$ & $0,00 \%$ & $4,81 \%$ & 02/10/1998 & $30 / 05 / 2014$ & 2618 & 0,143 & 0,0166 \\
\hline Energias BR & $0,05 \%$ & $0,00 \%$ & $2,12 \%$ & $13 / 07 / 2005$ & $30 / 12 / 2015$ & 2588 & 1,143 & 0,0026 \\
\hline Eneva & $-0,14 \%$ & $0,00 \%$ & $3,80 \%$ & $02 / 01 / 2008$ & $30 / 12 / 2015$ & 1955 & 1,091 & 0,0057 \\
\hline Epte & $0,10 \%$ & $0,00 \%$ & $6,00 \%$ & 01/04/1998 & $28 / 09 / 2001$ & 845 & 0,067 & 0,0000 \\
\hline Estacio Part & $0,05 \%$ & $0,00 \%$ & $2,64 \%$ & $14 / 07 / 2008$ & $30 / 12 / 2015$ & 1834 & 1,167 & 0,0051 \\
\hline Eternit & $0,09 \%$ & $0,00 \%$ & $2,10 \%$ & 01/07/1997 & $30 / 12 / 2015$ & 4003 & 0,781 & 0,0029 \\
\hline Eucatex & $0,05 \%$ & $0,00 \%$ & $3,34 \%$ & $02 / 05 / 2000$ & $30 / 12 / 2015$ & 2022 & 0,659 & 0,0086 \\
\hline F Cataguazes & $0,18 \%$ & $0,00 \%$ & $3,41 \%$ & 03/07/1995 & $30 / 03 / 2007$ & 2610 & 0,200 & 0,0114 \\
\hline Fer Heringer & $-0,09 \%$ & $-0,06 \%$ & $3,22 \%$ & $12 / 04 / 2007$ & $30 / 12 / 2015$ & 2156 & 1,286 & 0,0179 \\
\hline Ferbasa & $0,13 \%$ & $0,00 \%$ & $2,49 \%$ & 03/04/1997 & $30 / 12 / 2015$ & 3651 & 0,829 & 0,0044 \\
\hline Fertisul & $0,70 \%$ & $0,00 \%$ & $5,15 \%$ & 08/04/1996 & $30 / 06 / 1998$ & 438 & 0,200 & 0,0180 \\
\hline Fibria & $0,04 \%$ & $0,00 \%$ & $2,37 \%$ & $13 / 08 / 2009$ & $30 / 12 / 2015$ & 1578 & 0,731 & 0,0210 \\
\hline Fleury & $-0,01 \%$ & $0,00 \%$ & $1,81 \%$ & $04 / 01 / 2010$ & $30 / 12 / 2015$ & 1484 & 0,600 & 0,0036 \\
\hline Forja $\mathrm{T}$ & $-0,05 \%$ & $0,00 \%$ & $4,17 \%$ & $01 / 07 / 2011$ & $30 / 12 / 2014$ & 605 & 0,471 & 0,0000 \\
\hline Gerdau & $0,01 \%$ & $0,00 \%$ & $2,59 \%$ & $01 / 04 / 2004$ & $30 / 12 / 2015$ & 2867 & 1,125 & 0,0277 \\
\hline Gerdau Met & $-0,01 \%$ & $0,00 \%$ & $2,79 \%$ & 07/07/1997 & $30 / 12 / 2015$ & 2793 & 0,926 & 0,0050 \\
\hline Gol & $-0,05 \%$ & $-0,22 \%$ & $3,38 \%$ & $01 / 07 / 2004$ & $30 / 12 / 2015$ & 2844 & 0,979 & 0,0132 \\
\hline GPC Part & $0,20 \%$ & $0,00 \%$ & $6,82 \%$ & $06 / 02 / 2007$ & $30 / 09 / 2015$ & 1670 & 0,618 & 0,0185 \\
\hline Grazziotin & $0,05 \%$ & $0,00 \%$ & $2,14 \%$ & $02 / 01 / 2013$ & $30 / 06 / 2015$ & 415 & 0,500 & 0,0000 \\
\hline Grendene & $0,04 \%$ & $0,00 \%$ & $2,00 \%$ & 29/10/2004 & $30 / 12 / 2015$ & 2761 & 0,956 & 0,0056 \\
\hline Guarani & $-0,14 \%$ & $0,00 \%$ & $3,34 \%$ & $23 / 07 / 2007$ & $30 / 06 / 2010$ & 725 & 1,154 & 0,0619 \\
\hline Guararapes & $0,07 \%$ & $0,00 \%$ & $2,18 \%$ & 01/07/1996 & $30 / 12 / 2015$ & 2748 & 0,865 & 0,0201 \\
\hline GVT Holding & $0,15 \%$ & $0,07 \%$ & $3,21 \%$ & $02 / 04 / 2007$ & $31 / 03 / 2010$ & 739 & 1,500 & 0,0000 \\
\hline Habitasul & $0,41 \%$ & $0,00 \%$ & $6,87 \%$ & 09/10/2007 & $29 / 06 / 2012$ & 436 & 0,222 & 0,0227 \\
\hline Hypermarcas & $0,06 \%$ & $-0,02 \%$ & $2,55 \%$ & $02 / 05 / 2008$ & $30 / 12 / 2015$ & 1898 & 1,065 & 0,0225 \\
\hline Inds Romi & $-0,08 \%$ & $0,00 \%$ & $2,85 \%$ & $02 / 04 / 2007$ & $30 / 12 / 2015$ & 2140 & 0,738 & 0,0000 \\
\hline Inepar & $-0,05 \%$ & $0,00 \%$ & $4,58 \%$ & $01 / 10 / 2008$ & $30 / 09 / 2015$ & 1547 & 0,484 & 0,0359 \\
\hline Iochp-Maxion & $0,00 \%$ & $0,00 \%$ & $2,59 \%$ & $01 / 04 / 2008$ & $30 / 12 / 2015$ & 1919 & 1,353 & 0,0052 \\
\hline Ipiranga Dis & $0,38 \%$ & $0,00 \%$ & $2,53 \%$ & $01 / 04 / 1996$ & $28 / 12 / 2007$ & 1212 & 0,190 & 0,0077 \\
\hline Ipiranga Pet & $0,09 \%$ & $0,00 \%$ & $2,85 \%$ & 03/07/1995 & $28 / 12 / 2007$ & 3077 & 0,265 & 0,0075 \\
\hline Itausa & $0,07 \%$ & $0,00 \%$ & $2,60 \%$ & 02/04/1997 & $30 / 12 / 2015$ & 2242 & 0,843 & 0,0004 \\
\hline Itautec & $0,24 \%$ & $0,00 \%$ & $6,06 \%$ & 03/07/1995 & $27 / 06 / 2007$ & 1032 & 0,024 & 0,0000 \\
\hline JBS & $0,05 \%$ & $0,00 \%$ & $3,25 \%$ & $02 / 04 / 2007$ & $30 / 12 / 2015$ & 2163 & 1,278 & 0,0112 \\
\hline Jereissati & $0,07 \%$ & $0,00 \%$ & $3,17 \%$ & 01/10/1997 & $24 / 06 / 2015$ & 1856 & 0,976 & 0,0325 \\
\hline JHSF Part & $-0,04 \%$ & $0,00 \%$ & $3,12 \%$ & $12 / 04 / 2007$ & $30 / 12 / 2015$ & 2154 & 1,371 & 0,0348 \\
\hline Karsten & $0,31 \%$ & $0,00 \%$ & $5,55 \%$ & $02 / 10 / 2006$ & $30 / 12 / 2015$ & 1176 & 0,432 & 0,0798 \\
\hline Kepler Weber & $0,02 \%$ & $0,00 \%$ & $4,27 \%$ & $05 / 07 / 2004$ & $30 / 12 / 2015$ & 1937 & 0,705 & 0,0000 \\
\hline Klabin S/A & $0,08 \%$ & $0,00 \%$ & $2,88 \%$ & 03/07/1995 & $30 / 12 / 2015$ & 5006 & 0,513 & 0,0088 \\
\hline Kroton & $0,09 \%$ & $0,08 \%$ & $2,75 \%$ & $02 / 01 / 2013$ & $30 / 12 / 2015$ & 742 & 1,000 & 0,0000 \\
\hline Light S/A & $-0,01 \%$ & $-0,01 \%$ & $3,08 \%$ & 03/07/1995 & $30 / 12 / 2015$ & 5066 & 0,500 & 0,0322 \\
\hline $\operatorname{Lin} x$ & $0,07 \%$ & $0,00 \%$ & $2,12 \%$ & $08 / 02 / 2013$ & $30 / 12 / 2015$ & 716 & 0,917 & 0,0000 \\
\hline Log-In & $-0,10 \%$ & $0,00 \%$ & $3,10 \%$ & $02 / 07 / 2007$ & $30 / 12 / 2015$ & 2101 & 1,029 & 0,0392 \\
\hline Lojas Ma & $-0,02 \%$ & $0,00 \%$ & $2,44 \%$ & $22 / 10 / 2007$ & $30 / 12 / 2015$ & 2024 & 1,152 & 0,0025 \\
\hline Lojas Renner & $0,12 \%$ & $0,00 \%$ & $2,75 \%$ & $01 / 07 / 2005$ & $30 / 12 / 2015$ & 2596 & 1,119 & 0,0186 \\
\hline M G Poliest & $0,00 \%$ & $0,00 \%$ & $5,64 \%$ & 03/07/1995 & $31 / 05 / 2011$ & 1536 & 0,294 & 0,0000 \\
\hline M.Dia & $0,05 \%$ & $0,00 \%$ & $1,93 \%$ & $18 / 10 / 2006$ & $30 / 12 / 2015$ & 2264 & 1,054 & 0,0000 \\
\hline Magnesita & $0,19 \%$ & $0,00 \%$ & $2,63 \%$ & 08/01/1996 & $31 / 03 / 2008$ & 2823 & 0,224 & 0,0058 \\
\hline
\end{tabular}


(continuação)

\begin{tabular}{|c|c|c|c|c|c|c|c|c|}
\hline Empresa & Média & Mediana & $\begin{array}{c}\text { Desvio- } \\
\text { padrão }\end{array}$ & $\begin{array}{c}\text { Data } \\
\text { Mínima }\end{array}$ & $\begin{array}{c}\text { Data } \\
\text { Máxima }\end{array}$ & Observações & $\begin{array}{l}\text { Média } \\
C E C\end{array}$ & $\begin{array}{l}\text { Média } \\
\hat{\gamma} \cdot 10^{3}\end{array}$ \\
\hline Magnesita SA & $-0,06 \%$ & $0,00 \%$ & $2,58 \%$ & $03 / 04 / 2008$ & $30 / 12 / 2015$ & 1917 & 1,000 & 0,0086 \\
\hline Mangels Indl & $0,12 \%$ & $0,00 \%$ & $4,10 \%$ & 03/07/1996 & $31 / 08 / 2015$ & 3054 & 0,342 & 0,0063 \\
\hline Marcopolo & $0,07 \%$ & $0,00 \%$ & $2,50 \%$ & $03 / 04 / 2007$ & $30 / 12 / 2015$ & 1884 & 0,703 & 0,0076 \\
\hline Marfrig & $-0,02 \%$ & $0,00 \%$ & $3,22 \%$ & $02 / 07 / 2007$ & $30 / 12 / 2015$ & 2101 & 1,114 & 0,0885 \\
\hline Marisol & $0,23 \%$ & $0,00 \%$ & $5,62 \%$ & 01/04/1996 & $31 / 05 / 2011$ & 736 & 0,609 & 0,0098 \\
\hline Medial Saude & $-0,02 \%$ & $0,00 \%$ & $3,12 \%$ & $02 / 10 / 2006$ & $31 / 03 / 2010$ & 851 & 0,938 & 0,0000 \\
\hline Metal Iguacu & $0,18 \%$ & $0,00 \%$ & $7,88 \%$ & $13 / 02 / 2007$ & $30 / 09 / 2015$ & 1177 & 0,471 & 0,0000 \\
\hline Metal Leve & $0,07 \%$ & $0,00 \%$ & $1,74 \%$ & $02 / 05 / 2011$ & $30 / 12 / 2015$ & 1144 & 0,750 & 0,0000 \\
\hline Metalfrio & $0,00 \%$ & $0,00 \%$ & $3,21 \%$ & $13 / 04 / 2007$ & $29 / 12 / 2015$ & 1851 & 0,629 & 0,0416 \\
\hline Mills & $-0,09 \%$ & $-0,06 \%$ & $2,74 \%$ & $16 / 04 / 2010$ & $30 / 12 / 2015$ & 1414 & 1,000 & 0,0000 \\
\hline Minerva & $0,00 \%$ & $-0,08 \%$ & $2,70 \%$ & $20 / 07 / 2007$ & $30 / 12 / 2015$ & 2088 & 1,118 & 0,0192 \\
\hline MMX Miner & $-0,11 \%$ & $-0,01 \%$ & $5,06 \%$ & $02 / 01 / 2007$ & $30 / 12 / 2015$ & 2179 & 1,105 & 0,0021 \\
\hline Mundial & $0,22 \%$ & $0,00 \%$ & $6,77 \%$ & $04 / 07 / 2007$ & $30 / 09 / 2015$ & 998 & 0,250 & 0,0000 \\
\hline Natura & $0,05 \%$ & $0,00 \%$ & $2,28 \%$ & $01 / 07 / 2004$ & $30 / 12 / 2015$ & 2844 & 0,830 & 0,0021 \\
\hline Oi & $0,05 \%$ & $0,00 \%$ & $3,69 \%$ & $01 / 08 / 1995$ & $30 / 12 / 2015$ & 3370 & 0,403 & 0,0051 \\
\hline OSX Brasil & $-0,32 \%$ & $-0,15 \%$ & $5,54 \%$ & $01 / 04 / 2010$ & $30 / 09 / 2015$ & 1279 & 0,792 & 0,0064 \\
\hline P.Acucar-Cbd & $0,06 \%$ & $0,00 \%$ & $2,50 \%$ & $01 / 02 / 1996$ & $30 / 12 / 2015$ & 4872 & 0,663 & 0,0105 \\
\hline Paranapanema & $-0,02 \%$ & $-0,26 \%$ & $3,51 \%$ & $01 / 10 / 2003$ & $30 / 12 / 2015$ & 2173 & 0,791 & 0,0040 \\
\hline Paul F Luz & $0,13 \%$ & $0,00 \%$ & $3,20 \%$ & 03/07/1995 & $29 / 12 / 2005$ & 1427 & 0,346 & 0,0000 \\
\hline Petrobras & $0,08 \%$ & $0,00 \%$ & $2,87 \%$ & 03/07/1995 & $30 / 12 / 2015$ & 5062 & 0,963 & 0,0147 \\
\hline Petrobras Distrib & $0,07 \%$ & $0,00 \%$ & $2,85 \%$ & 03/07/1995 & $30 / 12 / 2002$ & 1852 & 0,345 & 0,0010 \\
\hline Petroflex & $0,15 \%$ & $0,00 \%$ & $2,33 \%$ & 02/05/1997 & $30 / 09 / 2008$ & 628 & 0,150 & 0,0000 \\
\hline Petrorio & $-0,26 \%$ & $-0,36 \%$ & $5,07 \%$ & $25 / 10 / 2010$ & $30 / 12 / 2015$ & 1283 & 0,905 & 0,0000 \\
\hline Pettenati & $0,27 \%$ & $0,00 \%$ & $3,41 \%$ & 05/07/1995 & $28 / 05 / 2012$ & 1037 & 0,359 & 0,0053 \\
\hline Plascar Part & $-0,20 \%$ & $0,00 \%$ & $3,68 \%$ & $02 / 05 / 2007$ & $30 / 12 / 2015$ & 1999 & 0,829 & 0,0000 \\
\hline Pomifrutas & $0,03 \%$ & $0,00 \%$ & $4,49 \%$ & $01 / 04 / 2005$ & $30 / 12 / 2015$ & 2312 & 0,386 & 0,0000 \\
\hline Positivo Inf & $-0,07 \%$ & $-0,10 \%$ & $3,76 \%$ & $02 / 01 / 2007$ & $30 / 12 / 2015$ & 2224 & 1,297 & 0,0000 \\
\hline Profarma & $-0,05 \%$ & $0,00 \%$ & $2,71 \%$ & $26 / 10 / 2006$ & $30 / 12 / 2015$ & 2169 & 0,595 & 0,0036 \\
\hline Providencia & $-0,01 \%$ & $0,00 \%$ & $2,38 \%$ & $01 / 08 / 2007$ & $30 / 06 / 2015$ & 1914 & 0,941 & 0,0041 \\
\hline Qgep Part & $-0,09 \%$ & $0,00 \%$ & $2,53 \%$ & $09 / 02 / 2011$ & $30 / 12 / 2015$ & 1211 & 1,150 & 0,0000 \\
\hline Quattor Petr & $0,16 \%$ & $0,00 \%$ & $2,91 \%$ & $03 / 04 / 2002$ & $26 / 03 / 2010$ & 1504 & 0,250 & 0,0030 \\
\hline Randon Part & $-0,02 \%$ & $0,00 \%$ & $3,32 \%$ & $05 / 10 / 2006$ & $30 / 12 / 2015$ & 719 & 0,632 & 0,0000 \\
\hline Rasip Agro & $0,10 \%$ & $0,00 \%$ & $4,96 \%$ & $02 / 07 / 2007$ & $28 / 08 / 2012$ & 662 & 0,591 & 0,0000 \\
\hline Ripasa & $0,15 \%$ & $0,00 \%$ & $3,00 \%$ & 08/10/1996 & $29 / 06 / 2006$ & 2179 & 0,179 & 0,0000 \\
\hline S Gobain Canal & $0,27 \%$ & $0,00 \%$ & $4,10 \%$ & 05/07/1995 & $30 / 03 / 2001$ & 1223 & 0,095 & 0,0000 \\
\hline Sabesp & $0,07 \%$ & $0,00 \%$ & $2,92 \%$ & 02/01/1997 & $30 / 12 / 2015$ & 4696 & 0,571 & 0,0058 \\
\hline Sadia S/A & $0,11 \%$ & $0,00 \%$ & $3,06 \%$ & $01 / 08 / 2005$ & $21 / 09 / 2009$ & 644 & 0,353 & 0,0000 \\
\hline Sanepar & $0,05 \%$ & $0,00 \%$ & $2,36 \%$ & $02 / 10 / 2000$ & $30 / 12 / 2015$ & 3398 & 0,413 & 0,0124 \\
\hline Santanense & $0,24 \%$ & $0,00 \%$ & $4,46 \%$ & $02 / 01 / 2008$ & $28 / 06 / 2013$ & 524 & 0,280 & 0,0000 \\
\hline Santistextil & $0,26 \%$ & $0,00 \%$ & $2,71 \%$ & 01/04/1996 & $29 / 09 / 2004$ & 823 & 0,000 & 0,0000 \\
\hline Sao Martinho & $0,06 \%$ & $0,00 \%$ & $2,83 \%$ & $12 / 02 / 2007$ & $30 / 12 / 2015$ & 2196 & 1,056 & 0,0072 \\
\hline Saraiva Livr & $0,01 \%$ & $0,00 \%$ & $2,51 \%$ & $03 / 04 / 2000$ & $30 / 12 / 2015$ & 2680 & 0,702 & 0,0111 \\
\hline Schulz & $0,16 \%$ & $0,00 \%$ & $2,49 \%$ & $01 / 02 / 2007$ & $30 / 12 / 2015$ & 1575 & 0,487 & 0,0000 \\
\hline Ser Educa & $-0,13 \%$ & $0,00 \%$ & $3,27 \%$ & $29 / 10 / 2013$ & $30 / 12 / 2015$ & 535 & 1,000 & 0,0000 \\
\hline Sharp & $0,07 \%$ & $0,00 \%$ & $6,29 \%$ & 03/07/1995 & $31 / 08 / 2000$ & 1184 & 0,136 & 0,0187 \\
\hline Sid Nacional & $0,09 \%$ & $0,00 \%$ & $2,99 \%$ & 03/07/1995 & $30 / 12 / 2015$ & 5060 & 0,750 & 0,0623 \\
\hline Sid Tubarao & $0,12 \%$ & $0,00 \%$ & $2,99 \%$ & 03/07/1995 & $30 / 09 / 2005$ & 2543 & 0,250 & 0,0052 \\
\hline SLC Agricola & $0,03 \%$ & $-0,05 \%$ & $2,96 \%$ & $02 / 07 / 2007$ & $30 / 12 / 2015$ & 2101 & 1,029 & 0,0000 \\
\hline Souza Cruz & $0,10 \%$ & $0,00 \%$ & $2,26 \%$ & 03/07/1995 & $30 / 11 / 2015$ & 4999 & 0,500 & 0,0019 \\
\hline Springer & $0,17 \%$ & $0,00 \%$ & $5,76 \%$ & 03/01/2011 & $26 / 06 / 2013$ & 528 & 0,615 & 0,0000 \\
\hline Springs & $-0,10 \%$ & $0,00 \%$ & $3,17 \%$ & $27 / 07 / 2007$ & $30 / 12 / 2015$ & 1904 & 0,824 & 0,0000 \\
\hline
\end{tabular}


(conclusão)

\begin{tabular}{|c|c|c|c|c|c|c|c|c|}
\hline sa & Média & Mediana & $\begin{array}{l}\text { Desvio- } \\
\text { padrão }\end{array}$ & $\begin{array}{l}\text { Data } \\
\text { Mínima }\end{array}$ & $\begin{array}{l}\text { Data } \\
\text { Máxima }\end{array}$ & $\mathrm{Ob}$ & $\begin{array}{c}\text { Média } \\
C E C\end{array}$ & $\begin{array}{l}\text { Média } \\
\hat{\gamma} \cdot 10^{3}\end{array}$ \\
\hline Sultepa & $0,43 \%$ & $0,00 \%$ & $5,90 \%$ & $07 / 08 / 2000$ & $28 / 12 / 2015$ & 1276 & 0,212 & 0,0209 \\
\hline Suzano Papel & $11 \%$ & $0,00 \%$ & $2,68 \%$ & 02/01/1996 & $30 / 12 / 2015$ & 4422 & 0,494 & 0,0053 \\
\hline Technos & $12 \%$ & $-0,07 \%$ & $2,37 \%$ & $01 / 07 / 2011$ & $30 / 12 / 2015$ & 1114 & 1,222 & 0,0000 \\
\hline Tecnosolo & $0,23 \%$ & $0,00 \%$ & $7,76 \%$ & $02 / 05 / 2008$ & $30 / 12 / 2015$ & 1246 & 0,393 & 0,0000 \\
\hline Tegma & $-0,05 \%$ & $0,00 \%$ & $2,65 \%$ & 03/07/2007 & $30 / 12 / 2015$ & 2100 & 1,206 & 0,0103 \\
\hline Tel B Campo & $0,37 \%$ & $0,00 \%$ & $3,69 \%$ & $02 / 05 / 1996$ & $30 / 11 / 1999$ & 659 & 0,188 & 0,0000 \\
\hline Tele Centroeste Cel & $0,24 \%$ & $0,00 \%$ & $4,03 \%$ & 01/10/1998 & $30 / 03 / 2006$ & 1825 & 0,032 & 0,0000 \\
\hline Tele Leste Celular & $0,12 \%$ & $0,00 \%$ & $4,65 \%$ & 01/10/1998 & $31 / 03 / 2005$ & 1537 & 0,000 & 0,0000 \\
\hline Tele Nordeste Celul & $0,21 \%$ & $0,00 \%$ & $4,61 \%$ & 01/10/1998 & $30 / 09 / 2004$ & 1465 & 0,000 & 0,0246 \\
\hline Tele Nort $\mathrm{Cl}$ & $0,22 \%$ & $0,00 \%$ & $5,82 \%$ & 01/10/1998 & $28 / 09 / 2007$ & 2155 & 0,027 & 0,0584 \\
\hline Tele Sudeste Celula & $0,12 \%$ & $0,00 \%$ & $3,34 \%$ & 01/10/1998 & $30 / 03 / 2006$ & 1773 & 0,000 & 0,0083 \\
\hline Telebras (Old) & $0,18 \%$ & $0,21 \%$ & $2,81 \%$ & 03/07/1995 & $30 / 06 / 1998$ & 742 & 0,818 & 0,0000 \\
\hline Telef Brasil & $0,06 \%$ & $0,00 \%$ & $2,42 \%$ & 03/07/1995 & $30 / 12 / 2015$ & 5070 & 0,488 & 0,0006 \\
\hline Telefonica Data Hld & $-0,06 \%$ & $0,00 \%$ & $3,50 \%$ & $02 / 07 / 2001$ & $29 / 08 / 2006$ & 1157 & 0,045 & 0,0525 \\
\hline Telemar & $0,10 \%$ & $0,00 \%$ & $3,29 \%$ & 02/10/1998 & $30 / 03 / 2012$ & 3339 & 0,426 & 0,0051 \\
\hline Telemar N L & $0,16 \%$ & $0,00 \%$ & $3,66 \%$ & 03/07/1995 & $18 / 06 / 2010$ & 1765 & 0,151 & 0,0048 \\
\hline Telemig & $0,42 \%$ & $0,00 \%$ & $3,73 \%$ & $07 / 07 / 1995$ & $29 / 09 / 2000$ & 830 & 0,087 & 0,0000 \\
\hline Telerj Cel & $0,00 \%$ & $0,00 \%$ & $5,11 \%$ & $19 / 05 / 1998$ & $30 / 06$ & . & 0,182 & 0,0000 \\
\hline Tereos & $-0,01 \%$ & $0,00 \%$ & $5,46 \%$ & $16 / 08 / 2010$ & $30 / 12 / 2$ & 1331 & 0,864 & 0,0000 \\
\hline Tim Nordeste & $0,24 \%$ & $0,00 \%$ & $5,15 \%$ & 05/04/1999 & $28 / 06 / 2005$ & 643 & 0,000 & 0,0000 \\
\hline Tim $\mathrm{Pa}$ & $0,09 \%$ & $0,00 \%$ & $3,53 \%$ & $01 / 10 / 1998$ & $30 / 12 / 2015$ & 4264 & 0,300 & 0,0106 \\
\hline Tim Sul & $1,02 \%$ & $0,00 \%$ & $5,75 \%$ & $01 / 07 / 1998$ & $27 / 06 /$ & 285 & 0,000 & 0,0075 \\
\hline Time For & $-0,13 \%$ & $0,00 \%$ & $2,85 \%$ & $13 / 04 / 2011$ & $30 / 12 / 2015$ & 1168 & 0,684 & 0,0402 \\
\hline Trafo & $0,36 \%$ & $0,00 \%$ & $4,01 \%$ & $01 / 07 / 1997$ & $30 / 09 / 2008$ & 912 & 0,073 & 0,0000 \\
\hline Triunfo Part & $0,03 \%$ & $0,00 \%$ & $3,34 \%$ & $23 / 07 / 2007$ & $30 / 12 / 2015$ & 2071 & 1,000 & 0,0401 \\
\hline Tupy & $0,12 \%$ & $0,00 \%$ & $2,67 \%$ & $03 / 08 / 2006$ & $30 / 12 / 2015$ & 1907 & 0,615 & 0,0161 \\
\hline Ultrapar & $0,06 \%$ & $-0,04 \%$ & $1,52 \%$ & $03 / 10 / 2011$ & $30 / 12 / 2015$ & 1049 & 1,667 & 0,0025 \\
\hline Unicasa & $-0,20 \%$ & $-0,10 \%$ & $2,70 \%$ & $27 / 04 / 2012$ & $30 / 12 / 2015$ & & 0,800 & 0,0000 \\
\hline Uol & $0,01 \%$ & $0,00 \%$ & $2,57 \%$ & $02 / 01 / 2006$ & $29 / 12 / 2011$ & 1476 & 1,120 & 0,0167 \\
\hline Usiminas & $0,07 \%$ & $0,00 \%$ & $3,49 \%$ & $03 / 07 / 2000$ & $30 / 12 / 2015$ & 2981 & 0,912 & 0,0517 \\
\hline V-Agro & $-0,22 \%$ & $0,00 \%$ & $3,89 \%$ & $02 / 01 / 2007$ & $30 / 12 / 2015$ & 2144 & 1,189 & 0,3659 \\
\hline Vale & $0,07 \%$ & $0,00 \%$ & $2,62 \%$ & 07/07/1995 & $30 / 12 / 2015$ & 4782 & 0,738 & 0,0044 \\
\hline Valefe & & $0,00 \%$ & $2,54 \%$ & $03 / 0$ & $23 / 1$ & 40 &, 484 & 0,0080 \\
\hline Valid & & 0 , & & $27 / 0$ & $30 /$ & 2392 & 000 & 0,0005 \\
\hline Viavarejo & & & $5,08 \%$ & $01 / 0$ & $30 /$ & &, 400 & 0,0000 \\
\hline Vigor & & $0,00 \%$ & $3,67 \%$ & $05 / 0$ & $30 / 1$ & & 208 & 0,0000 \\
\hline Viver & & & & $02 / 0$ & $30 / 0$ & & 000 & 0,0344 \\
\hline Vivo & & & & $01 / 10 / 1$ & & 3022 & 192 & 0,0042 \\
\hline Weg & & $0,00 \%$ & $2,11 \%$ & $02 / 07 / 2007$ & $30 / 12 / 2015$ & 2101 & 1,286 & 0,0093 \\
\hline White & $-0,03 \%$ & $0,00 \%$ & $2,68 \%$ & 03/07/1995 & $29 / 02 / 2000$ & 1129 & 0,529 & 0,0000 \\
\hline \multirow[t]{2}{*}{ Wlm Ind Com } & $0,65 \%$ & $0,00 \%$ & $5,05 \%$ & $04 / 07 / 1995$ & $23 / 09 / 2008$ & 1050 & 0,040 & 0,0022 \\
\hline & & & & $03 / 07 / 1995$ & $30 / 12 / 2015$ & 79.582 & & \\
\hline
\end{tabular}

Fonte: Economática ${ }^{\circledR}$

Elaborado pelo autor. Índices $C E C$ e $\hat{\gamma}$ estimados pelas equações (21) e (29) respectivamente. 


\section{APÊNDICE C - ESTATÍSTICAS DOS MODELOS DE REGRESSÃO}

Tabela C1- Testes da modelagem VAR-GARCH

\begin{tabular}{|c|c|c|c|c|c|c|}
\hline Empresa & $\begin{array}{c}\text { ADF } \\
\text { Estatística } \\
\text { Tau }\end{array}$ & $\begin{array}{l}\text { Phillips- } \\
\text { Perron } \\
\text { p-valor }\end{array}$ & $\begin{array}{l}\text { Critério de } \\
\text { informação }\end{array}$ & $\begin{array}{c}\text { Defasagens } \\
\text { no modelo } \\
\text { VAR }\end{array}$ & $\begin{array}{l}\text { VAR } \\
\text { teste F } \\
\text { p-valor }\end{array}$ & $\begin{array}{l}\text { GARCH } \\
\text { Ljung-Box } \\
\text { p-valor }\end{array}$ \\
\hline Setor Financeiro & $-45,86$ & 0,01 & - & - & - & - \\
\hline Abyara & $-18,49$ & 0,01 & $\mathrm{SC}$ & 1 & 0,000 & 0,772 \\
\hline Aco Altona & $-26,08$ & 0,01 & $\mathrm{SC}$ & 1 & 0,316 & 0,619 \\
\hline Acos Vill & $-28,86$ & 0,01 & $\mathrm{SC}$ & 1 & 0,007 & 0,692 \\
\hline All Amer Lat & $-25,67$ & 0,01 & $\mathrm{SC}$ & 1 & 0,035 & 0,680 \\
\hline Alpargatas & $-25,10$ & 0,01 & $\mathrm{SC}$ & 1 & 0,215 & 0,926 \\
\hline Ambev S/A & $-49,70$ & 0,01 & $\mathrm{SC}$ & 1 & 0,093 & 0,983 \\
\hline Amil & $-28,51$ & 0,01 & $\mathrm{SC}$ & 1 & 0,003 & 0,594 \\
\hline Ampla Energ & $-35,47$ & 0,01 & $\mathrm{SC}$ & 1 & 0,031 & 0,675 \\
\hline Anhanguera & $-24,51$ & 0,01 & $\mathrm{SC}$ & 1 & 0,292 & 0,961 \\
\hline Anima & $-15,85$ & 0,01 & $\mathrm{SC}$ & 1 & 0,005 & 0,057 \\
\hline Aracruz & $-22,47$ & 0,01 & $\mathrm{SC}$ & 1 & 0,005 & 0,906 \\
\hline Arcelor BR & $-30,90$ & 0,01 & $\mathrm{SC}$ & 1 & 0,051 & 0,780 \\
\hline Arezzo Co & $-25,73$ & 0,01 & $\mathrm{SC}$ & 1 & 0,003 & 0,988 \\
\hline Autometal & $-22,99$ & 0,01 & $\mathrm{SC}$ & 1 & 0,028 & 0,616 \\
\hline B2W Digital & $-32,96$ & 0,01 & $\mathrm{SC}$ & 1 & 0,003 & 0,302 \\
\hline Bahia Sul & $-24,89$ & 0,01 & $\mathrm{SC}$ & 1 & 0,000 & 0,412 \\
\hline Bandeirante Energ & $-20,34$ & 0,01 & $\mathrm{SC}$ & 1 & 0,000 & 0,570 \\
\hline Bardella & $-37,95$ & 0,01 & $\mathrm{SC}$ & 1 & 0,000 & 0,528 \\
\hline Bombril & $-43,32$ & 0,01 & $\mathrm{SC}$ & 2 & 0,000 & 0,678 \\
\hline BR Pharma & $-22,21$ & 0,01 & $\mathrm{SC}$ & 1 & 0,064 & 0,964 \\
\hline Brasil T Par & $-37,61$ & 0,01 & $\mathrm{SC}$ & 1 & 0,000 & 0,414 \\
\hline Braskem & $-37,03$ & 0,01 & $\mathrm{SC}$ & 1 & 0,007 & 0,792 \\
\hline BRF SA & $-35,18$ & 0,01 & $\mathrm{SC}$ & 1 & 0,001 & 0,828 \\
\hline Bunge Alimentos & $-22,83$ & 0,01 & $\mathrm{SC}$ & 1 & 0,001 & 0,989 \\
\hline Bunge Fertilizantes & $-26,58$ & 0,01 & $\mathrm{SC}$ & 1 & 0,259 & 0,995 \\
\hline Caemi & $-35,56$ & 0,01 & $\mathrm{SC}$ & 1 & 0,000 & 0,582 \\
\hline Cambuci & $-20,49$ & 0,01 & $\mathrm{SC}$ & 1 & 0,120 & 0,997 \\
\hline CCR SA & $-41,64$ & 0,01 & $\mathrm{SC}$ & 1 & 0,010 & 0,787 \\
\hline Celesc & $-49,28$ & 0,01 & $\mathrm{SC}$ & 2 & 0,000 & 0,321 \\
\hline Celpe & $-16,67$ & 0,01 & $\mathrm{SC}$ & 2 & 0,000 & 0,834 \\
\hline Cemig & $-52,45$ & 0,01 & $\mathrm{SC}$ & 1 & 0,000 & 0,040 \\
\hline Cesp & $-50,79$ & 0,01 & $\mathrm{SC}$ & 1 & 0,002 & 0,348 \\
\hline Cia Hering & $-33,66$ & 0,01 & $\mathrm{SC}$ & 1 & 0,000 & 0,640 \\
\hline Coelba & $-19,05$ & 0,01 & $\mathrm{SC}$ & 1 & 0,000 & 0,601 \\
\hline Confab & $-45,76$ & 0,01 & $\mathrm{SC}$ & 1 & 0,292 & 0,936 \\
\hline Contax & $-29,92$ & 0,01 & $\mathrm{SC}$ & 1 & 0,000 & 0,568 \\
\hline Copasa & $-36,72$ & 0,01 & $\mathrm{SC}$ & 1 & 0,000 & 0,671 \\
\hline Copel & $-50,99$ & 0,01 & $\mathrm{SC}$ & 1 & 0,000 & 0,623 \\
\hline Copesul & $-37,63$ & 0,01 & $\mathrm{SC}$ & 2 & 0,000 & 0,425 \\
\hline Cosan & $-37,04$ & 0,01 & $\mathrm{SC}$ & 1 & 0,003 & 0,786 \\
\hline CPFL Energia & $-39,30$ & 0,01 & $\mathrm{SC}$ & 1 & 0,000 & 0,573 \\
\hline CPFL Renovav & $-19,89$ & 0,01 & $\mathrm{SC}$ & 1 & 0,033 & 0,831 \\
\hline Cremer & $-30,86$ & 0,01 & $\mathrm{SC}$ & 1 & 0,000 & 0,311 \\
\hline
\end{tabular}

(continua) 
(continuação)

\begin{tabular}{|c|c|c|c|c|c|c|}
\hline Empresa & $\begin{array}{c}\text { ADF } \\
\text { Estatística } \\
\text { Tau } \\
\end{array}$ & $\begin{array}{l}\text { Phillips- } \\
\text { Perron } \\
\text { p-valor }\end{array}$ & $\begin{array}{l}\text { Critério de } \\
\text { informação }\end{array}$ & $\begin{array}{c}\text { Defasagens } \\
\text { no modelo } \\
\text { VAR }\end{array}$ & $\begin{array}{l}\text { VAR } \\
\text { teste F } \\
\text { p-valor }\end{array}$ & $\begin{array}{c}\text { GARCH } \\
\text { Ljung-Box } \\
\text { p-valor }\end{array}$ \\
\hline Crt Celular & $-15,86$ & 0,01 & $\mathrm{SC}$ & 1 & 0,003 & 0,553 \\
\hline Crt Ciargtelec & $-22,64$ & 0,01 & $\mathrm{SC}$ & 1 & 0,000 & 0,615 \\
\hline Csu Cardsyst & $-35,44$ & 0,01 & $\mathrm{SC}$ & 1 & 0,143 & 0,804 \\
\hline Dasa & $-37,25$ & 0,01 & $\mathrm{SC}$ & 1 & 0,000 & 0,609 \\
\hline Dimed & $-21,48$ & 0,01 & $\mathrm{SC}$ & 1 & 0,004 & 0,878 \\
\hline Dixie Toga & $-18,14$ & 0,01 & $\mathrm{SC}$ & 1 & 0,002 & 0,842 \\
\hline Doc Imbituba & $-30,26$ & 0,01 & $\mathrm{SC}$ & 1 & 0,000 & 0,658 \\
\hline Duratex & $-33,52$ & 0,01 & $\mathrm{SC}$ & 1 & 0,000 & 0,648 \\
\hline Eletrobras & $-52,00$ & 0,01 & $\mathrm{SC}$ & 1 & 0,011 & 0,750 \\
\hline Eleva & $-27,36$ & 0,01 & $\mathrm{SC}$ & 1 & 0,070 & 0,574 \\
\hline Embraer & $-45,36$ & 0,01 & $\mathrm{SC}$ & 2 & 0,000 & 0,717 \\
\hline Embratel Part & $-37,57$ & 0,01 & $\mathrm{SC}$ & 1 & 0,004 & 0,774 \\
\hline Energias BR & $-36,67$ & 0,01 & $\mathrm{SC}$ & 1 & 0,003 & 0,756 \\
\hline Eneva & $-32,27$ & 0,01 & $\mathrm{SC}$ & 1 & 0,005 & 0,627 \\
\hline Epte & $-22,41$ & 0,01 & $\mathrm{SC}$ & 1 & 0,351 & 0,643 \\
\hline Estacio Part & $-30,93$ & 0,01 & $\mathrm{SC}$ & 1 & 0,059 & 0,609 \\
\hline Eternit & $-46,02$ & 0,01 & $\mathrm{SC}$ & 1 & 0,004 & 0,850 \\
\hline Eucatex & $-32,91$ & 0,01 & $\mathrm{SC}$ & 1 & 0,003 & 0,859 \\
\hline F Cataguazes & $-36,51$ & 0,01 & $\mathrm{SC}$ & 1 & 0,000 & 0,628 \\
\hline Fer Heringer & $-31,85$ & 0,01 & $\mathrm{SC}$ & 1 & 0,000 & 0,450 \\
\hline Ferbasa & $-43,87$ & 0,01 & $\mathrm{SC}$ & 1 & 0,000 & 0,937 \\
\hline Fertisul & $-16,14$ & 0,01 & $\mathrm{SC}$ & 1 & 0,006 & 0,907 \\
\hline Fibria & $-30,07$ & 0,01 & $\mathrm{SC}$ & 1 & 0,003 & 0,677 \\
\hline Fleury & $-27,66$ & 0,01 & $\mathrm{SC}$ & 1 & 0,002 & 0,771 \\
\hline Forja Taurus & $-19,74$ & 0,01 & $\mathrm{SC}$ & 1 & 0,007 & 0,836 \\
\hline Gerdau & $-38,54$ & 0,01 & $\mathrm{SC}$ & 1 & 0,000 & 0,346 \\
\hline Gerdau Met & $-36,76$ & 0,01 & $\mathrm{SC}$ & 1 & 0,014 & 0,740 \\
\hline Gol & $-39,21$ & 0,01 & $\mathrm{SC}$ & 1 & 0,000 & 0,964 \\
\hline GPC Part & $-31,49$ & 0,01 & $\mathrm{SC}$ & 2 & 0,000 & 0,669 \\
\hline Grazziotin & $-18,34$ & 0,01 & $\mathrm{SC}$ & 1 & 0,001 & 0,547 \\
\hline Grendene & $-36,94$ & 0,01 & $\mathrm{SC}$ & 1 & 0,040 & 0,866 \\
\hline Guarani & $-17,92$ & 0,01 & $\mathrm{SC}$ & 1 & 0,221 & 0,541 \\
\hline Guararapes & $-35,60$ & 0,01 & $\mathrm{SC}$ & 1 & 0,000 & 0,335 \\
\hline GVT Holding & $-20,16$ & 0,01 & $\mathrm{SC}$ & 1 & 0,011 & 0,736 \\
\hline Habitasul & $-17,18$ & 0,01 & $\mathrm{SC}$ & 1 & 0,004 & 0,594 \\
\hline Hypermarcas & $-30,20$ & 0,01 & $\mathrm{SC}$ & 2 & 0,000 & 0,090 \\
\hline Inds Romi & $-34,35$ & 0,01 & $\mathrm{SC}$ & 1 & 0,004 & 0,266 \\
\hline Inepar & $-27,87$ & 0,01 & $\mathrm{SC}$ & 1 & 0,002 & 0,861 \\
\hline Iochp-Maxion & $-30,23$ & 0,01 & $\mathrm{SC}$ & 1 & 0,001 & 0,819 \\
\hline Ipiranga Dis & $-27,07$ & 0,01 & $\mathrm{SC}$ & 1 & 0,002 & 0,815 \\
\hline Ipiranga Pet & $-39,67$ & 0,01 & $\mathrm{SC}$ & 1 & 0,031 & 0,577 \\
\hline Itausa & $-38,30$ & 0,01 & $\mathrm{SC}$ & 1 & 0,002 & 0,662 \\
\hline Itautec & $-22,86$ & 0,01 & $\mathrm{SC}$ & 2 & 0,000 & 0,595 \\
\hline JBS & $-35,10$ & 0,01 & $\mathrm{SC}$ & 1 & 0,105 & 0,591 \\
\hline Jereissati & $-30,52$ & 0,01 & $\mathrm{SC}$ & 1 & 0,004 & 0,606 \\
\hline JHSF Part & $-31,69$ & 0,01 & $\mathrm{SC}$ & 1 & 0,011 & 0,593 \\
\hline Karsten & $-27,22$ & 0,01 & $\mathrm{SC}$ & 1 & 0,012 & 0,955 \\
\hline Kepler Weber & $-31,07$ & 0,01 & $\mathrm{SC}$ & 1 & 0,011 & 0,762 \\
\hline Klabin S/A & $-50,45$ & 0,01 & $\mathrm{SC}$ & 1 & 0,009 & 0,886 \\
\hline Kroton & $-20,29$ & 0,01 & $\mathrm{SC}$ & 1 & 0,487 & 0,462 \\
\hline
\end{tabular}


(continuação)

\begin{tabular}{|c|c|c|c|c|c|c|}
\hline Empresa & $\begin{array}{c}\text { ADF } \\
\text { Estatística } \\
\text { Tau }\end{array}$ & $\begin{array}{l}\text { Phillips- } \\
\text { Perron } \\
\text { p-valor }\end{array}$ & $\begin{array}{l}\text { Critério de } \\
\text { informação }\end{array}$ & $\begin{array}{c}\text { Defasagens } \\
\text { no modelo } \\
\text { VAR }\end{array}$ & $\begin{array}{l}\text { VAR } \\
\text { teste F } \\
\text { p-valor }\end{array}$ & $\begin{array}{l}\text { GARCH } \\
\text { Ljung-Box } \\
\text { p-valor }\end{array}$ \\
\hline Light S/A & $-50,81$ & 0,01 & $\mathrm{SC}$ & 2 & 0,000 & 0,818 \\
\hline $\operatorname{Lin} x$ & $-19,21$ & 0,01 & $\mathrm{SC}$ & 1 & 0,002 & 0,515 \\
\hline Log-In & $-30,67$ & 0,01 & $\mathrm{SC}$ & 1 & 0,001 & 0,465 \\
\hline Lojas Marisa & $-31,68$ & 0,01 & $\mathrm{SC}$ & 1 & 0,035 & 0,867 \\
\hline Lojas Renner & $-38,20$ & 0,01 & $\mathrm{SC}$ & 1 & 0,000 & 0,600 \\
\hline M G Poliest & $-27,06$ & 0,01 & $\mathrm{SC}$ & 1 & 0,175 & 0,864 \\
\hline M.Diasbranco & $-35,61$ & 0,01 & $\mathrm{SC}$ & 1 & 0,025 & 0,803 \\
\hline Magnesita & $-39,34$ & 0,01 & $\mathrm{SC}$ & 2 & 0,000 & 0,609 \\
\hline Magnesita SA & $-31,13$ & 0,01 & $\mathrm{SC}$ & 1 & 0,023 & 0,751 \\
\hline Mangels Indl & $-43,50$ & 0,01 & $\mathrm{SC}$ & 1 & 0,001 & 0,528 \\
\hline Marcopolo & $-33,20$ & 0,01 & $\mathrm{SC}$ & 2 & 0,000 & 0,979 \\
\hline Marfrig & $-33,50$ & 0,01 & $\mathrm{SC}$ & 1 & 0,014 & 0,734 \\
\hline Marisol & $-23,11$ & 0,01 & $\mathrm{SC}$ & 2 & 0,000 & 0,366 \\
\hline Medial Saude & $-20,68$ & 0,01 & $\mathrm{SC}$ & 1 & 0,000 & 0,369 \\
\hline Metal Iguacu & $-23,65$ & 0,01 & $\mathrm{SC}$ & 1 & 0,014 & 0,663 \\
\hline Metal Leve & $-23,45$ & 0,01 & $\mathrm{SC}$ & 1 & 0,139 & 0,765 \\
\hline Metalfrio & $-32,09$ & 0,01 & $\mathrm{SC}$ & 1 & 0,000 & 0,552 \\
\hline Mills & $-28,78$ & 0,01 & $\mathrm{SC}$ & 1 & 0,084 & 0,707 \\
\hline Minerva & $-31,93$ & 0,01 & $\mathrm{SC}$ & 1 & 0,001 & 0,592 \\
\hline MMX Miner & $-33,31$ & 0,01 & $\mathrm{SC}$ & 1 & 0,002 & 0,626 \\
\hline Mundial & $-22,58$ & 0,01 & $\mathrm{SC}$ & 1 & 0,010 & 0,454 \\
\hline Natura & $-38,37$ & 0,01 & $\mathrm{SC}$ & 1 & 0,003 & 0,532 \\
\hline $\mathrm{Oi}$ & $-44,12$ & 0,01 & $\mathrm{SC}$ & 2 & 0,000 & 0,326 \\
\hline OSX Brasil & $-25,45$ & 0,01 & $\mathrm{SC}$ & 1 & 0,018 & 0,638 \\
\hline P.Acucar-Cbd & $-51,71$ & 0,01 & $\mathrm{SC}$ & 1 & 0,002 & 0,749 \\
\hline Paranapanema & $-31,84$ & 0,01 & $\mathrm{SC}$ & 1 & 0,002 & 0,806 \\
\hline Paul F Luz & $-27,25$ & 0,01 & $\mathrm{SC}$ & 1 & 0,000 & 0,631 \\
\hline Petrobras & $-52,99$ & 0,01 & $\mathrm{SC}$ & 1 & 0,026 & 0,809 \\
\hline Petrobras Distrib & $-29,47$ & 0,01 & $\mathrm{SC}$ & 1 & 0,000 & 0,328 \\
\hline Petroflex & $-20,76$ & 0,01 & $\mathrm{SC}$ & 2 & 0,000 & 0,524 \\
\hline Petrorio & $-25,80$ & 0,01 & $\mathrm{SC}$ & 1 & 0,125 & 0,280 \\
\hline Pettenati & $-24,49$ & 0,01 & $\mathrm{SC}$ & 1 & 0,000 & 0,620 \\
\hline Plascar Part & $-32,69$ & 0,01 & $\mathrm{SC}$ & 1 & 0,016 & 0,663 \\
\hline Pomifrutas & $-35,05$ & 0,01 & $\mathrm{SC}$ & 1 & 0,000 & 0,545 \\
\hline Positivo Inf & $-34,40$ & 0,01 & $\mathrm{SC}$ & 1 & 0,002 & 0,717 \\
\hline Profarma & $-31,90$ & 0,01 & $\mathrm{SC}$ & 1 & 0,032 & 0,456 \\
\hline Providencia & $-31,19$ & 0,01 & $\mathrm{SC}$ & 2 & 0,000 & 0,658 \\
\hline Qgep Part & $-25,65$ & 0,01 & $\mathrm{SC}$ & 1 & 0,008 & 0,579 \\
\hline Quattor Petr & $-29,58$ & 0,01 & $\mathrm{SC}$ & 1 & 0,017 & 0,703 \\
\hline Randon Part & $-22,11$ & 0,01 & $\mathrm{SC}$ & 1 & 0,010 & 0,578 \\
\hline Rasip Agro & $-22,15$ & 0,01 & $\mathrm{SC}$ & 1 & 0,000 & 0,989 \\
\hline Ripasa & $-36,35$ & 0,01 & $\mathrm{SC}$ & 1 & 0,012 & 0,348 \\
\hline S Gobain Canal & $-25,11$ & 0,01 & $\mathrm{SC}$ & 1 & 0,056 & 0,786 \\
\hline Sabesp & $-48,12$ & 0,01 & $\mathrm{SC}$ & 1 & 0,160 & 0,820 \\
\hline Sadia S/A & $-19,79$ & 0,01 & $\mathrm{SC}$ & 1 & 0,001 & 0,842 \\
\hline Sanepar & $-45,00$ & 0,01 & $\mathrm{SC}$ & 1 & 0,010 & 0,522 \\
\hline Santanense & $-21,57$ & 0,01 & $\mathrm{SC}$ & 1 & 0,000 & 0,609 \\
\hline Santistextil & $-24,18$ & 0,01 & $\mathrm{SC}$ & 1 & 0,424 & 0,825 \\
\hline Sao Martinho & $-34,67$ & 0,01 & $\mathrm{SC}$ & 1 & 0,000 & 0,945 \\
\hline Saraiva Livr & $-38,57$ & 0,01 & $\mathrm{SC}$ & 1 & 0,000 & 0,633 \\
\hline
\end{tabular}


(continuação)

\begin{tabular}{|c|c|c|c|c|c|c|}
\hline Empresa & $\begin{array}{c}\text { ADF } \\
\text { Estatística } \\
\text { Tau }\end{array}$ & $\begin{array}{l}\text { Phillips- } \\
\text { Perron } \\
\text { p-valor }\end{array}$ & $\begin{array}{l}\text { Critério de } \\
\text { informação }\end{array}$ & $\begin{array}{c}\text { Defasagens } \\
\text { no modelo } \\
\text { VAR }\end{array}$ & $\begin{array}{l}\text { VAR } \\
\text { teste F } \\
\text { p-valor }\end{array}$ & $\begin{array}{l}\text { GARCH } \\
\text { Ljung-Box } \\
\text { p-valor }\end{array}$ \\
\hline Schulz & $-32,12$ & 0,01 & $\mathrm{SC}$ & 1 & 0,188 & 0,370 \\
\hline Ser Educa & $-15,28$ & 0,01 & $\mathrm{SC}$ & 1 & 0,355 & 0,937 \\
\hline Sharp & $-21,84$ & 0,01 & $\mathrm{SC}$ & 1 & 0,000 & 0,897 \\
\hline Sid Nacional & $-49,49$ & 0,01 & $\mathrm{SC}$ & 1 & 0,009 & 0,514 \\
\hline Sid Tubarao & $-34,15$ & 0,01 & $\mathrm{SC}$ & 1 & 0,000 & 0,115 \\
\hline SLC Agricola & $-31,82$ & 0,01 & $\mathrm{SC}$ & 1 & 0,004 & 0,774 \\
\hline Souza Cruz & $-51,05$ & 0,01 & $\mathrm{SC}$ & 1 & 0,050 & 0,871 \\
\hline Springer & $-17,23$ & 0,01 & $\mathrm{SC}$ & 1 & 0,001 & 0,545 \\
\hline Springs & $-32,91$ & 0,01 & $\mathrm{SC}$ & 1 & 0,001 & 0,764 \\
\hline Sultepa & $-31,79$ & 0,01 & $\mathrm{SC}$ & 1 & 0,003 & 0,580 \\
\hline Suzano Papel & $-47,71$ & 0,01 & $\mathrm{SC}$ & 1 & 0,126 & 0,514 \\
\hline Technos & $-23,48$ & 0,01 & $\mathrm{SC}$ & 1 & 0,007 & 0,596 \\
\hline Tecnosolo & $-25,45$ & 0,01 & $\mathrm{SC}$ & 1 & 0,000 & 0,671 \\
\hline Tegma & $-32,25$ & 0,01 & $\mathrm{SC}$ & 1 & 0,099 & 0,855 \\
\hline Tel B Campo & $-20,15$ & 0,01 & $\mathrm{SC}$ & 1 & 0,000 & 0,083 \\
\hline Tele Centroeste Cel & $-29,33$ & 0,01 & $\mathrm{SC}$ & 1 & 0,027 & 0,995 \\
\hline Tele Leste Celular & $-29,32$ & 0,01 & $\mathrm{SC}$ & 1 & 0,000 & 0,698 \\
\hline Tele Nordeste Celul & $-27,87$ & 0,01 & $\mathrm{SC}$ & 1 & 0,009 & 0,465 \\
\hline Tele Nort Cl & $-35,43$ & 0,01 & $\mathrm{SC}$ & 1 & 0,010 & 0,745 \\
\hline Tele Sudeste Celula & $-30,63$ & 0,01 & $\mathrm{SC}$ & 1 & 0,000 & 0,417 \\
\hline Telebras (Old) & $-18,01$ & 0,01 & $\mathrm{SC}$ & 1 & 0,065 & 0,623 \\
\hline Telef Brasil & $-52,13$ & 0,01 & $\mathrm{SC}$ & 1 & 0,007 & 0,531 \\
\hline Telefonica Data Hld & $-24,82$ & 0,01 & $\mathrm{SC}$ & 1 & 0,000 & 0,561 \\
\hline Telemar & $-41,62$ & 0,01 & $\mathrm{SC}$ & 1 & 0,020 & 0,618 \\
\hline Telemar N L & $-31,70$ & 0,01 & $\mathrm{SC}$ & 1 & 0,000 & 0,520 \\
\hline Telemig & $-20,27$ & 0,01 & $\mathrm{SC}$ & 1 & 0,000 & 0,358 \\
\hline Telerj Cel & $-15,46$ & 0,01 & $\mathrm{SC}$ & 1 & 0,026 & 0,892 \\
\hline Tereos & $-24,84$ & 0,01 & $\mathrm{SC}$ & 1 & 0,000 & 0,610 \\
\hline Tim Nordeste & $-21,89$ & 0,01 & $\mathrm{SC}$ & 2 & 0,000 & 0,914 \\
\hline Tim Part S/A & $-47,94$ & 0,01 & $\mathrm{SC}$ & 1 & 0,024 & 0,473 \\
\hline Tim Sul & $-14,50$ & 0,01 & $\mathrm{SC}$ & 2 & 0,000 & 0,597 \\
\hline Time For Fun & $-22,98$ & 0,01 & $\mathrm{SC}$ & 1 & 0,009 & 0,500 \\
\hline Trafo & $-24,95$ & 0,01 & $\mathrm{SC}$ & 1 & 0,073 & 0,000 \\
\hline Triunfo Part & $-33,09$ & 0,01 & $\mathrm{SC}$ & 1 & 0,003 & 0,647 \\
\hline Tupy & $-34,32$ & 0,01 & $\mathrm{SC}$ & 1 & 0,000 & 0,234 \\
\hline Ultrapar & $-23,57$ & 0,01 & $\mathrm{SC}$ & 1 & 0,018 & 0,644 \\
\hline Unicasa & $-21,72$ & 0,01 & $\mathrm{SC}$ & 1 & 0,204 & 0,715 \\
\hline Uol & $-27,74$ & 0,01 & $\mathrm{SC}$ & 1 & 0,009 & 0,901 \\
\hline Usiminas & $-38,47$ & 0,01 & $\mathrm{SC}$ & 2 & 0,000 & 0,921 \\
\hline V-Agro & $-31,45$ & 0,01 & $\mathrm{SC}$ & 1 & 0,001 & 0,884 \\
\hline Vale & $-52,05$ & 0,01 & $\mathrm{SC}$ & 1 & 0,005 & 0,570 \\
\hline Valefert & $-45,80$ & 0,01 & $\mathrm{SC}$ & 2 & 0,000 & 0,619 \\
\hline Valid & $-36,33$ & 0,01 & $\mathrm{SC}$ & 1 & 0,269 & 0,826 \\
\hline Viavarejo & $-17,90$ & 0,01 & $\mathrm{SC}$ & 1 & 0,001 & 0,963 \\
\hline Vigor & $-18,34$ & 0,01 & $\mathrm{SC}$ & 1 & 0,002 & 0,519 \\
\hline
\end{tabular}


(conclusão)

\begin{tabular}{lcccccc}
\hline Empresa & $\begin{array}{c}\text { ADF } \\
\text { Estatística } \\
\text { Tau }\end{array}$ & $\begin{array}{c}\text { Phillips- } \\
\text { Perron } \\
\text { p-valor }\end{array}$ & $\begin{array}{c}\text { Critério de } \\
\text { informação }\end{array}$ & $\begin{array}{c}\text { Defasagens } \\
\text { no modelo } \\
\text { VAR }\end{array}$ & $\begin{array}{c}\text { VAR } \\
\text { teste F } \\
\text { p-valor }\end{array}$ & $\begin{array}{c}\text { GARCH } \\
\text { Ljung-Box } \\
\text { p-valor }\end{array}$ \\
\hline Viver & $-28,36$ & 0,01 & SC & 2 & 0,000 & 0,631 \\
Vivo & $-40,76$ & 0,01 & SC & 1 & 0,003 & 0,814 \\
Weg & $-34,54$ & 0,01 & SC & 1 & 0,249 & 0,384 \\
White Martins & $-23,12$ & 0,01 & SC & 1 & 0,008 & 0,530 \\
Wlm Ind Com & $-26,14$ & 0,01 & SC & 1 & 0,000 & 0,047 \\
\hline
\end{tabular}

Elaborado pelo autor.

As estatísticas Tau e p-valor Phillips-Perron são aplicadas na série de retornos das ações de cada empresa e do setor financeiro; o p-valor do teste F apresentado é aplicado em cada modelo VAR na equação do retorno do setor financeiro.

Tabela C2 - Correlação das variáveis do modelo de investimento

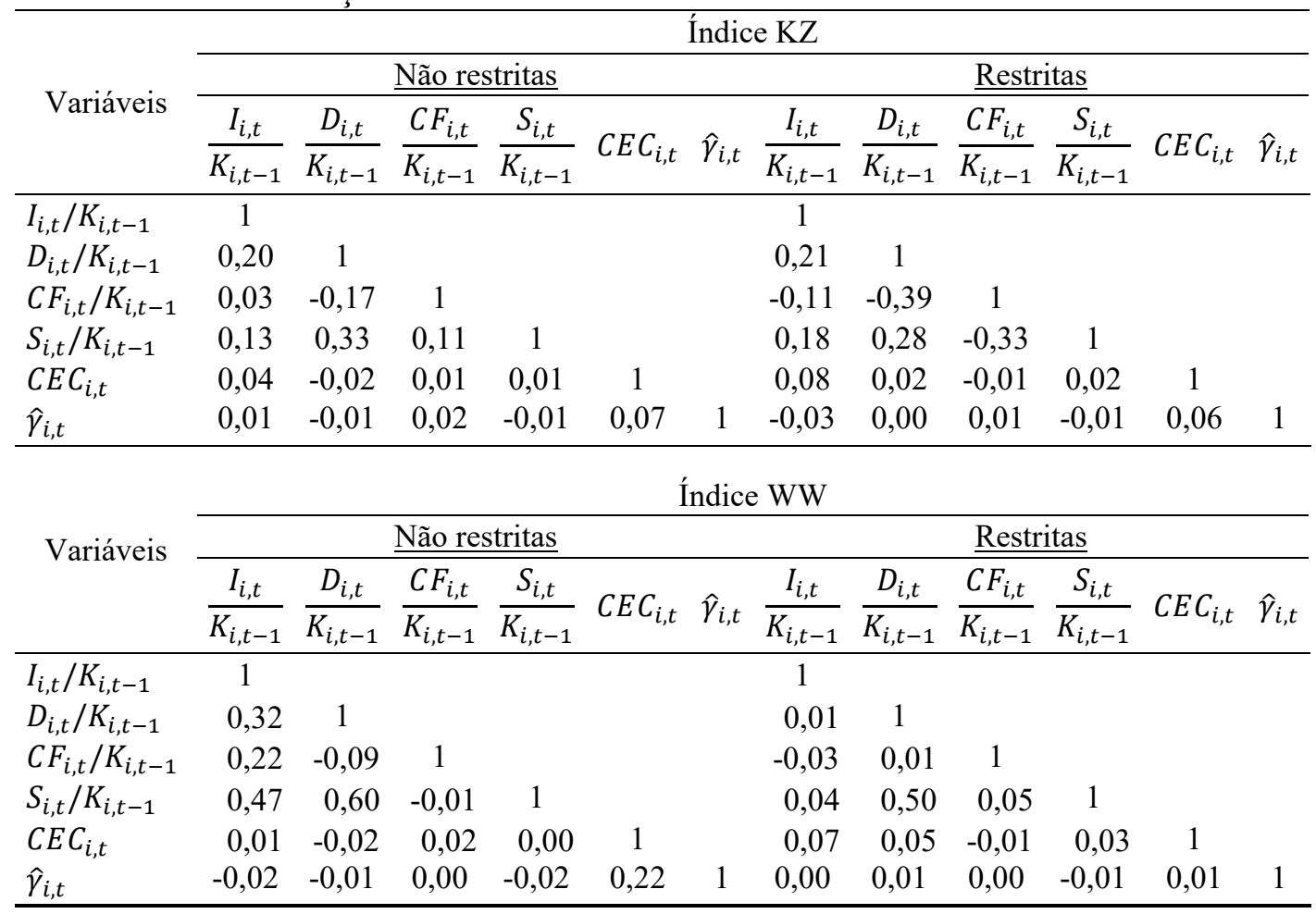

Elaborado pelo autor. 


\section{REFERÊNCIAS BIBLIOGRÁFICAS}

AFTALION, A. La Réalité des surproductions générales. Revue d'Economie Politique, v. 18, p. 696-706, 1909.

AKERLOF, G. A. The market for "lemons": Quality uncertainty and the market mechanism. Quarterly Journal of Economics, v. 84, p. 488-500, 1970.

AKTAS, N.; DE BODT, E.; ROLL, R. Learning from repetitive acquisitions: Evidence from the time between deals. Journal of Financial Economics, v. 108, n. 1, p. 99-117, 2013.

ALLEN, F.; GALE, D. Financial Contagion. Journal of Political Economy, v. 108, n. 1, p. 1, fev. 2000.

ALMEIDA, H.; CAMPELLO, M. Financial constraints, asset tangibility, and corporate investment. Review of Financial Studies, v. 20, n. 5, p. 1429-1460, 2007.

AMORE, M. D.; SCHNEIDER, C.; ŽALDOKAS, A. Credit supply and corporate innovation. Journal of Financial Economics, v. 109, n. 3, p. 835-855, 2013.

ARELLANO, M.; BOND, S. Some tests of specification for panel data: Monte Carlo evidence and an application to employment equations. The review of economic studies, v. 58, n. 2, p. 277-297, 1991.

ARELLANO, M.; BOVER, O. Another look at the instrumental variable estimation of errorcomponents models. Journal of econometrics, v. 68, n. 1, p. 29-51, 1995.

BAE, K.-H.; KAROLYI, G. A.; STULZ, R. M. A new approach to measuring financial contagion. Review of Financial studies, v. 16, n. 3, p. 717-763, 2003.

BANERJEE, A. V. A simple model of herd behavior. The Quarterly Journal of Economics, p. $797-817,1992$.

BASSETTO, C. F.; KALATZIS, A. E. G. Financial distress, financial constraint and investment decision: Evidence from Brazil. Economic Modelling, v. 28, n. 1, p. 264-271, 2011.

BERNANKE, B. Non-monetary effects of the financial crisis in the propagation of the Great 
Depression. The American Economic Review, v. 73, n. 3, p. 257-276, 1983.

BERNANKE, B.; GERTLER, M. Agency Costs, Net Worth, and Business Fluctuations. The American Economic Review, v. 79, n. 1, p. 14-31, 1 mar. 1989.

BICKERDIKE, C. F. A non-monetary cause of fluctuations in employment. The Economic Journal, v. 24, n. 95, p. 357-370, 1914.

BLINDER, A. S. Credit rationing and effective supply failures. The Economic Journal, v. 97, n. 386, p. 327-352, 1987.

BLUNDELL, R.; BOND, S. Initial conditions and moment restrictions in dynamic panel data models. Journal of econometrics, v. 87, n. 1, p. 115-143, 1998.

BOLLERSLEV, T. Generalized autoregressive conditional heteroskedasticity. Journal of econometrics, v. 31, n. 3, p. 307-327, 1986.

CAPORALE, G. M.; CIPOLLINI, A.; SPAGNOLO, N. Testing for contagion: a conditional correlation analysis. Journal of Empirical Finance, v. 12, n. 3, p. 476-489, jun. 2005.

CARPENTER, R. E. et al. Inventory Investment, Internal-Finance Fluctuations, and the Business Cycle. Brookings Papers on Economic Activity, v. 1994, n. 2, p. 75-138, 1994.

CARVALHO, J. V. DE F.; CHIANN, C. Redes Bayesianas: um método para avaliação de interdependência e contágio em séries temporais multivariadas. Revista Brasileira de Economia, v. 67, n. 2, p. 201-217, 2013.

CARVER, T. N. A Suggestion for a Theory of Industrial Depression. Quarterly Journal of Economics, v. 17, n. 3, p. 457-500, 1903.

CHIRINKO, R. S. Business fixed investment spending: Modeling strategies, empirical results, and policy implications. Journal of Economic literature, v. 31, n. 4, p. 1875-1911, 1993.

CHIU, W.-C.; PEÑA, J. I.; WANG, C.-W. Industry characteristics and financial risk contagion. Journal of Banking \& Finance, v. 50, p. 411-427, 2015.

CHRISTIANSEN, C.; RANALDO, A. Extreme coexceedances in new EU member states' stock markets. Journal of banking \& finance, v. 33, n. 6, p. 1048-1057, 2009. 
CLAESSENS, S.; DJANKOV, S.; LANG, L. H. P. The separation of ownership and control in East Asian corporations. Journal of financial Economics, v. 58, n. 1, p. 81-112, 2000.

CLAESSENS, S.; DORNBUSCH, R.; PARK, Y. C. Contagion: Why crises spread and how this can be stopped. In: International financial contagion. Springer, 2001. p. 19-41.

CLAESSENS, S.; FORBES, K. International financial contagion: The theory, evidence and policy implications. Conference "The IMF's role in emerging market economies: Reassessing the adequacy of its resources", Amsterdam. Anais...2004

CLARK, J. M. Business acceleration and the law of demand: A technical factor in economic cycles. The Journal of Political Economy, p. 217-235, 1917.

CLEARY, S. The relationship between firm investment and financial status. Journal of Finance, v. 54, n. 2, p. 673-692, 1999.

CORSETTI, G.; PERICOLI, M.; SBRACIA, M. "Some contagion, some interdependence": More pitfalls in tests of financial contagion. Journal of International Money and Finance, $v$. 24, n. 8, p. 1177-1199, 2005.

DAMODARAN, A. Equity Risk Premiums (ERP): Determinants, Estimation and ImplicationsThe 2016 Edition. Estimation and Implications-the, 2016.

DEVEREUX, M.; SCHIANTARELLI, F. Investment, Financial Factors , and Cash Row: Evidence from U.K. Panel Data. In: Asymmetric Information, Corporate Finance, and investment. University of Chicago Press, 1990. p. 279-306.

DICKEY, D. A.; FULLER, W. A. Distribution of the estimators for autoregressive time series with a unit root. Journal of the American statistical association, v. 74, n. 366a, p. 427-431, 1979.

DICKEY, D. A.; FULLER, W. A. Likelihood ratio statistics for autoregressive time series with a unit root. Econometrica: Journal of the Econometric Society, p. 1057-1072, 1981.

ENGLE, R. F. Autoregressive conditional heteroscedasticity with estimates of the variance of United Kingdom inflation. Econometrica: Journal of the Econometric Society, p. 987-1007, 1982.

ERICKSON, T.; WHITED, T. M. Measurement Error and the Relationship between Investment and q. Journal of Political Economy, v. 108, n. 5, p. 1027-1057, 2000. 
FAZZARI, S. M. et al. Financing Constraints and Corporate Investment. Brookings Papers on Economic Activity, n. 1, p. 141-206, 1 jan. 1988.

FAZZARI, S. M.; HUBBARD, R. G.; PETERSEN, B. C. Investment-Cash Flow Sensitivities are Useful: A Comment on Kaplan and Zingales. The Quarterly Journal of Economics, v. 115 , n. 2, p. 695-705, 2000.

FAZZARI, S. M.; PETERSEN, B. C. Working Capital and Fixed Investment: New Evidence on Financing Constraints. The RAND Journal of Economics, v. 24, n. 3, p. 328-342, 1993.

FORBES, K. J.; RIGOBON, R. No contagion, only interdependence: Measuring stock market comovements. Journal of Finance, v. 57, n. 5, p. 2223-2261, 2002.

FORBES, K.; RIGOBON, R. Measuring contagion: conceptual and empirical issues. In: International financial contagion. Springer, 2001. p. 43-66.

FRIEDMAN, M.; SCHWARTZ, A. J. A monetary history of the United States, 1867-1960. Princeton University Press, 1963.

FRY-MCKIBBIN, R.; MARTIN, V. L.; TANG, C. Financial contagion and asset pricing. Journal of Banking \& Finance, v. 47, p. 296-308, 2014.

GRANGER, C. W. J. Investigating causal relations by econometric models and cross-spectral methods. Econometrica: Journal of the Econometric Society, p. 424-438, 1969.

HADLOCK, C. J.; PIERCE, J. R. New evidence on measuring financial constraints: Moving beyond the KZ index. Review of Financial studies, v. 23, n. 5, p. 1909-1940, 2010.

HALL, R. E.; JORGENSON, D. W. Tax policy and Investment Behavior. American Economic Review, v. 57 (3), n. jun, p. 391-414, 1967.

HANN, R. N.; OGNEVA, M.; OZBAS, O. Corporate diversification and the cost of capital. The journal of finance, v. 68, n. 5, p. 1961-1999, 2013.

HSIAO, C.; TAHMISCIOGLU, A. K. A Panel Analysis of Liquidity Constraints and Firm Investment. Journal of the American Statistical Association, v. 92, n. 438, p. 455-465, 1 jun. 1997. 
Review, v. 53, n. 2, p. 247-259, 1963.

JORION, P. International portfolio diversification with estimation risk. Journal of Business, p. 259-278, 1985.

KALATZIS, A. E. G.; AZZONI, C. R. Investment decisions in troubled times: A Bayesian approach applied to Brazilian firms. International Journal of Production Economics, v. 120, n. 2, p. 595-606, 2009.

KAPLAN, S. N.; ZINGALES, L. Do investment-cash flow sensitivities provide useful measures of financing constraints? The Quarterly Journal of Economics, p. 169-215, 1997.

KAROLYI, G. A. Does international financial contagion really exist? International Finance, v. 6, n. 2, p. 179-199, 2003.

KEYNES, J. M. The general theory of employment, interest and money. 1. ed. London: Macmillan and Co. Limited, 1936.

KING, M. A.; WADHWANI, S. Transmission of volatility between stock markets. Review of Financial studies, v. 3, n. 1, p. 5-33, 1990.

KIRCH, G.; PROCIANOY, J. L.; TERRA, P. R. S. Restrições financeiras e a decisão de investimento das firmas brasileiras Revista Brasileira de Economia scielo , , 2014.

KODRES, L. E.; PRITSKER, M. A rational expectations model of financial contagion. Journal of Finance, v. 57, n. 2, p. 769-799, 2002.

KOYCK, L. M. Distributed lags and investment analysis. Amsterdam: Noth-Holland, 1954.

KROZNER, R.; LAEVEN, L.; KLINGEBIEL, D. Banking crises, financial dependence, and growth. Journal of Financial Economics, v. 84, n. 1, p. 187-228, abr. 2007.

LAMONT, O.; POLK, C.; SAA-REQUEJO, J. Financial constraints and stock returns. Review of financial studies, v. 14, n. 2, p. 529-554, 2001.

LIU, Y. A.; PAN, M.-S. Mean and volatility spillover effects in the US and Pacific-Basin stock markets. Multinational Finance Journal, v. 1, n. 1, p. 47-62, 1997. 
MACKINNON, J. G. Critical Values for Cointegration Tests, Chapter 13 in RF Engle and CWJ Granger (eds.),. In: Long-run Economic Relationships: Readings in Cointegration. 1. ed. Nova York: Oxford University Press, 1991.

MARKOWITZ, H. Portfolio selection. The journal of finance, v. 7, n. 1, p. 77-91, 1952.

MERTON, R. C. On estimating the expected return on the market: An exploratory investigation. Journal of financial economics, v. 8, n. 4, p. 323-361, 1980.

MODIGLIANI, F.; MILLER, M. H. The Cost of Capital, Corporation Finance and the Theory of Investment. The American Economic Review, v. 48, n. 3, p. 261-297, jul. 1958.

MODIGLIANI, F.; MILlER, M. H. Corporate income taxes and the cost of capital: a correction. The American economic review, p. 433-443, 1963.

NICKELL, S. Biases in dynamic models with fixed effects. Econometrica: Journal of the Econometric Society, p. 1417-1426, 1981.

OPGEN-RHEIN, R.; STRIMMER, K. Accurate ranking of differentially expressed genes by a distribution-free shrinkage approach. Statistical applications in genetics and molecular biology, v. 6, n. 1, p. 18, 2007.

PATTON, A. J. Modelling asymmetric exchange rate dependence. International economic review, v. 47, n. 2, p. 527-556, 2006.

PERICOLI, M.; SBRACIA, M. A primer on financial contagion. Journal of Economic Surveys, v. 17, n. 4, p. 571-608, 2003.

PEROBELLI, F. F. C.; VIDAL, T. L.; SECURATO, J. R. Avaliando o Efeito Contágio entre Economias durante Crises Financeiras. Estudos Econômicos, v. 43, p. 557-594, 2013.

PHILLIPS, P. C. B.; PERRON, P. Testing for a unit root in time series regression. Biometrika, v. 75, n. 2, p. 335-346, 1988.

RUPPERT, D.; MATTESON, D. S. Portfolio Selection. In: Statistics and Data Analysis for Financial Engineering. New York, NY: Springer New York, 2015. p. 465-493.

SAMUELSON, P. A. Interactions between the multiplier analysis and the principle of acceleration. The Review of Economics and Statistics, v. 21, n. 2, p. 75-78, 1939. 
SCHALLER, H. Asymmetric information, liquidity constraints, and Canadian investment. Canadian Journal of Economics, p. 552-574, 1993.

SIMS, C. A. Macroeconomics and reality. Econometrica: Journal of the Econometric Society, p. 1-48, 1980.

STIGLITZ, J. E.; WEISS, A. Credit Rationing in Markets with Imperfect Information. The American Economic Review, v. 71, n. 3, p. 393-410, 1981.

TERRA, M. C. T. Credit constraints in Brazilian firms: evidence from panel data. Revista Brasileira de Economia, v. 57, n. 2, p. 443-464, 2003.

TOBIN, J. A general equilibrium approach to monetary theory. Journal of money, credit and banking, v. 1, n. 1, p. 15-29, 1969.

VOGT, S. C. The cash flow/investment relationship: evidence from US manufacturing firms. Financial management, p. 3-20, 1994.

WHITED, T. M.; WU, G. Financial constraints risk. Review of Financial Studies, v. 19, n. 2, p. 531-559, 2006.

WINDMEIJER, F. A finite sample correction for the variance of linear efficient two-step GMM estimators. Journal of econometrics, v. 126, n. 1, p. 25-51, 2005.

YUNG, K.; NAFAR, N. A. Creditor rights and corporate cash holdings: International evidence. International Review of Economics \& Finance, v. 33, p. 111-127, 2014. 